\title{
BWR Progression Problems
}

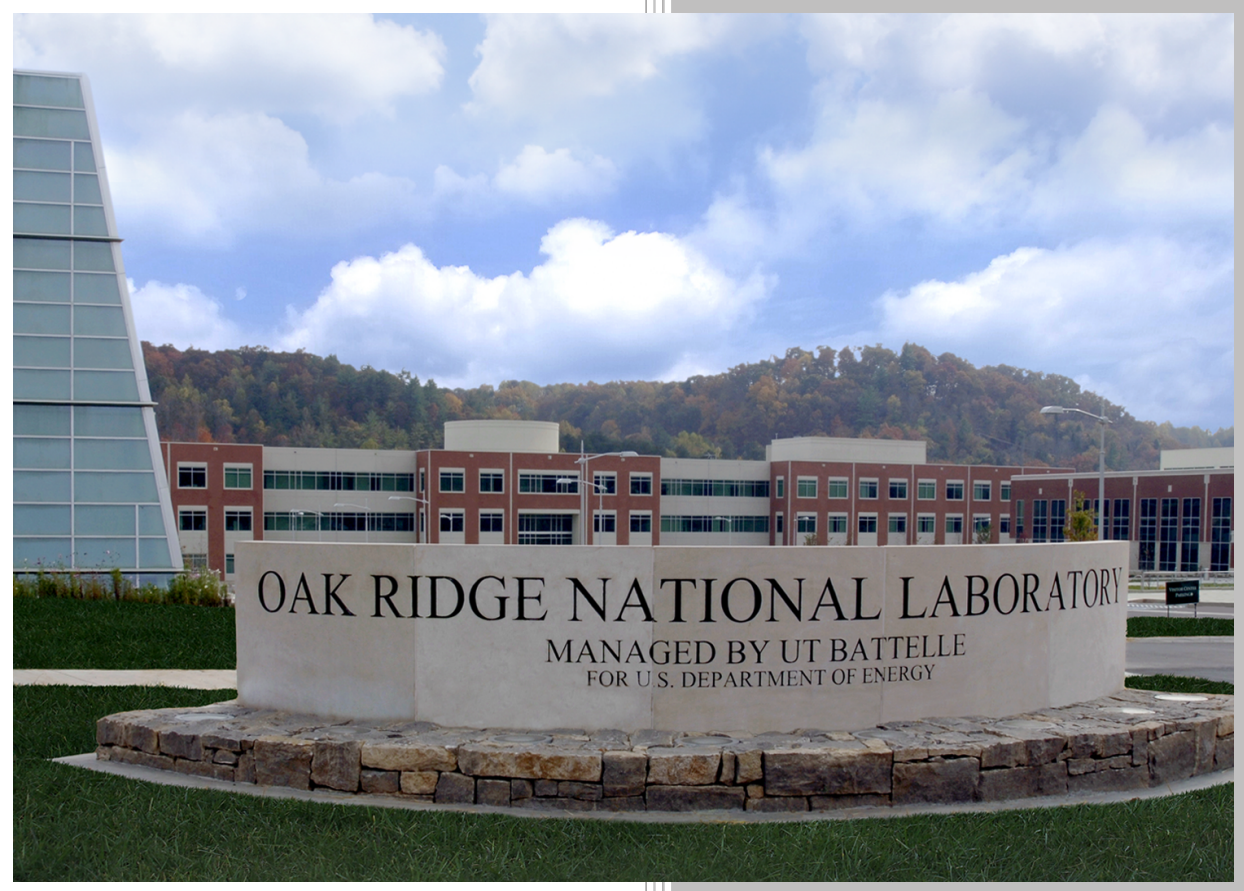

Chase Lawing, NCSU

Scott Palmtag, NCSU

Mehdi Asgari, ORNL

September 30, 2021 


\section{DOCUMENT AVAILABILITY}

Reports produced after January 1, 1996, are generally available free via US Department of Energy (DOE) SciTech Connect.

Website: www.osti.gov/

Reports produced before January 1, 1996, may be purchased by members of the public from the following source:

National Technical Information Service

5285 Port Royal Road

Springfield, VA 22161

Telephone: 703-605-6000 (1-800-553-6847)

TDD: $703-487-4639$

Fax: 703-605-6900

E-mail: info@ntis.gov

Website: http://classic.ntis.gov/

Reports are available to DOE employees, DOE contractors, Energy Technology Data Exchange representatives, and International Nuclear Information System representatives from the following source:

Office of Scientific and Technical Information

PO Box 62

Oak Ridge, TN 37831

Telephone: 865-576-8401

Fax: 865-576-5728

E-mail: report@osti.gov

Website: http://www.osti.gov/contact.html

This report was prepared as an account of work sponsored by an agency of the United States Government. Neither the United States Government nor any agency thereof, nor any of their employees, makes any warranty, express or implied, or assumes any legal liability or responsibility for the accuracy, completeness, or usefulness of any information, apparatus, product, or process disclosed, or represents that its use would not infringe privately owned rights. Reference herein to any specific commercial product, process, or service by trade name, trademark, manufacturer, or otherwise, does not necessarily constitute or imply its endorsement, recommendation, or favoring by the United States Government or any agency thereof. The views and opinions of authors expressed herein do not necessarily state or reflect those of the United States Government or any agency thereof. 
Nuclear Energy and Fuel Cycle Division

\title{
BWR Progression Problems
}

\author{
Chase Lawing, NCSU \\ Scott Palmtag, NCSU \\ Mehdi Asgari, ORNL
}

Date Published: September 30, 2021

\author{
Prepared by \\ OAK RIDGE NATIONAL LABORATORY \\ Oak Ridge, TN 37831-6283 \\ managed by \\ UT-Battelle, LLC \\ for the \\ US DEPARTMENT OF ENERGY \\ under contract DE-AC05-00OR22725
}





\section{CONTENTS}

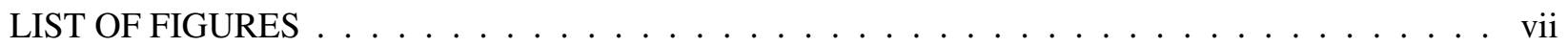

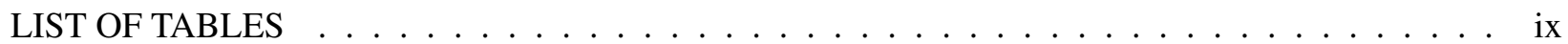

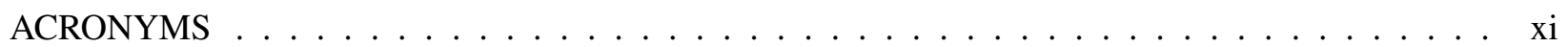

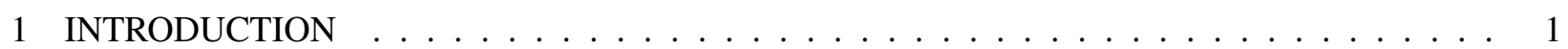

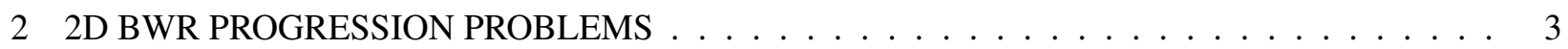

2.1 Peach Bottom Assembly Type $6 \ldots \ldots \ldots \ldots \ldots$

2.2 GE-9 Lattice . . . . . . . . . . . . . . . . . . . . . . . . . . . 8

2.3 Representative GE-14 Lattice . . . . . . . . . . . . . . . . . . . . . . . . . . . . 11

2.4 GE-14 Lattice with Vanished Rods . . . . . . . . . . . . . . . . . . . . . . . . . 14

2.5 2D Mini-Core . . . . . . . . . . . . . . . . . . . . . . . . . 15

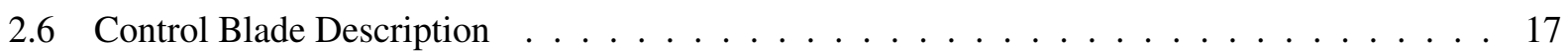

2.7 Lattice Depletions . . . . . . . . . . . . . . . . . . . . . . . 18

3 3D BWR PROGRESSION PROBLEMS . . . . . . . . . . . . . . . . . . . . . . . . . . . . . 19

3.1 GE-14 Bundle Specification . . . . . . . . . . . . . . . . . . . . . . . . . 19

3.2 Axial Control Blade Description . . . . . . . . . . . . . . . . . 25

3.3 Assumptions and Approximations for the 3D GE-14 Bundle Design . . . . . . . . . . . 25

$3.3 .1 \quad$ Spacer Grid Data $\ldots \ldots \ldots \ldots \ldots \ldots$

3.3 .2 Nozzle Data . . . . . . . . . . . . . . . . . . . . . . . 26

3.3 .3 Plug Regions . . . . . . . . . . . . . . . . . . . 26

3.3 .4 Plenum Region . . . . . . . . . . . . . . . . . . . . 26

3.3.5 Axial Void Distribution . . . . . . . . . . . . . . . . . 26

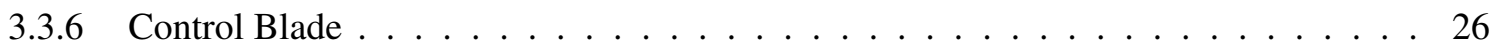

3.4 3D Single Bundle Problems . . . . . . . . . . . . . . . . . . . . . 27

3.5 3D Single Bundle Problems with Control Blade . . . . . . . . . . . . . . . 28

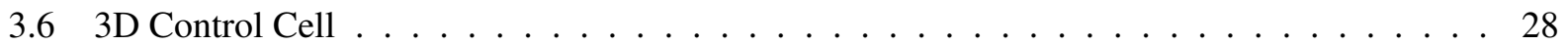

3.7 3D Mini-Core Problems $\ldots \ldots \ldots \ldots \ldots \ldots$

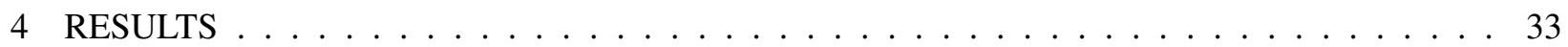

$4.1 \quad 2 \mathrm{D}$ Results . . . . . . . . . . . . . . . . . . . . . 33

4.1 .1 Peach Bottom Lattice Type $6 \ldots \ldots \ldots \ldots$

4.1 .2 GE-9 Single Assembly . . . . . . . . . . . . . . . . . . . . 37

4.1 .3 GE-14 Single Assembly . . . . . . . . . . . . . . . . . . . . . 41

4.1.4 GE-14 Single Assembly with Vanished Rods . . . . . . . . . . . . . . . . . . 45

4.1 .5 2D Mini-Core . . . . . . . . . . . . . . . . . . . . . . . . 49

4.1 .6 2D Lattice Depletions . . . . . . . . . . . . . . . . . . . . . . 49

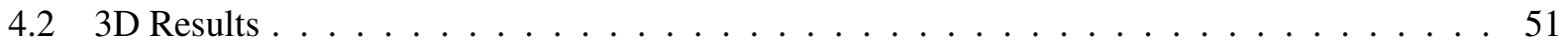

4.2.1 3D GE-14 Single Bundle Problems . . . . . . . . . . . . . . . . . . 51

4.2.2 Controlled 3D GE-14 Single Bundle Problems . . . . . . . . . . . . . . . . . 53

4.2 .3 3D Control Cell . . . . . . . . . . . . . . . . . . . . . . . 54

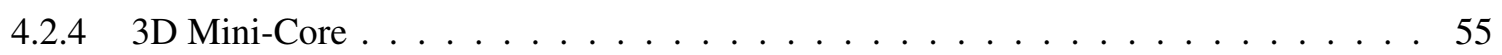

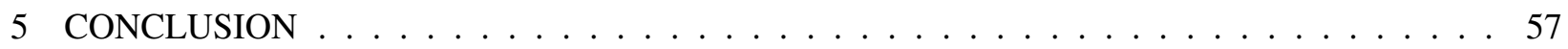

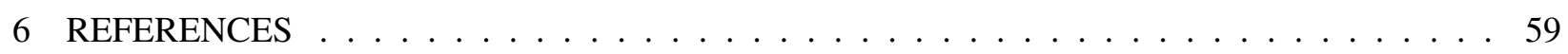

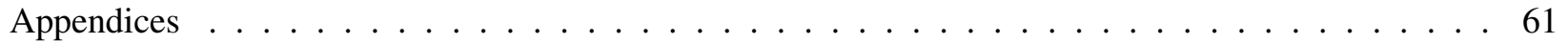

A Number Densities for All Materials . . . . . . . . . . . . . . . . . . . . . . . . 61

A.1 Structural Material for the Peach Bottom 6 Lattice . . . . . . . . . . . . . . . . . . . . 62 
A.2 Structural Materials for All Problems Except the Peach Bottom 6 Lattice . . . . . . . . . . 62

A.3 Fuels . . . . . . . . . . . . . . . . . . . . . . . . 64

A.3.1 Peach Bottom Type $6 \ldots \ldots \ldots \ldots \ldots \ldots$

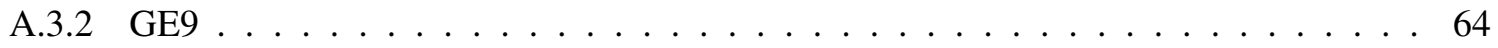

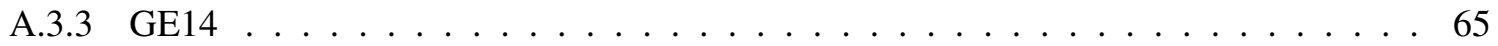

A.4 Smeared Grid and Nozzle Number Densities . . . . . . . . . . . . . . . . . . 67

A.5 Coolant Number Densities . . . . . . . . . . . . . . . . . . . . . . 68 



\section{LIST OF FIGURES}

1 Dimensions for the Peach Bottom type 6 bundle design. All dimensions are in centimeters. . 5

2 Dimensions for the Peach Bottom type 6 bundle fuel pin (left) and water rod (right).

Dimensions are in centimeters and are not to scale. . . . . . . . . . . . . 6

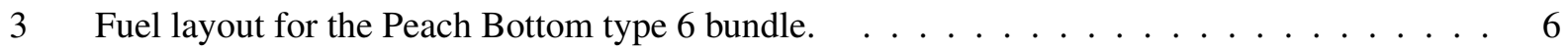

4 Dimensions for the GE-9 lattice. All dimensions are in centimeters. . . . . . . . . . . 8

5 Dimensions for the GE-9 fuel pin (left) and water rod (right). These two figures are not to

scale. All dimensions are in centimeters. . . . . . . . . . . . . . . . . . . 9

6 Fuel layout for the GE-9 bundle. . . . . . . . . . . . . . . . . . . . . . . . . . . 9

7 Dimensions for the GE-14 bundle design. All dimensions are in centimeters. . . . . . . . . 11

8 Dimensions for the GE-14 bundle fuel pin (left) and water rod (right). These two figures are not to scale. All dimensions are in centimeters. . . . . . . . . . . . . . . 12

9 Fuel layout for the GE-14 bundle. . . . . . . . . . . . . . . . . . . . . . . . . 12

10 Fuel layout for the GE-14 lattice with vanished rods. . . . . . . . . . . . . . . . . . . 14

11 Geometry of the 2D mini-core progression problem with the control blade inserted in the

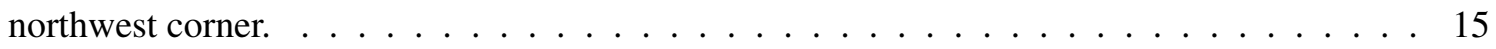

12 Void distribution for the uncontrolled 2D mini-core at 20\% (left) and 60\% (right)

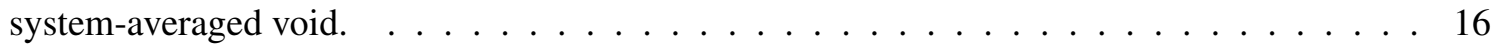

13 Void distribution for the controlled 2D mini-core at 20\% (left) and 60\% (right) system-averaged void. . . . . . . . . . . . . . . . . . 16

14 Dimensions for the original equipment manufacturer (OEM) control blade. All dimensions are in centimeters. . . . . . . . . . . . . . . . . 17

15 Axial breakdown of GE-14 bundle. All dimensions are shown in centimeters. . . . . . . . . 21

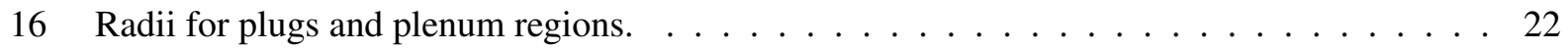

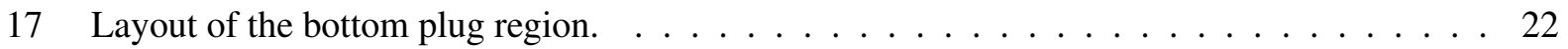

18 Fuel layout in NAT region (natural blanket at the base of the bundle) . . . . . . . . . . . 22

19 Fuel layout in the PSZ region (power shaping zone). . . . . . . . . . . . . . . . 23

20 Fuel layout in the DOM region (dominate zone) . . . . . . . . . . . . . . . 23

21 Fuel layout in the PLE region (plenum region for part-length rods) . . . . . . . . . . . . 23

22 Fuel layout in the PLP region (upper plug region for part-length rods) . . . . . . . . . . 23

23 Fuel layout in the VAN region (the part length rods "vanish" in this region). . . . . . . . . . 24

24 Fuel layout in the NV region (natural blanket in the top of the bundle where only full-length rods exist). . . . . . . . . . . . . . . . . . . . . . . 24

25 Fuel layout in the NT region (similar to the NV region, but full-length rods containing gadolinia at lower levels are now empty rods containing helium and no fuel inside the clad). 24

26 Layout in the PLEN region (plenum region for the full-length rods containing only helium inside the cladding). . . . . . . . . . . . . . . . . . . . . 24

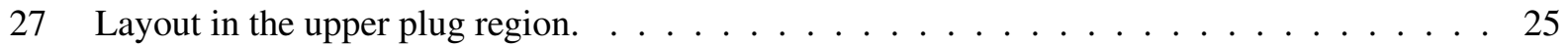

28 Radial void profile of the 3D control cell. Units are percentages. . . . . . . . . . . . . 28

29 Radial void profile and control blade map. The top values are void (\%), and the bottom values are steps withdrawn of the control blade to the northwest corner of the given bundle (for the mixed blade mini-core problem). The letters represent the control blade

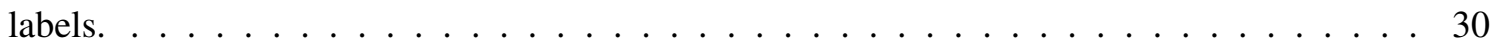

30 Normalized fission rates from Serpent (left) and $\Delta P_{i, j}$ (right) for the Peach Bottom 6 lattice at $0 \%$ void. . . . . . . . . . . . . . . . . 34 
31 Normalized fission rates from Serpent (left) and $\Delta P_{i, j}$ (right) for the Peach Bottom 6 lattice at $40 \%$ void. . . . . . . . . . . . . . . . . . . . . 35

32 Normalized fission rates from Serpent (left) and $\Delta P_{i, j}$ (right) for the Peach Bottom 6 lattice at $80 \%$ void. . . . . . . . . . . . . . . . . . . 35

33 Normalized fission rates from Serpent (left) and $\Delta P_{i, j}$ (right) for the controlled Peach Bottom 6 lattice at $0 \%$ void. . . . . . . . . . . . . . . . . . . . 36

34 Normalized fission rates from Serpent (left) and $\Delta P_{i, j}$ (right) for the controlled Peach Bottom 6 lattice at $40 \%$ void. . . . . . . . . . . . . . . . . . 36

35 Normalized fission rates from Serpent (left) and $\Delta P_{i, j}$ (right) for the controlled Peach Bottom 6 lattice at $80 \%$ void. . . . . . . . . . . . . . . . . . . 37

36 Normalized fission rates from Serpent (left) and $\Delta P_{i, j}$ (right) for the GE-9 lattice at $0 \%$

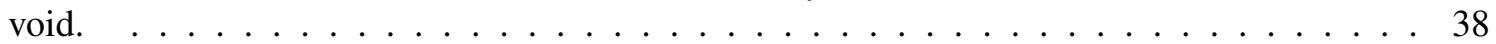

37 Normalized fission rates from Serpent (left) and $\Delta P_{i, j}$ (right) for the GE-9 lattice at $40 \%$

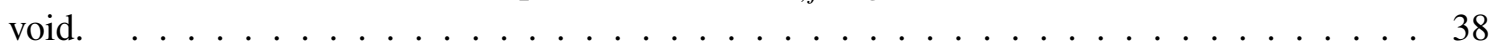

38 Normalized fission rates from Serpent (left) and $\Delta P_{i, j}$ (right) for the GE-9 lattice at $80 \%$

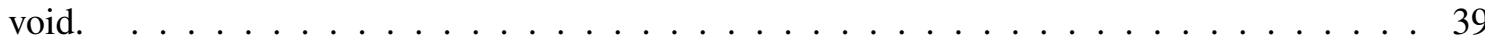

39 Normalized fission rates from Serpent (left) and $\Delta P_{i, j}$ (right) for the controlled GE-9 lattice at $0 \%$ void. . . . . . . . . . . . . . . . . . . . . 39

40 Normalized fission rates from Serpent (left) and $\Delta P_{i, j}$ (right) for the controlled GE-9 lattice at $40 \%$ void. . . . . . . . . . . . . . . . . . . . . . 40

41 Normalized fission rates from Serpent (left) and $\Delta P_{i, j}$ (right) for the controlled GE-9 lattice at $80 \%$ void. . . . . . . . . . . . . . . . . . . . 40

42 Normalized fission rates from Serpent (left) and $\Delta P_{i, j}$ (right) for the GE-14 lattice at $0 \%$

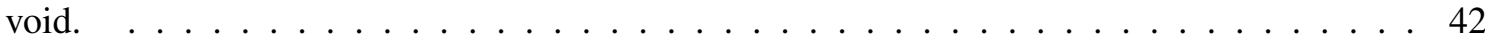

43 Normalized fission rates from Serpent (left) and $\Delta P_{i, j}$ (right) for the GE-14 lattice at $40 \%$

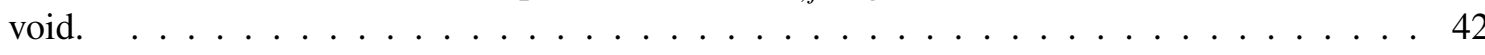

44 Normalized fission rates from Serpent (left) and $\Delta P_{i, j}$ (right) for the GE-14 lattice at $80 \%$

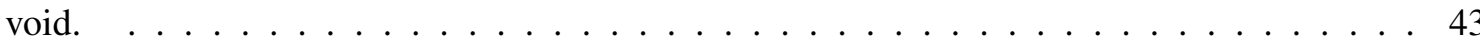

45 Normalized fission rates from Serpent (left) and $\Delta P_{i, j}$ (right) for the controlled GE-14

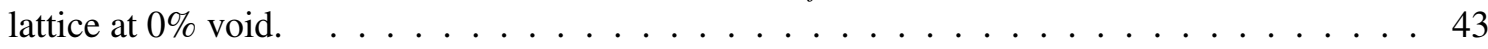

46 Normalized fission rates from Serpent (left) and $\Delta P_{i, j}$ (right) for the controlled GE-14 lattice at $40 \%$ void. . . . . . . . . . . . . . . . . . . . 44

47 Normalized fission rates from Serpent (left) and $\Delta P_{i, j}$ (right) for the controlled GE-14 lattice at $80 \%$ void. . . . . . . . . . . . . . . . . . . . . 44

48 Normalized fission rates from Serpent (left) and $\Delta P_{i, j}$ (right) for the GE-14 lattice with vanished rods at $0 \%$ void. . . . . . . . . . . . . . . . . . 46

49 Normalized fission rates from Serpent (left) and $\Delta P_{i, j}$ (right) for the GE-14 lattice with vanished rods at $40 \%$ void. . . . . . . . . . . . . . . . . . . . 46

50 Normalized fission rates from Serpent (left) and $\Delta P_{i, j}$ (right) for the GE-14 lattice with vanished rods at $80 \%$ void. . . . . . . . . . . . . . . . . . . . . 47

51 Normalized fission rates from Serpent (left) and $\Delta P_{i, j}$ (right) for the controlled GE-14 lattice with vanished rods at $0 \%$ void. . . . . . . . . . . . . . . . . 47

52 Normalized fission rates from Serpent (left) and $\Delta P_{i, j}$ (right) for the controlled GE-14 lattice with vanished rods at $40 \%$ void. 
53 Normalized fission rates from Serpent (left) and $\Delta P_{i, j}$ (right) for the controlled GE-14 lattice with vanished rods at $80 \%$ void. . . . . . . . . . . . . . . . . 48

54 Eigenvalue as a function of burnup from the Serpent reference solutions for the GE-9 depletions (left) and the difference in eigenvalue compared with MPACT (right). Results are shown for 0,40 , and $80 \%$ void cases. . . . . . . . . . . . . . . 50

55 Eigenvalue as a function of burnup from the Serpent reference solutions for the GE-14 depletions (left) and difference in eigenvalue compared with MPACT (right). Results are shown for 0,40 , and $80 \%$ void cases. . . . . . . . . . . . . . . 50

56 Normalized fission rates in 4 pins from Serpent (left) and $\Delta P_{i, j}$ (right) for the HZP single

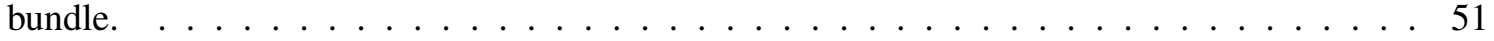

57 Normalized fission rates from Serpent (left) and $\Delta P_{i, j}$ (right) at $195.5 \mathrm{~cm}$ for the HZP

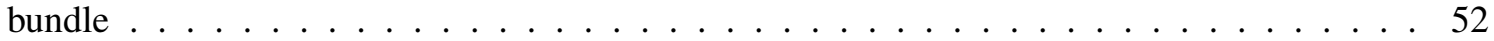

58 Normalized fission rates in 4 pins from Serpent (left) and $\Delta P_{i, j}$ (right) for the HFP single

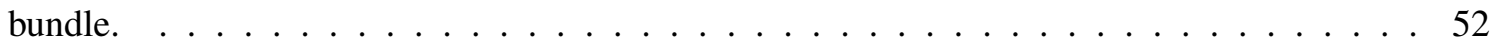

59 Normalized fission rates in 4 pins from Serpent (left) and $\Delta P_{i, j}$ (right) for the CZP single bundle. . . . . . . . . . . . . . . . . . . . 53 



\section{LIST OF TABLES}

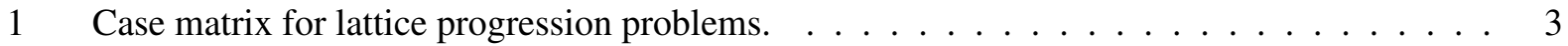

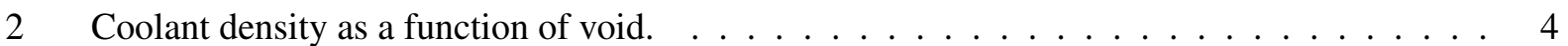

3 Fuel descriptions for Peach Bottom type 6 bundle. . . . . . . . . . . . . . . 7

4 Input parameters for the Peach Bottom type 6 lattice. . . . . . . . . . . . . . 7

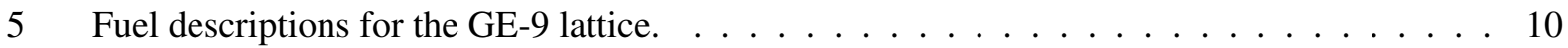

6 Input parameters for the GE-9 lattice. . . . . . . . . . . . . . . . . . . . . . 10

7 Fuel descriptions for the GE-14 lattice. . . . . . . . . . . . . . . . . . . . . 13

8 Input parameters for the GE-14 lattice. . . . . . . . . . . . . . . . . . . . 13

9 Input parameters for the GE OEM control blade. . . . . . . . . . . . . . . . 18

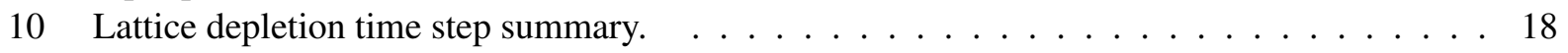

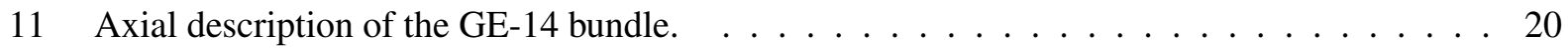

12 Description of grids and nozzles for the GE-14 bundle. . . . . . . . . . . . . . . 20

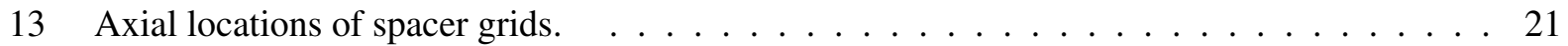

14 Axial data for control blade. . . . . . . . . . . . . . . . . . . . 25

15 Input parameters for the 3D single bundle progression problems. . . . . . . . . . . 27

16 Case specific parameters for the 3D single bundle problems. . . . . . . . . . . . 27

17 Axial void distribution for the 3D single bundle case at hot full power (HFP). . . . . . . . 27

18 Height of control blade for each of the thirteen controlled single bundle problems. . . . . . 28

19 Input parameters for the 3D control cell . . . . . . . . . . . . . . . . . . . . 29

20 Input parameters for the $3 \mathrm{D}$ mini-core. $\ldots \ldots \ldots \ldots \ldots \ldots \ldots \ldots \ldots$

213 D mini-core control blade placements in the mixed blade position problem. . . . . . . . 31

22 Summary of comparison between MPACT and Serpent results for the Peach Bottom 6 lattice. 34

23 Summary of comparison between MPACT and Serpent results for the GE-9 lattice. . . . . . 37

24 Summary of comparison between MPACT and Serpent results for the GE-14 lattice. . . . . . 41

25 Summary of comparison between MPACT and Serpent results for the GE-14 lattice with vanished rods. . . . . . . . . . . . . . . . . . . . . . . . 45

26 Summary of comparison between MPACT and Serpent results for the 2D Mini-Core. . . . . 49

27 Summary of comparison between Serpent and MPACT results for the 3D Single bundle

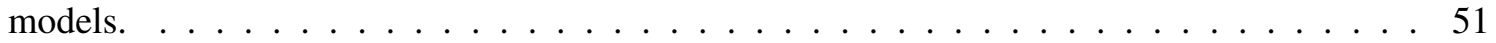

28 Summary of comparison between Serpent and MPACT results for the 3D controlled single bundles. . . . . . . . . . . . . . . . . . . . . . 54

29 Summary of comparison between Serpent and MPACT results for the 3D Control Cell. . . . 54

30 Summary of comparison between Serpent and MPACT results for the 3D Mini Core Cases. 55 



\section{ACRONYMS}

ARI All Rods In

ARO All Rods Out

BWR boiling water reactor

CASL Consortium for the Advanced Simulation of Light Water Reactors

CZP cold zero power

HFP hot full power

HZP hot zero power

MC Monte Carlo

NCSU North Carolina State University

OEM original equipment manufacturer

ORNL Oak Ridge National Laboratory

PWR pressurized water reactor

RMS Root Mean Square

VERA Virtual Environment for Reactor Applications 



\section{INTRODUCTION}

Under the Consortium for the Advanced Simulation of Light Water Reactors (CASL) Program, the Virtual Environment for Reactor Applications (VERA) was developed with the primary focus to model pressurized water reactors (PWRs). Recently, a new project was started to extend the modeling capability in VERA to model boiling water reactors (BWRs). The new project is called "Modeling and Analysis of Exelon BWRs for Eigenvalue and Thermal Limits Predictability," and it is led by Oak Ridge National Laboratory (ORNL) and Exelon with participation from Global Nuclear Fuel and three universities: North Carolina State University (NCSU), the University of Michigan, and the University of Illinois.

Under the CASL program, the PWR development was guided by a series of "Progression Problems" which guided development and defined project milestones. This report outlines a series of similar progression problems designed to guide the development of BWR capabilities in VERA. The BWR progression problems were developed as a collaboration between NCSU and ORNL.

The progression problems are used to supplement software requirements by providing a development path with problems of increasing complexity. Each progression problem provides useful capabilities to users, which encourages early adoption. Additionally, each progression problem can be validated so that any errors can be found faster. The ability to receive user feedback and validate intermediate results helps speed up the development process and deliver higher quality software.

In addition to helping users and developers, the ability to model each progression problem provides useful milestones for tracking development progress.

The BWR progression problems are influenced by the PWR progression problems used in the early VERA development [5]. The progressions start with a single 2D assembly and progressively add more complexity, as shown in the following list.

1. 2D BWR Lattice

2. 2 D Mini-Core $(4 \times 4)$

3. 3D Single Bundle

4. 3D Control Cell $(2 \times 2)$

5. 3D Mini-Core $(4 \times 4)$

Section 2 of this document provides the specifications for the 2D progression problems, Section 3 provides the specifications for the 3D progression problems, and Section 4 provides the Monte Carlo (MC) results for all the progression problems. Where feasible, normalized fission rates are provided from the MC solutions, however, for larger cases only the eigenvalue is provided in this document. Full fission rate distributions can be found for all cases in the BWR progression problems Github repository [10]. 



\section{2D BWR PROGRESSION PROBLEMS}

The BWR progression problems start with 2D lattice calculations as the simplest problems. Previous progression problems were developed to demonstrate VERA's capability to solve pincell calculations [5], and these do not need to be repeated. Therefore, the BWR progression problems start at the assembly level. Four lattice types are considered in the 2D lattice progression problems:

- $8 \times 8$ bundle from cycle 2 of the Peach Bottom unit 2 core with two small water rods,

- $8 \times 8$ GE-9 bundle with a large water rod,

- $10 \times 10$ GE-14 bundle with two large water rods, and

- $10 \times 10 \mathrm{GE}-14$ bundle with two large water rods and part length rods.

The geometry and material specifications for these lattices can be found in Section 2.1, Section 2.2, Section 2.3, and Section 2.4. For each lattice, there are six progression problems made up from the state points shown in Table 1, each with a controlled and an uncontrolled version. The control blade used for each controlled case is described in Section 2.6.

Table 1. Case matrix for lattice progression problems.

\begin{tabular}{|c|c|}
\hline Moderator temperature (K) & 600 \\
\hline Fuel temperature (K) & 900 \\
\hline Pressure (psia) & 1,040 \\
\hline Void (\%) & $0.0,40.0,80.0$ \\
\hline
\end{tabular}

In addition to the four BWR lattice geometries, one $4 \times 4$ 2D mini-core was considered and is described in Section 2.5. In this problem, all bundles are the GE-14 bundle described in Section 2.3. For the 2D mini-core, a similar case matrix as the single assemblies was used; however, the system-average voids were 0,20, and 60\%, and the radial void distributions are specified in Section 2.5. A coolant density table that represents the densities used in all the progression problems is shown in Table 2. The coolant density is defined as a function of void in increments of $5 \%$ void and was calculated by assuming $\rho_{l}=0.73669 \mathrm{~g} / \mathrm{cc}$ and $\rho_{g}=0.037523 \mathrm{~g} / \mathrm{cc}$ [6]. All moderator-water flowing outside the channel box and through the water rods-is assumed to be at $0 \%$ void. 
Table 2. Coolant density as a function of void.

\begin{tabular}{|c|c||c|c|}
\hline Void (\%) & Density $(\mathrm{g} / \mathrm{cc})$ & Void (\%) & Density $(\mathrm{g} / \mathrm{cc})$ \\
\hline \hline 0 & 0.73669000 & 55 & 0.35214815 \\
\hline 5 & 0.70173165 & 60 & 0.31718980 \\
\hline 10 & 0.66677330 & 65 & 0.28223145 \\
\hline 15 & 0.63181495 & 70 & 0.24727310 \\
\hline 20 & 0.59685660 & 75 & 0.21231475 \\
\hline 25 & 0.56189825 & 80 & 0.17735640 \\
\hline 30 & 0.52693990 & 85 & 0.14239805 \\
\hline 35 & 0.49198155 & 90 & 0.10743970 \\
\hline 40 & 0.45702320 & 95 & 0.07248135 \\
\hline 45 & 0.42206485 & 100 & 0.03752300 \\
\hline 50 & 0.38710650 & & \\
\hline
\end{tabular}

This coolant density specification is used throughout all calculations for $2 \mathrm{D}$ and $3 \mathrm{D}$ problems. Detailed descriptions of number densities used for moderator and coolant are provided in Appendix A. 


\subsection{Peach Bottom Assembly Type 6}

The first 2D lattice progression problem is an $8 \times 8$ assembly from cycle 2 of Peach Bottom unit 2 . This section describes the geometry and material composition of the lattice. All specifications were found in Solis, Ivanov, and Sarikaya [14] and are based on the type 6 assembly in this document. The dimensions for the lattice are depicted in Figure 1. The radii for the fuel pins and water rods are shown in Figure 2. The fuel layout is described in Figure 3, and the corresponding compositions are listed in Table 3. A concise listing of input parameters used in modeling the lattice is provided in Table 4. The Zircaloy densities shown in Table 4 were obtained from Solis, Ivanov, and Sarikaya [14].

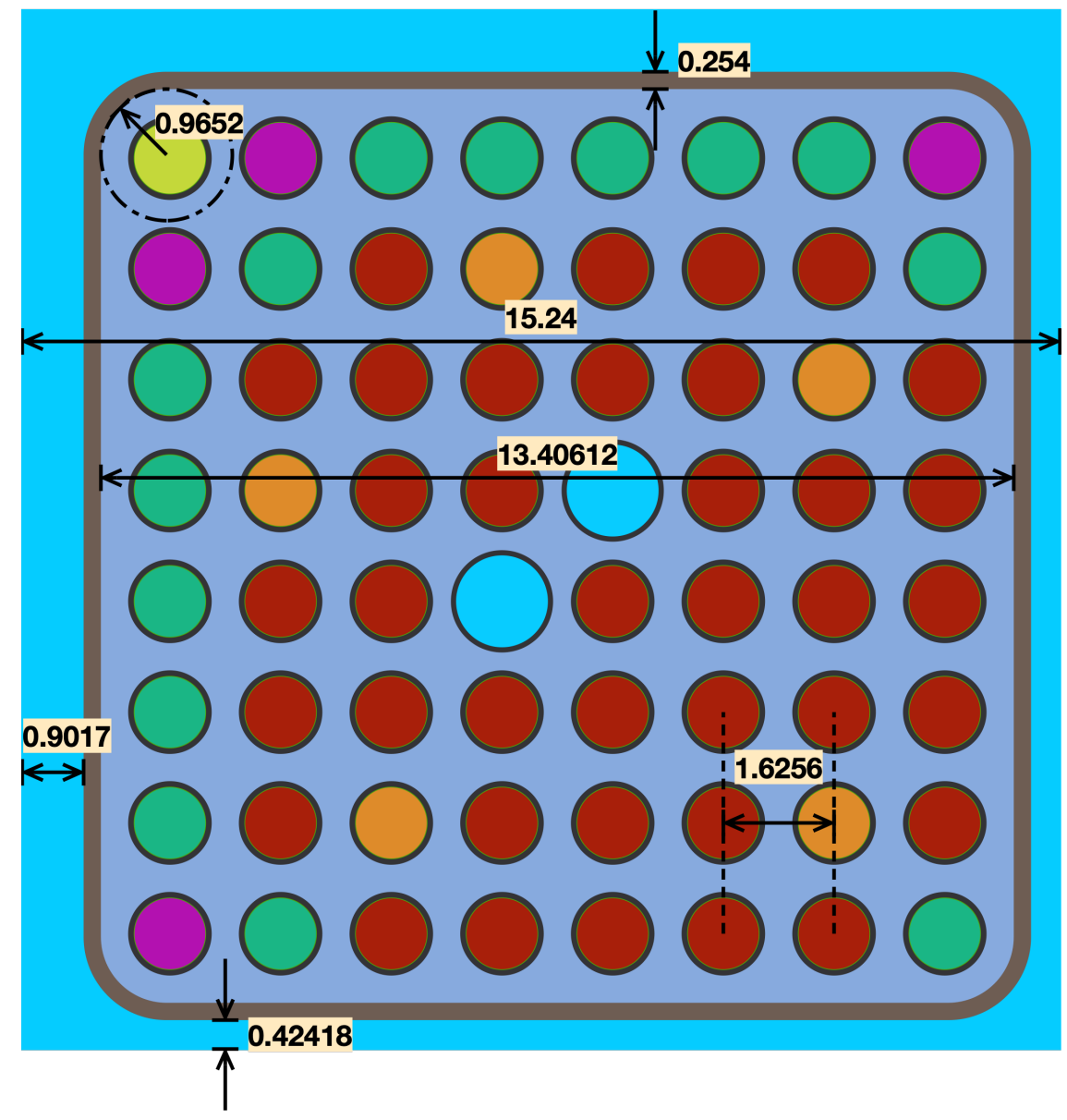

Figure 1. Dimensions for the Peach Bottom type 6 bundle design. All dimensions are in centimeters. 

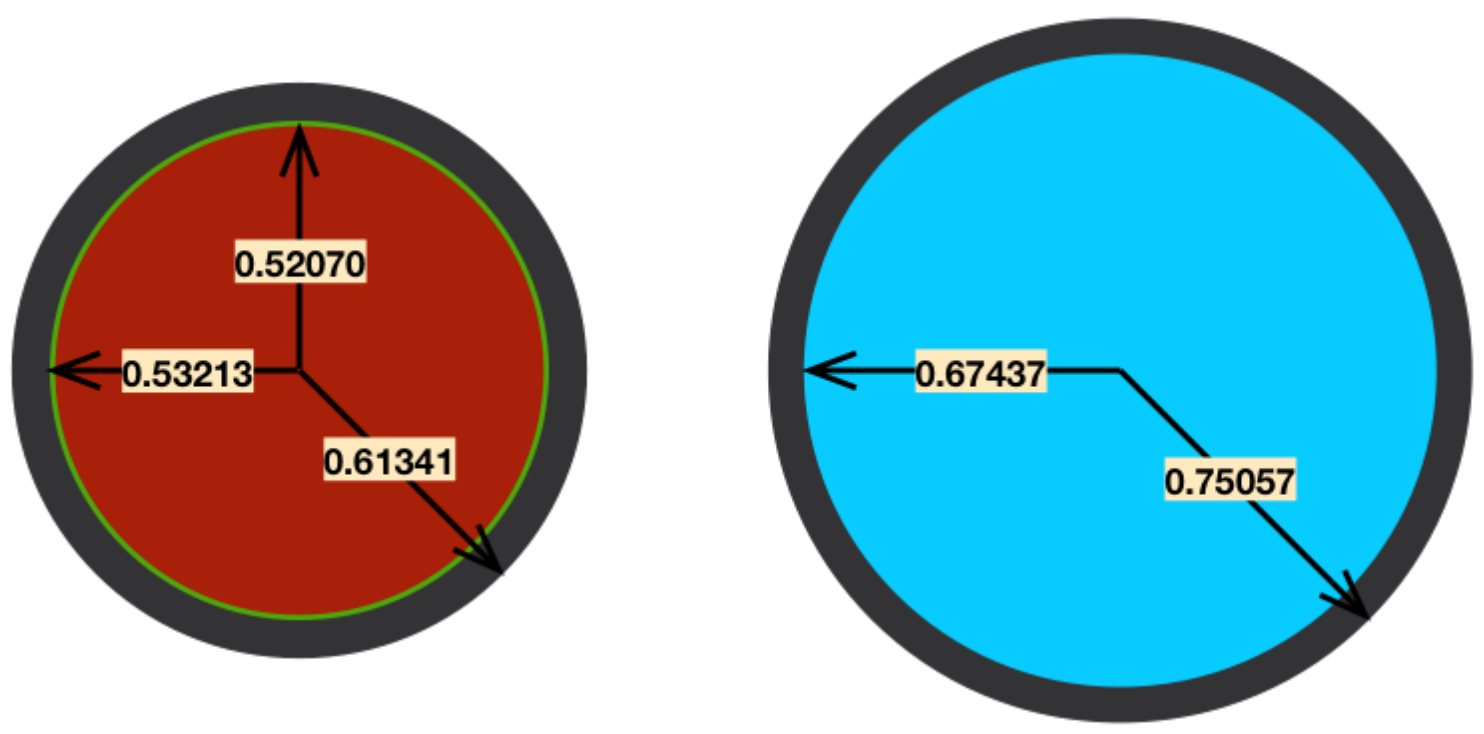

Figure 2. Dimensions for the Peach Bottom type 6 bundle fuel pin (left) and water rod (right). Dimensions are in centimeters and are not to scale.

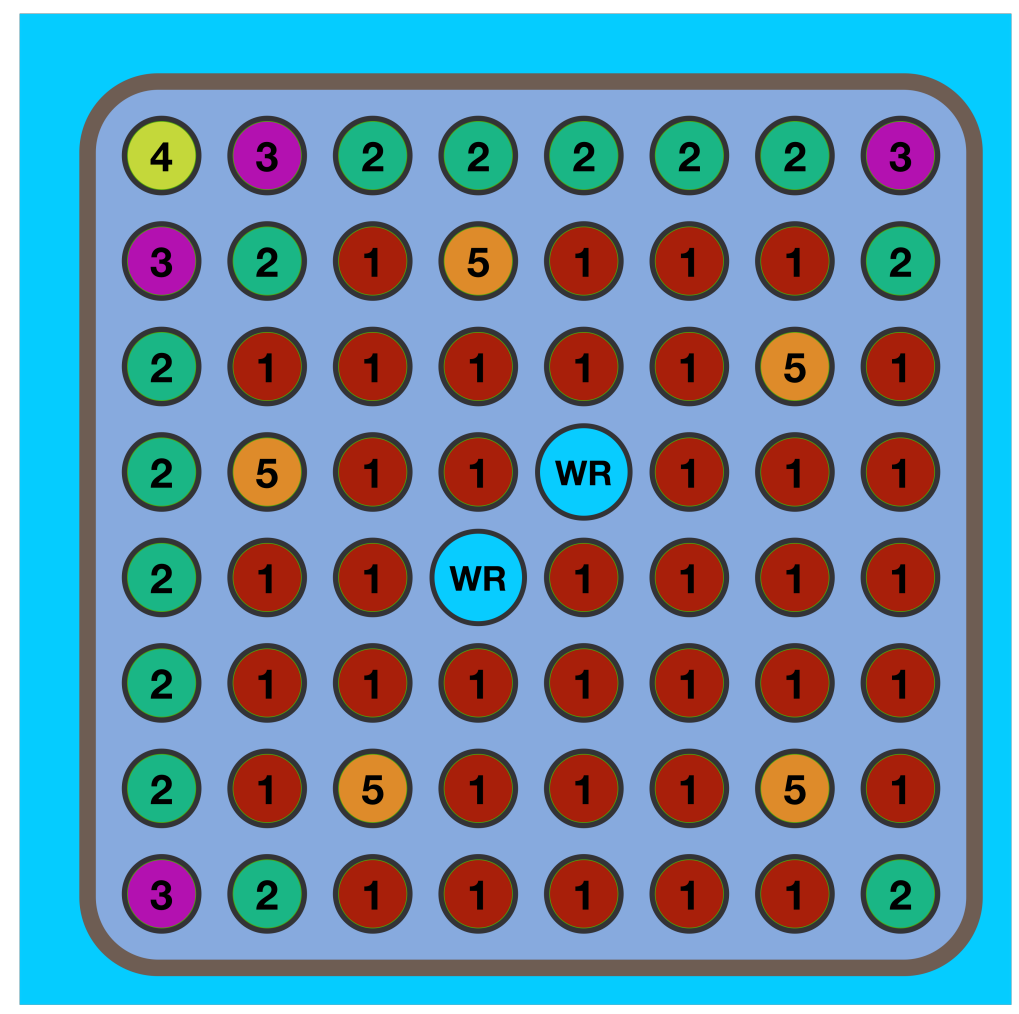

Figure 3. Fuel layout for the Peach Bottom type 6 bundle. 
Table 3. Fuel descriptions for Peach Bottom type 6 bundle.

\begin{tabular}{|c|c|c|c|}
\hline Rod label & ${ }^{235} \mathrm{U}$ enrichment (\%) & Gadolinia loading (\%) & Stack density (g/cc) \\
\hline \hline 1 & 3.01 & 0.0 & 10.32 \\
2 & 2.22 & 0.0 & 10.32 \\
3 & 1.87 & 0.0 & 10.32 \\
4 & 1.45 & 0.0 & 10.32 \\
5 & 3.01 & 2.0 & 10.23 \\
\hline
\end{tabular}

Table 4. Input parameters for the Peach Bottom type 6 lattice.

\begin{tabular}{|c|c|}
\hline Moderator temp. (K) & 600 \\
Fuel temp. (K) & 900 \\
Pressure (psia) & 1,040 \\
Void (\%) & $0,40,80$ \\
Assembly pitch (cm) & 15.24 \\
Height (cm) & 1.0 \\
Boundary condition (all) & Reflecting \\
Pin pitch (cm) & 1.6256 \\
Gap (wide/narrow) (cm) & $0.9017 / 0.42418$ \\
Channel box thickness (cm) & 0.254 \\
Channel box corner radius (cm) & 0.9652 \\
Fuel pellet outer radius $(\mathrm{cm})$ & 0.5207 \\
Fuel clad inner radius $(\mathrm{cm})$ & 0.53213 \\
Fuel clad outer radius $(\mathrm{cm})$ & 0.61341 \\
Water rod inner radius $(\mathrm{cm})$ & 0.67437 \\
Water rod outer radius $(\mathrm{cm})$ & 0.75057 \\
Channel box material (name/density) $(\mathrm{g} / \mathrm{cc})$ & Zircaloy-4/6.5514 \\
Cladding Material (name/density) $(\mathrm{g} / \mathrm{cc})$ & Zircaloy-2/6.5514 \\
\hline
\end{tabular}




\subsection{GE-9 Lattice}

A second $8 \times 8$ BWR lattice based on the GE-9 bundle was considered for the progression problems. The geometry of the GE-9 lattice was obtained from Kelly [8], which was also the source of the fuel layout and compositions. The GE-9 bundle contains one large water rod at its center center and eight gadolinia-bearing fuel pins.

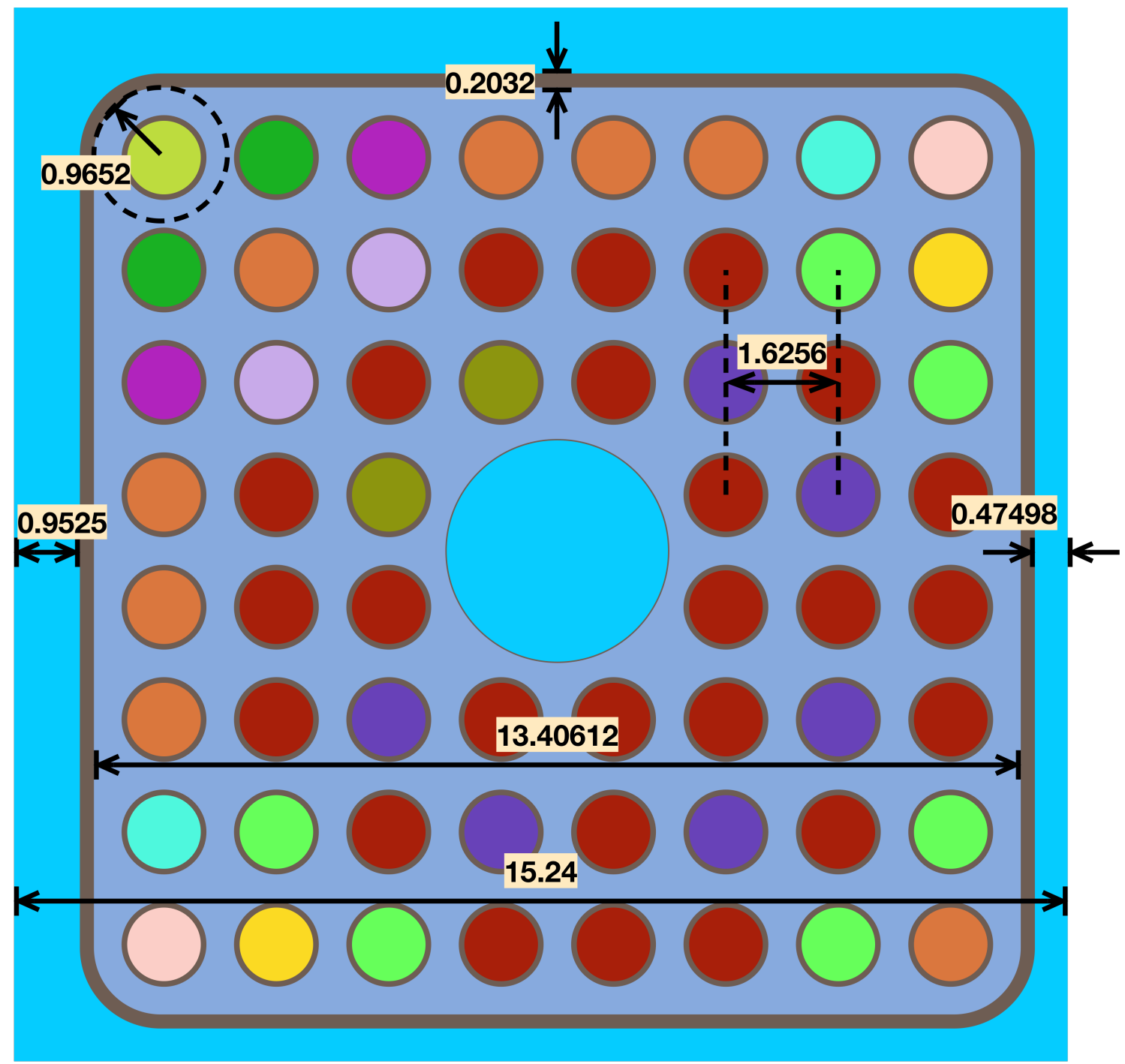

Figure 4. Dimensions for the GE-9 lattice. All dimensions are in centimeters. 

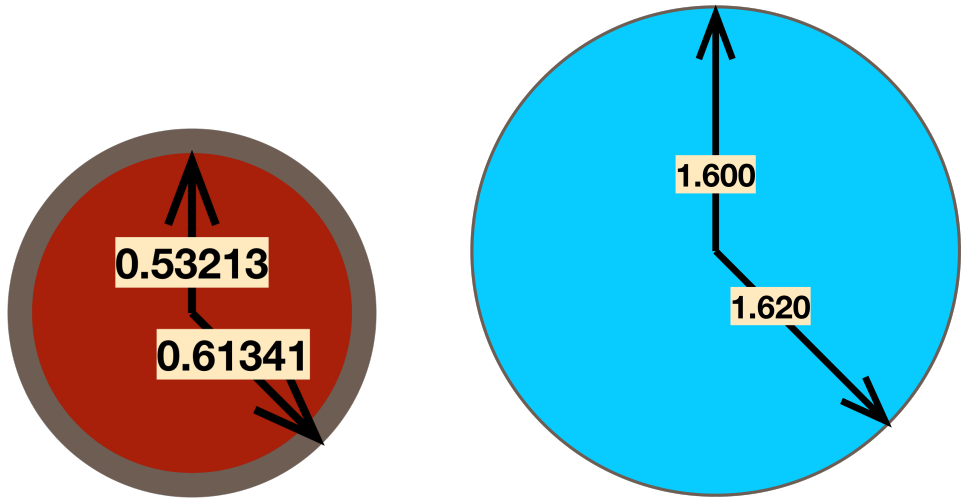

Figure 5. Dimensions for the GE-9 fuel pin (left) and water rod (right). These two figures are not to scale. All dimensions are in centimeters.

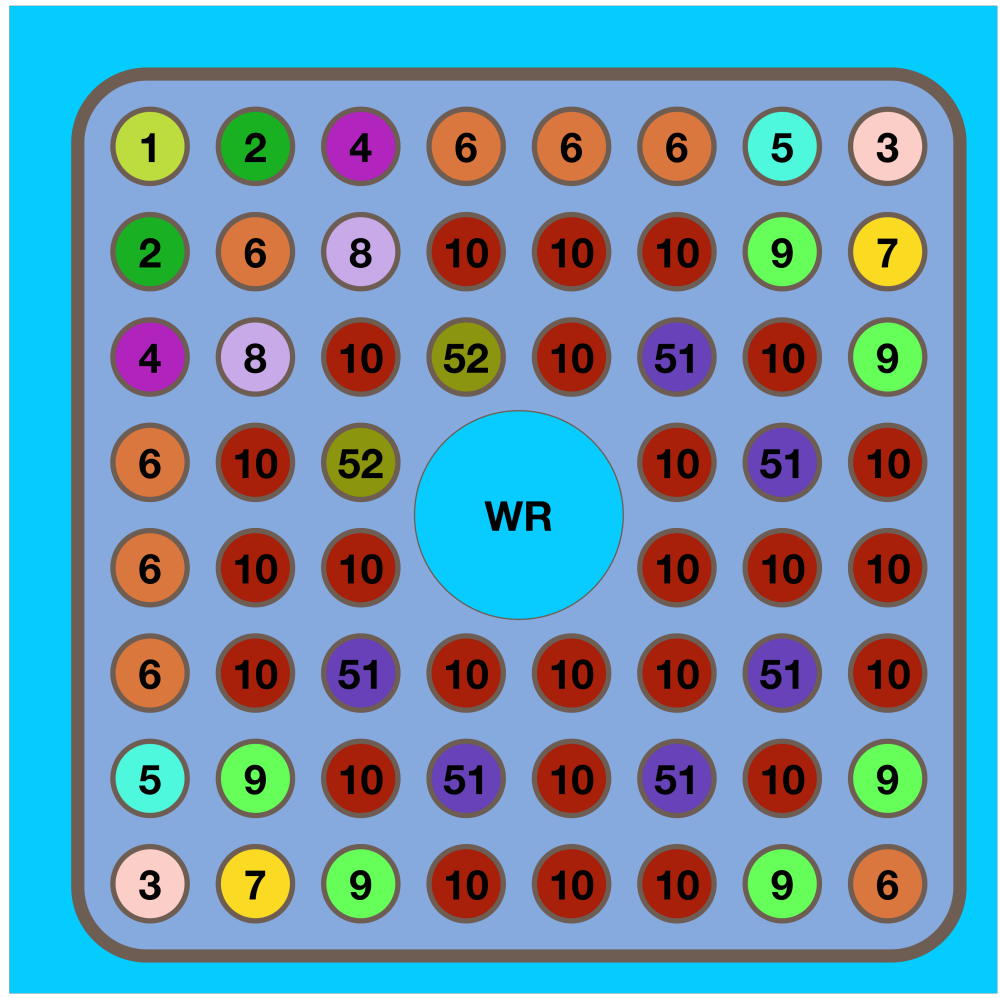

Figure 6. Fuel layout for the GE-9 bundle. 
Table 5. Fuel descriptions for the GE-9 lattice.

\begin{tabular}{|c|c|c|c|}
\hline Rod label & ${ }^{235} \mathrm{U}$ enrichment (\%) & Gadolinia loading (\%) & Stack density $(\mathrm{g} / \mathrm{cc})$ \\
\hline \hline 1 & 1.60 & 0.0 & 10.0642 \\
2 & 2.00 & 0.0 & 10.0642 \\
3 & 2.20 & 0.0 & 10.0642 \\
4 & 2.40 & 0.0 & 10.0642 \\
5 & 2.60 & 0.0 & 10.0642 \\
6 & 2.80 & 0.0 & 10.0642 \\
7 & 3.00 & 0.0 & 10.0642 \\
8 & 3.60 & 0.0 & 10.0642 \\
9 & 3.80 & 0.0 & 10.0642 \\
10 & 3.95 & 0.0 & 10.0642 \\
51 & 3.95 & 4.0 & 9.9390 \\
52 & 3.60 & 4.0 & 9.9390 \\
\hline
\end{tabular}

The rod labels in Figure 6 and Table 5 are consistent. The oversized water rod is located in the center of the lattice and is labeled with "WR" in Figure 6. In MPACT, the oversized water rods must fit within two pincells. For this reason, the water rod dimensions were reduced slightly from the original dimensions in Kelly [8]. Important input parameters are provided for the GE-9 lattice in Table 6. For the GE-9 lattice, the fuel pellet was expanded out to the clad, and the density was reduced to preserve fuel mass. This is consistent with the model presented in Kelly [8]. This means that the fuel pellet outer radius is identical to the cladding inner radius. The densities for Zircaloy shown in Table 6 were found in Palmtag et al. [13].

Table 6. Input parameters for the GE-9 lattice.

\begin{tabular}{|c|c|}
\hline Moderator temp. (K) & 600 \\
Fuel temp. (K) & 900 \\
Pressure (psia) & 1,040 \\
Void (\%) & $0,40,80$ \\
Assembly pitch (cm) & 15.24 \\
Height (cm) & 1.0 \\
Boundary condition (all) & Reflecting \\
Pin pitch (cm) & 1.6256 \\
Gap (wide/narrow) (cm) & $0.9525 / 0.47498$ \\
Channel box thickness $(\mathrm{cm})$ & 0.2032 \\
Channel box corner radius $(\mathrm{cm})$ & 0.9652 \\
Fuel pellet outer radius $(\mathrm{cm})$ & 0.53213 \\
Fuel clad inner radius $(\mathrm{cm})$ & 0.53213 \\
Fuel clad outer radius $(\mathrm{cm})$ & 0.61341 \\
Water rod inner radius $(\mathrm{cm})$ & 1.60000 \\
Water rod outer radius $(\mathrm{cm})$ & 1.62000 \\
Channel box material (name/density) $(\mathrm{g} / \mathrm{cc})$ & Zircaloy-4/6.56 \\
Cladding material (name/density) (g/cc) & Zircaloy-2/6.56 \\
\hline
\end{tabular}




\subsection{Representative GE-14 Lattice}

A representative $10 \times 10$ GE-14 bundle was developed by compiling data from several public sources. Much of the geometry is defined based on Table A-3 in Kärnbränslehantering [2]. The GE-14 dimensions are depicted in Figure 7. Radii for the fuel pins and water rods are shown in Figure 8. The fuel layout is described in Figure 9, and the corresponding compositions are listed in Table 7.

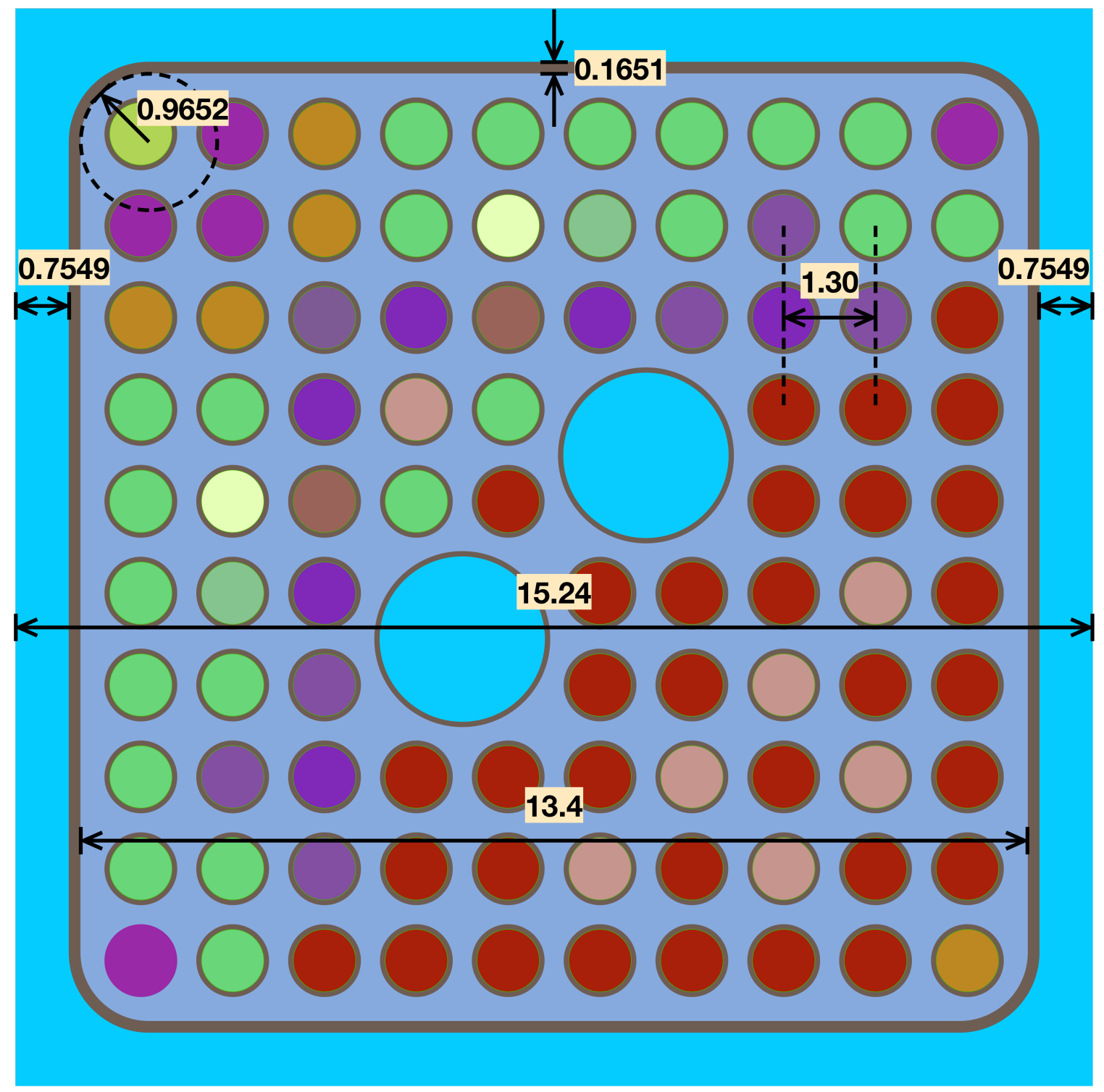

Figure 7. Dimensions for the GE-14 bundle design. All dimensions are in centimeters. 

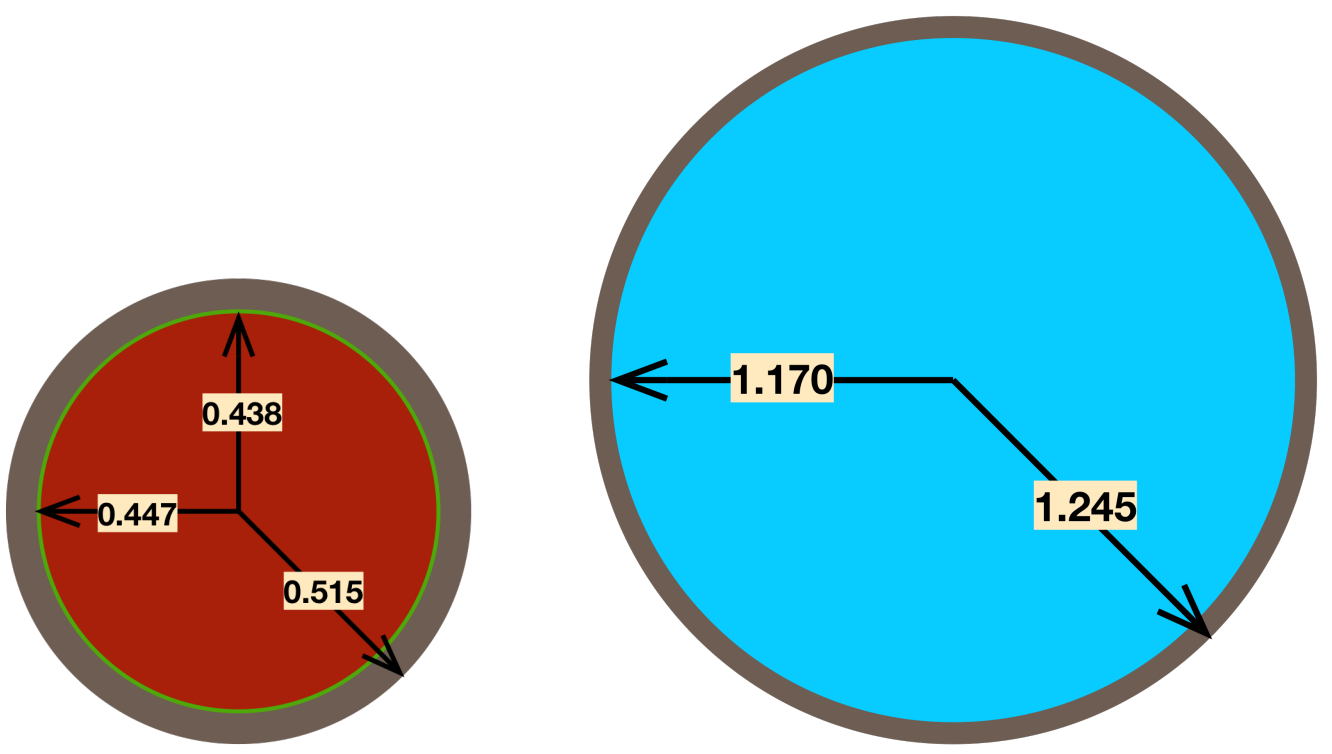

Figure 8. Dimensions for the GE-14 bundle fuel pin (left) and water rod (right). These two figures are not to scale. All dimensions are in centimeters.

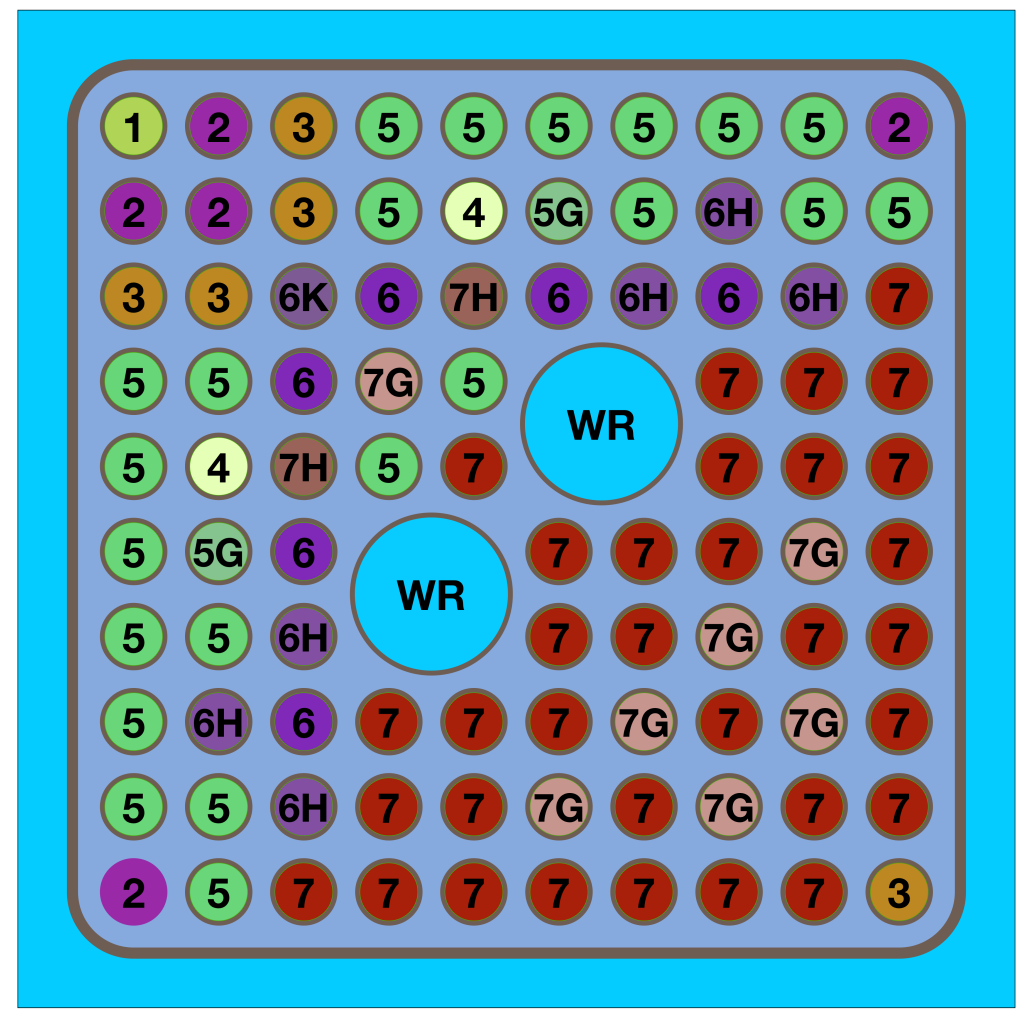

Figure 9. Fuel layout for the GE-14 bundle. 
Table 7. Fuel descriptions for the GE-14 lattice.

\begin{tabular}{|c|c|c|c|}
\hline Rod label & ${ }^{235} \mathrm{U}$ enrichment (\%) & Gadolinia loading (\%) & Stack density (g/cc) \\
\hline \hline 1 & 1.60 & 0.0 & 10.40 \\
2 & 2.80 & 0.0 & 10.40 \\
3 & 3.20 & 0.0 & 10.40 \\
4 & 3.60 & 0.0 & 10.40 \\
5 & 3.95 & 0.0 & 10.40 \\
$5 \mathrm{G}$ & 3.95 & 8.0 & 10.19 \\
6 & 4.40 & 0.0 & 10.40 \\
$6 \mathrm{H}$ & 4.40 & 6.0 & 10.19 \\
$6 \mathrm{~K}$ & 4.40 & 3.0 & 10.19 \\
7 & 4.90 & 0.0 & 10.40 \\
$7 \mathrm{G}$ & 4.90 & 8.0 & 10.19 \\
$7 \mathrm{H}$ & 4.90 & 6.0 & 10.19 \\
$\mathrm{~N}$ & 0.71 & 0.0 & 10.40 \\
\hline
\end{tabular}

The rod labels in Figure 9 and Table 7 are consistent. The two oversized water rods are labeled with "WR" in Figure 9. The fuel layout and fuel specifications were found in Fensin [4]. The densities for fuel rods without gadolinia were obtained from Fensin [2]; however, for gadolinia-bearing fuels, the density is estimated by using data from Solis, Ivanov, and Sarikaya [14]. A more concise description of the problem dimensions is provided in Table 8. The densities for Zircaloy were obtained from Palmtag et al. [13].

Table 8. Input parameters for the GE-14 lattice.

\begin{tabular}{|c|c|}
\hline Moderator temp. (K) & 600 \\
Fuel temp. (K) & 900 \\
Pressure (psia) & 1,040 \\
Void (\%) & $0,40,80$ \\
Assembly pitch (cm) & 15.24 \\
Height (cm) & 1.0 \\
Boundary condition (all) & Reflecting \\
Pin pitch (cm) & 1.3 \\
Gap (wide/narrow) (cm) & $0.7549 / 0.7549$ \\
Channel box thickness (cm) & 0.1651 \\
Channel box corner radius (cm) & 0.9652 \\
Fuel pellet outer radius (cm) & 0.438 \\
Fuel clad inner radius (cm) & 0.447 \\
Fuel clad outer radius (cm) & 0.515 \\
Water rod inner radius $(\mathrm{cm})$ & 1.170 \\
Water rod outer radius (cm) & 1.245 \\
Channel box material (name/density) (g/cc) & Zircaloy-4/6.56 \\
Cladding material (name/density) (g/cc) & Zircaloy-2/6.56 \\
\hline
\end{tabular}




\subsection{GE-14 Lattice with Vanished Rods}

The GE-14 bundle with vanished rods is geometrically identical to the GE-14 bundle in Section 2.3, except for the 14 fuel pins that are removed. The fuel layout is slightly different for the vanished rod case and is depicted in Figure 10. This fuel layout was gathered from Fensin [4].

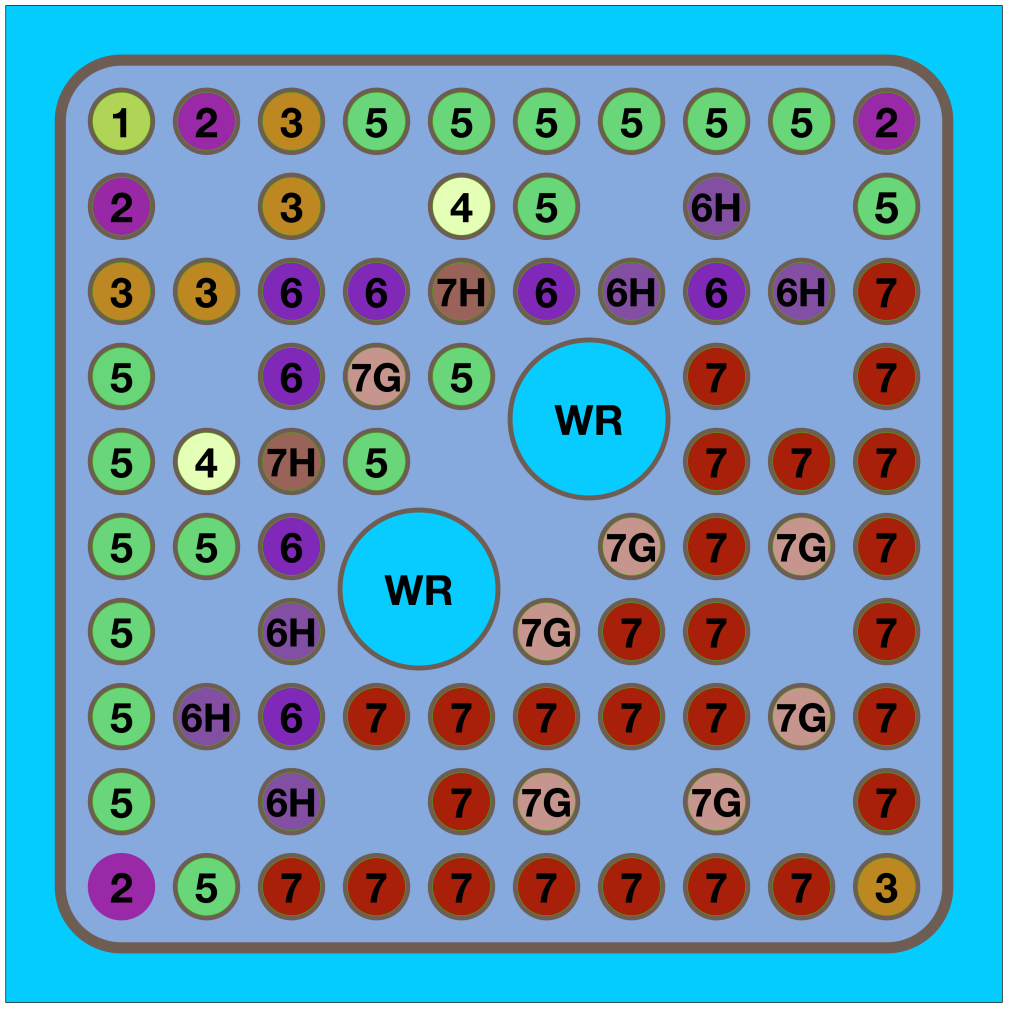

Figure 10. Fuel layout for the GE-14 lattice with vanished rods.

The fuel descriptions corresponding to the fuel labels in Figure 10 are shown in Table 7. Although the fuel layout for the remaining rods in Figure 10 is similar to that in the previous GE-14 lattice in Figure 9, they are not identical. The dimensions for the GE-14 lattice with vanished rods are shown in Figure 7 and Figure 8. The information in Table 8 is also applicable to the GE-14 vanished rod lattice. 


\subsection{D Mini-Core}

The mini-core test case comprises 16 GE-14 bundles that all have the fuel layout from Figure 9 and the dimensions from Figure 7 and Figure 8. Controlled and uncontrolled configurations are tested with problem-averaged voids of 0,20, and 60\%. The specific assembly void distributions are shown in Figure 12 and Figure 13. The controlled problem is shown in Figure 11, which demonstrates the bundle orientations for each location. The uncontrolled problem geometry is identical to the controlled problem, except that the control blade in the northwest corner of the problem is removed. All boundary conditions are reflective.

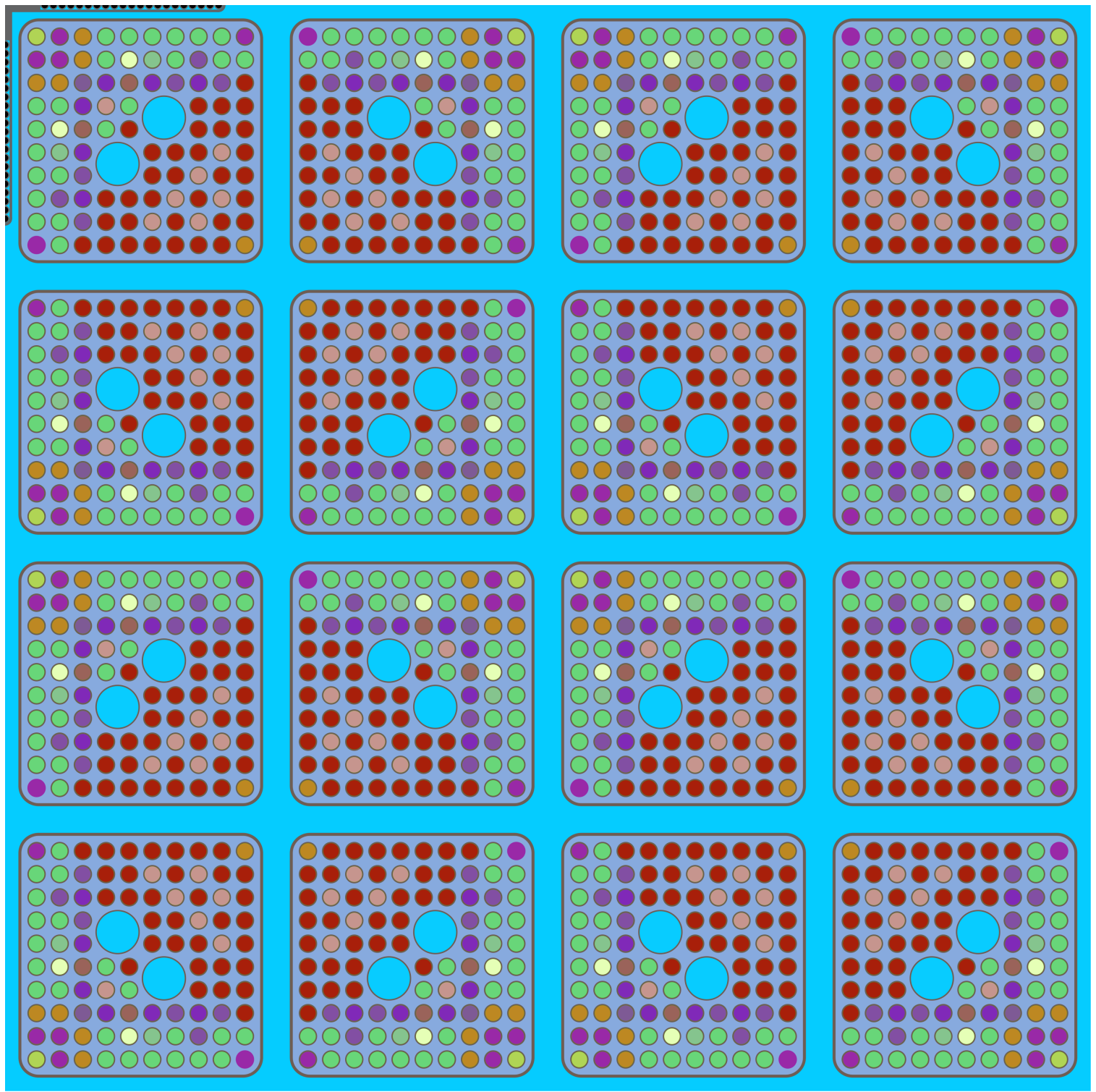

Figure 11. Geometry of the 2D mini-core progression problem with the control blade inserted in the northwest corner. 


\begin{tabular}{|l|l|l|l|}
\hline 10 & 20 & 20 & 10 \\
\hline 20 & 30 & 30 & 20 \\
\hline 20 & 30 & 30 & 20 \\
\hline 10 & 20 & 20 & 10 \\
\hline
\end{tabular}

\begin{tabular}{|l|l|l|l|}
\hline 50 & 60 & 60 & 50 \\
\hline 60 & 70 & 70 & 60 \\
\hline 60 & 70 & 70 & 60 \\
\hline 50 & 60 & 60 & 50 \\
\hline & 60 & & \\
\hline & 70 & & \\
\hline
\end{tabular}

Figure 12. Void distribution for the uncontrolled 2D mini-core at $20 \%$ (left) and $60 \%$ (right) systemaveraged void.

\begin{tabular}{|l|l|l|l|}
\hline 0 & 5 & 20 & 25 \\
\hline 5 & 5 & 20 & 25 \\
\hline 20 & 20 & 25 & 30 \\
\hline 25 & 25 & 30 & 40 \\
\hline
\end{tabular}

\begin{tabular}{|l|l|l|l|}
\hline 20 & 40 & 60 & 70 \\
\hline 40 & 40 & 60 & 70 \\
\hline 60 & 60 & 70 & 75 \\
\hline 70 & 70 & 75 & 80 \\
\hline
\end{tabular}

Figure 13. Void distribution for the controlled 2D mini-core at $20 \%$ (left) and $60 \%$ (right) systemaveraged void. 


\subsection{Control Blade Description}

The geometry and material composition of the original equipment manufacturer (OEM) control blade are described in Figure 14. This control blade is used in all 2D controlled cases for each lattice type and is always placed in the wide-wide gap in the northwest corner of the lattice. The dimensions and control blade material data were obtained from Solis, Ivanov, and Sarikaya [14]. The dimensions of the control blade are shown in Figure 14, and the input parameters corresponding to these dimensions are listed in Table 9. The blade comprises stainless-steel 304 structures and $\mathrm{B}_{4} \mathrm{C}$ granules. The steel density is shown in Table 9 and was obtained from Palmtag et al. [13]. The $\mathrm{B}_{4} \mathrm{C}$ density is taken to be $70 \%$ of the theoretical density as stated in Solis, Ivanov, and Sarikaya [14], and a theoretical density of $2.504 \mathrm{~g} / \mathrm{cc}$ was obtained from Williamson and Zimmerman [15].

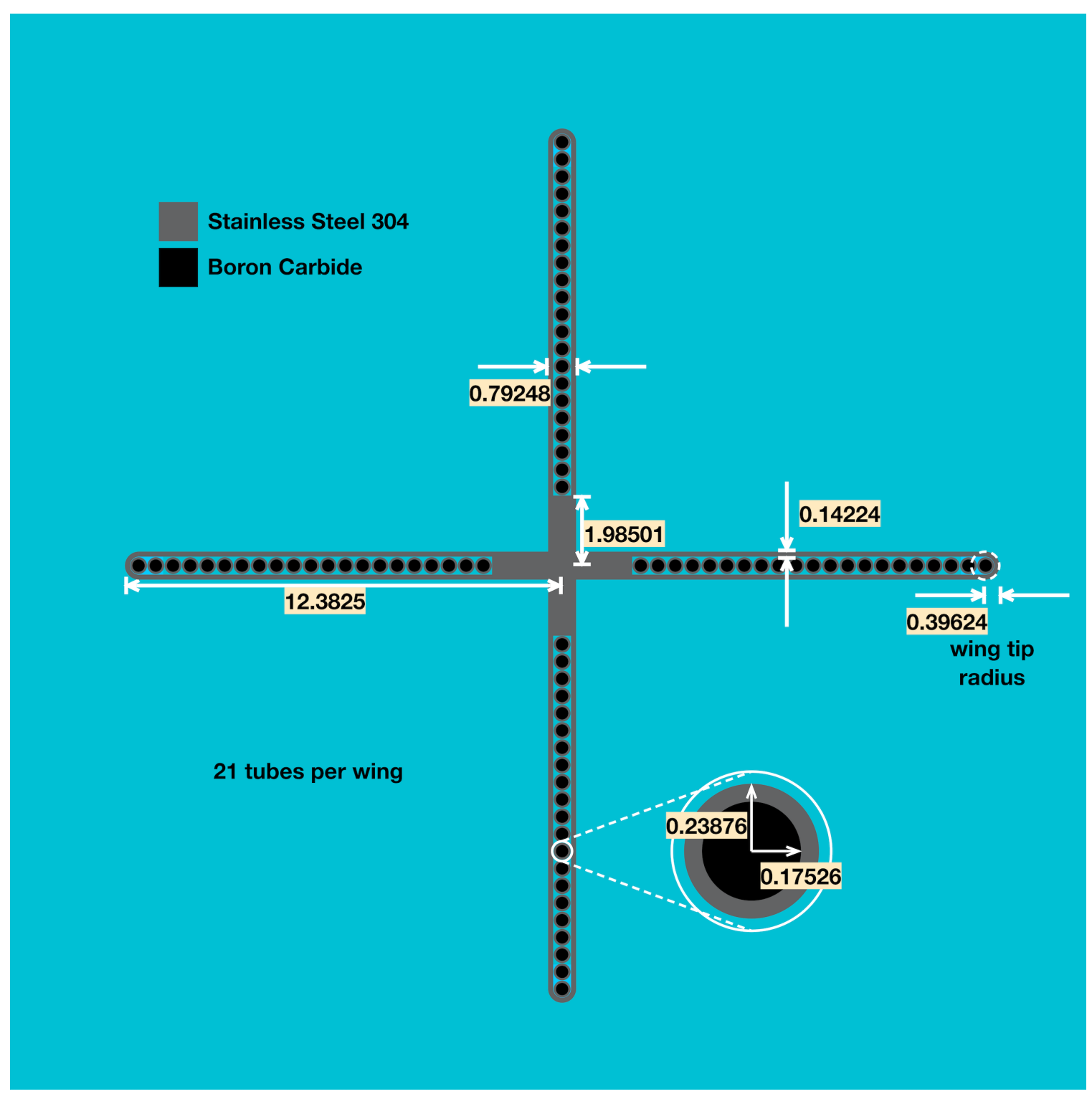

Figure 14. Dimensions for the OEM control blade. All dimensions are in centimeters. 
Table 9. Input parameters for the GE OEM control blade.

\begin{tabular}{|c|c|}
\hline Blade half-span $(\mathrm{cm})$ & 12.3825 \\
Blade thickness $(\mathrm{cm})$ & 0.79248 \\
Number of tubes per wing & 21 \\
Tip radius $(\mathrm{cm})$ & 0.39624 \\
Central structure half-span $(\mathrm{cm})$ & 1.98501 \\
Sheath thickness $(\mathrm{cm})$ & 0.14224 \\
Absorber tube inner radius $(\mathrm{cm})$ & 0.17526 \\
Absorber tube outer radius $(\mathrm{cm})$ & 0.23876 \\
Absorber material (name/density) $(\mathrm{g} / \mathrm{cc})$ & $\mathrm{B}_{4} \mathrm{C} / 1.7528$ \\
Structure material (name/density) $(\mathrm{g} / \mathrm{cc})$ & Stainless-steel 304/8.0 \\
\hline
\end{tabular}

\subsection{Lattice Depletions}

In addition to the static calculations performed on the fresh fuel, six depletion cases were considered. These cases are the uncontrolled GE- 9 and GE-14 bundles at 0,40 , and $80 \%$ void. To perform the depletion, a power density of $40 \mathrm{~W} / \mathrm{gHM}$ was used. For the GE-14 bundle with $500 \mathrm{~g}$ of heavy metal, this equals around $86 \mathrm{~kW} / \mathrm{L}$. This is representative of a power density that can be seen in the peak axial power locations. For the hot full power (HFP) 3D single bundle case described in Section 3.1, axial peaking factors of approximately 1.6 were estimated by using normalized fission rates from MCNP and Serpent calculations. Because of the strong shelf-shielding effect of the gadolinium present in the fuel, small time steps are needed in the initial depletion to ensure the accurate burnout of the burnable absorber. Thus, the depletion can be divided into three segments: the initial fission product accumulation, the gadolinium burnout, and the final depletion during with the calculation is not as sensitive to the step size. The depletion steps are described in Table 10.

Table 10. Lattice depletion time step summary.

\begin{tabular}{|c|c|}
\hline Initial fission product accumulation & $0.00,0.10,0.25$ \\
\hline Gadolinium burnout & $0.50,0.75,1.00, \ldots, 25.0$ \\
\hline Final depletion & $25.0,26.0,27.0, \ldots, 50.0$ \\
\hline
\end{tabular}




\section{3D BWR PROGRESSION PROBLEMS}

To test the modeling capabilities for more realistic geometries, twenty 3D progression problems were specified. All 3D progression problems are based on an approximate GE-14 bundle. A description of each problem is as follows:

- one GE-14 bundle at hot zero power (HZP) conditions,

- one GE-14 bundle at cold zero power (CZP) conditions,

- one GE-14 bundle at HFP conditions and a specified axial void distribution,

- thirteen GE-14 bundles with control blades withdrawn between 0 and 48 steps at HZP conditions,

- one $2 \times 2$ control cell with a 12 step withdrawn control blade in the center at HFP conditions,

- one $4 \times 4$ mini-core with 4 control blades at mixed positions at HFP conditions,

- one $4 \times 4$ mini-core with all control blades fully inserted at HFP conditions, and

- one $4 \times 4$ mini-core with all control blades fully withdrawn at HFP conditions.

These 3D problems have significant axial detail with top and bottom end plugs, part length rods, homogenized upper and lower nozzles, and a homogenized bottom reflector region. Spacer grids are also present in the 3D models, all of which are homogenized radially with the coolant at their specified location. All 3D progression problems are made up entirely of the approximate GE-14 bundle specified in Section 3.1. In addition, the OEM control blade present in many of the problems is based on the radial dimensions shown in Section 2.6 and the axial dimensions in Section 3.2. The descriptions of the problems are broken into four categories: single bundle, single bundle with control blade, control cell, and mini-core. The progression problems for each are specified in Section 3.4, Section 3.5, Section 3.6, and Section 3.7, respectively.

\subsection{GE-14 Bundle Specification}

The fuel bundle considered in all 3D progression problems is a representative GE-14 bundle designed based on data from several publicly available sources. The bundle is $413.6263 \mathrm{~cm}$ tall, including the top and bottom nozzle regions. The axial description of the fuel was obtained from Fensin [4] and is detailed in Table 11. Some modifications were made to the axial description found in Fensin [4]. These include the addition of the top and bottom nozzle regions and the inclusion of a top and bottom plug region. The data for these additional regions were obtained from Larsen [9]. A $25.4 \mathrm{~cm}$ plenum is added to the top of the bundle based on the information in the General Electric Systems and Technology Manual [1]. The radial dimensions of the bundle are the same as those shown for the GE-14 lattice in Figure 7 and Figure 8. Additionally, all fuels match those described in Table 7. In plenum rods or empty rods, only the cladding exists which is filled with helium. In vanished rods, no pin exists, and the full pincell is filled only with coolant. The radial boundary conditions are reflective, whereas the top and bottom boundary conditions are a vacuum. 
Table 11. Axial description of the GE-14 bundle.

\begin{tabular}{|c|c|c|}
\hline Region label & Height at base of region $(\mathrm{cm})$ & Height at top of region $(\mathrm{cm})$ \\
\hline \hline Top nozzle & 405.1427 & 413.6263 \\
\hline Top plug & 403.0091 & 405.1427 \\
\hline PLEN & 377.6091 & 403.0091 \\
\hline NT & 362.3691 & 377.6091 \\
\hline NV & 347.1291 & 362.3691 \\
\hline VAN & 252.5395 & 347.1291 \\
\hline PLP & 250.4059 & 252.5395 \\
\hline PLE & 222.0595 & 250.4059 \\
\hline DOM & 145.8595 & 222.0595 \\
\hline PSZ & 23.9395 & 145.8595 \\
\hline NAT & 8.6995 & 23.9395 \\
\hline Bottom plug & 7.1120 & 8.6995 \\
\hline Bottom nozzle & 0.0000 & 7.1120 \\
\hline Bottom reflector & -10.0584 & 0.0000 \\
\hline
\end{tabular}

Data for the nozzles and grids are provided in Table 12. The nozzles sit within the channel box in the axial positions shown in Table 11. The homogenized bottom reflector fills the full pitch of the bundle; it is not bounded by the channel box. Eight spacer grids are used in the 3D GE-14 model [3]. The midpoints of the grids are listed in Table 13.

Table 12. Description of grids and nozzles for the GE-14 bundle.

\begin{tabular}{|c|c|c|c|}
\hline & Material & Height $(\mathrm{cm})$ & Mass $(\mathrm{g})$ \\
\hline \hline Top nozzle & Stainless-steel 304 & 8.4836 & 1,200 \\
\hline Bottom nozzle & Stainless-steel 304 & 7.1120 & 2,392 \\
\hline Lower reflector & Stainless-steel 304 & 10.0548 & $2,392^{1}$ \\
\hline MID grid & Zircaloy-4 & 4.1275 & 348 \\
\hline
\end{tabular}

\footnotetext{
${ }^{1}$ In the VERA input, the lower reflector is specified with the structure material name, height, and volume fraction of the structure. In this case, the volume fraction of stainless-steel 304 (with a density of $8.0 \mathrm{~g} / \mathrm{cc}$ ) is approximately $13 \%$.
} 
Table 13. Axial locations of spacer grids.

\begin{tabular}{|c|}
\hline Grid midpoint $(\mathrm{cm})$ \\
\hline 379.6729 \\
\hline 329.0761 \\
\hline 279.7874 \\
\hline 230.4987 \\
\hline 181.2100 \\
\hline 131.9213 \\
\hline 82.6326 \\
\hline 33.3439 \\
\hline
\end{tabular}

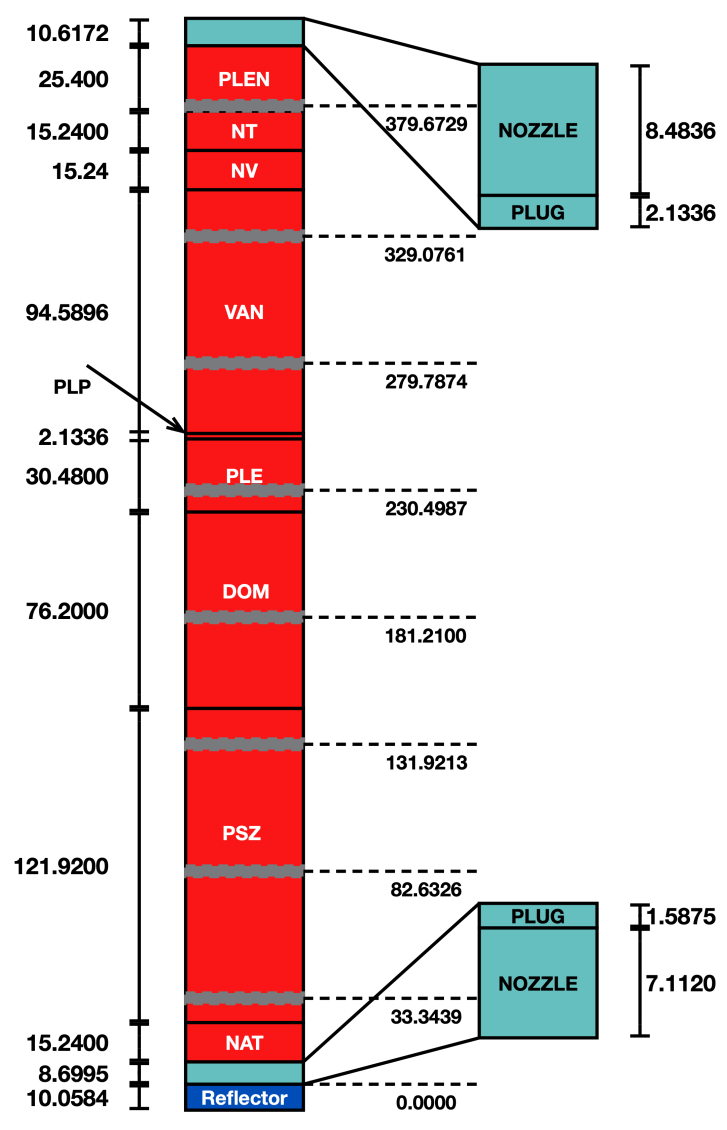

Figure 15. Axial breakdown of GE-14 bundle. All dimensions are shown in centimeters.

The axial breakdown of the bundle and grid spacings is shown in Figure 15. All red regions are either fuel regions or plenum regions. The light blue regions represent top and bottom plugs and nozzles, and the dark 
blue region is the bottom reflector. The heights of all regions are shown on the left in Figure 15. The spacer grids are shown in gray, and the midpoints are labeled on the right.

The fuel layouts for each region in Table 11 and Figure 15 are shown in Figure 17 through Figure 27. All fuel rod labels are consistent with those in Table 7. In the 3D bundle, the label "P" is used for plenum cells, which consist of helium inside of the Zircaloy-2 cladding. The top and bottom plug cells are labeled as "PT" and "PB," respectively. Their radial dimensions are shown in Figure 16. The fuel pin layouts were sourced from Fensin [4].
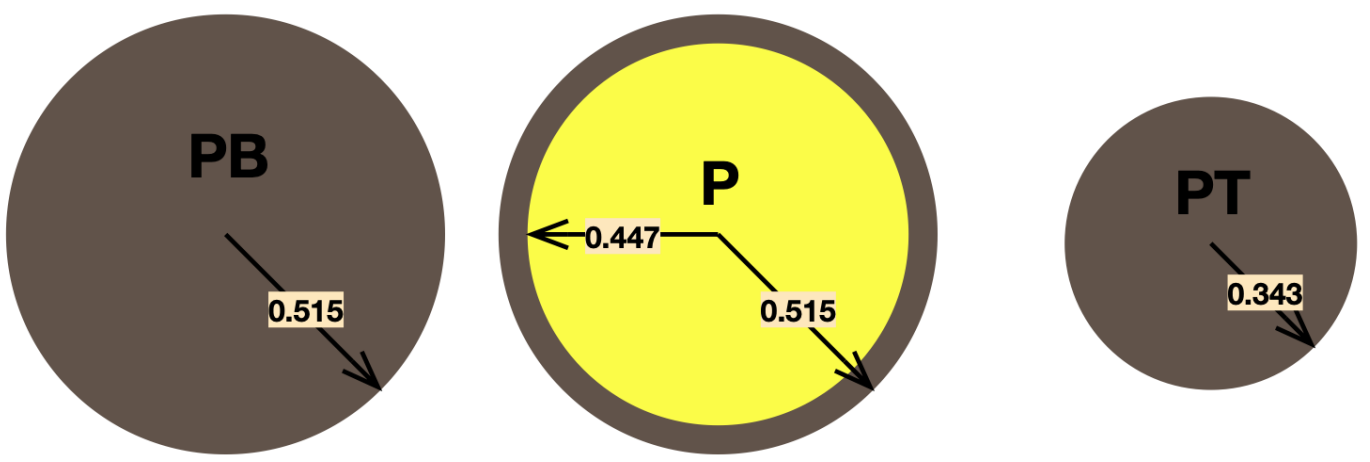

Figure 16. Radii for plugs and plenum regions.

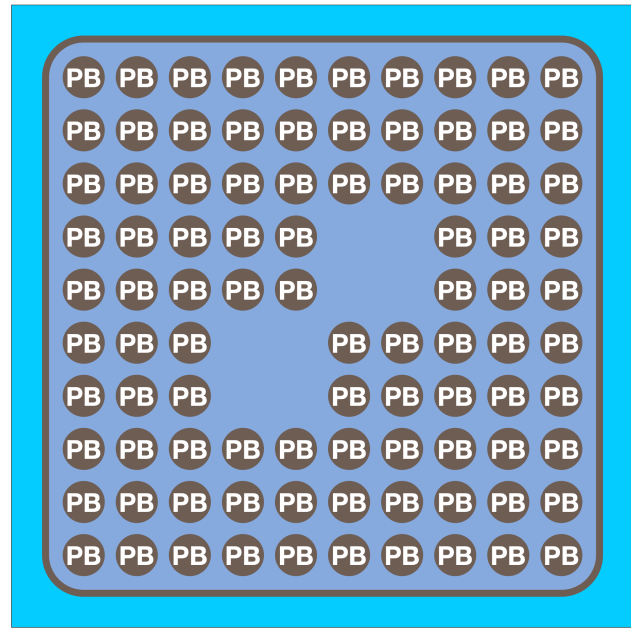

Figure 17. Layout of the bottom plug region.

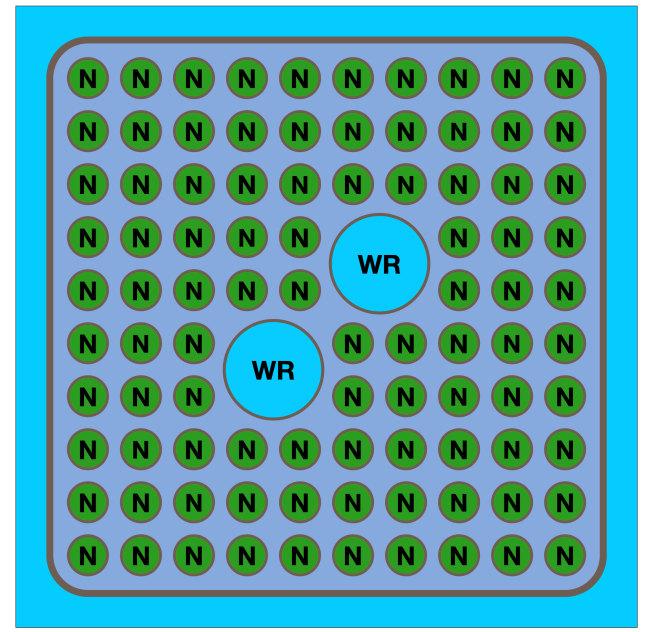

Figure 18. Fuel layout in NAT region (natural blanket at the base of the bundle). 
(1) 2 (3) 5 (5) 5 (5) 5 (5) 2

(2) 2 (3) (5) (4) 5G (5) 6G (5) (5)

(3) (3) $6 K$ (6) 79 (G) $6 \mathrm{G}(6) 6 \mathrm{G} / 7$

(5) (5) 6 (79) 5

(5) (4) 7G 57 WR 777

(5) 5G 6 (TR 7 ( 7 7G 7

(5) (5) $6 \mathrm{G}$ WR 7 (7) $7 \mathrm{G} 7$

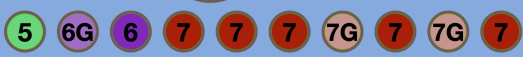

(5) (5) $6 \mathrm{G}$ (7) 7 (7G) 7 (7G 7 ( 7 (2) (5) 7 (7) 7 (7) 7 (7) 7 (3)

Figure 19. Fuel layout in the PSZ region (power shaping zone).
(1) 2 (3) 5 (5) (5) 5 (5) 5 ( 2

(2) 2 (3) (5) (4) 5G (5) $6 \mathrm{H}$ (5) (5)

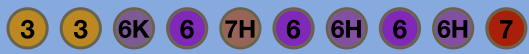

(5) (5) 6 (7G) 5 WR 7 ( 7 ( 7

(5) (4) $7 H$ (5) 7 WR 7 ( 7 (

(5) 5G 6 (7) 7 7 79

(5) 5 6H WR 7 (7) 7 (7)

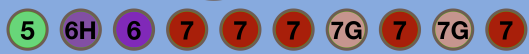

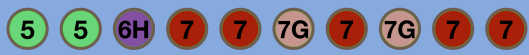

(2) 5 (7) 7 (7) 7 (7) 7 (3)

Figure 20. Fuel layout in the DOM region (dominate zone).

\section{(1) 2 (3) 5 (5) 5 (5) 5 (5) (2) P (3) P 4 (5) P 6 H P 5 (3) 3 (3) 6 (6) 7 7H 6 (6) 6 6 6 6H 7 (5) P 6 7G 5 ( 7 P P 7 (5) 4 ( $7 H$ ( 5 P 777 (5) 5 ( 6 WR $P(7) 79$ (5) $P$ 6H WR 7 (7) 7 ( P 7

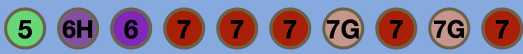 (5) P $6 \mathrm{H}$ P 7 7G $P$ (7G $P(7$ (2) (5) 7 7 7 (7) 7 ( 7 (}

Figure 21. Fuel layout in the PLE region (plenum region for part-length rods).

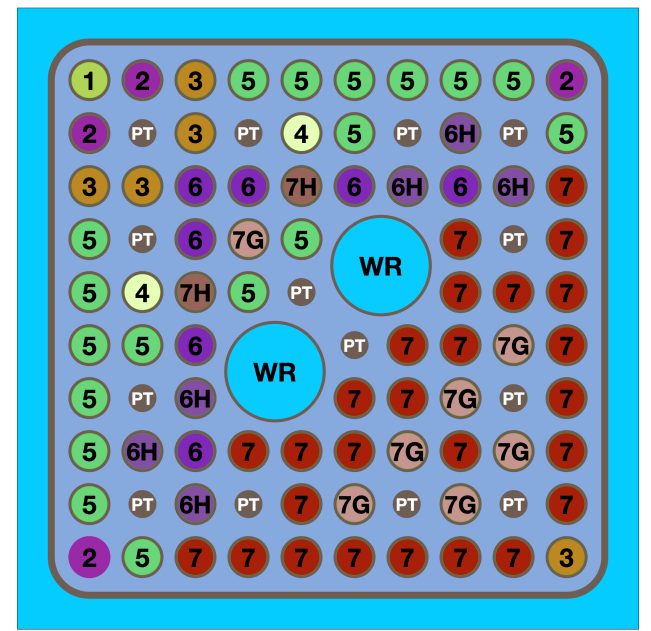

Figure 22. Fuel layout in the PLP region (upper plug region for part-length rods). 


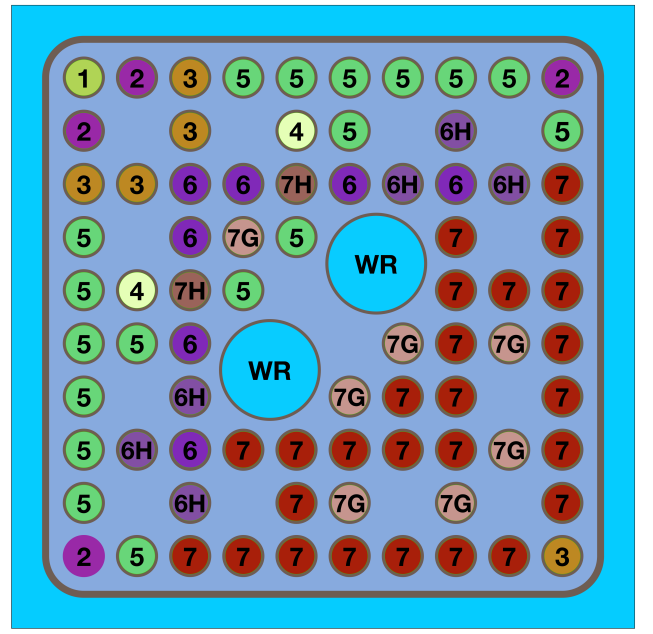

Figure 23. Fuel layout in the VAN region (the part length rods "vanish" in this region).

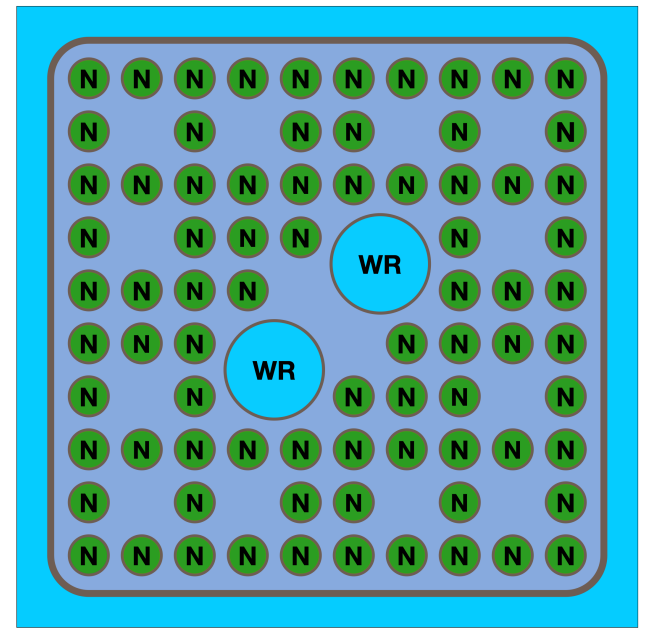

Figure 24. Fuel layout in the NV region (natural blanket in the top of the bundle where only fulllength rods exist).

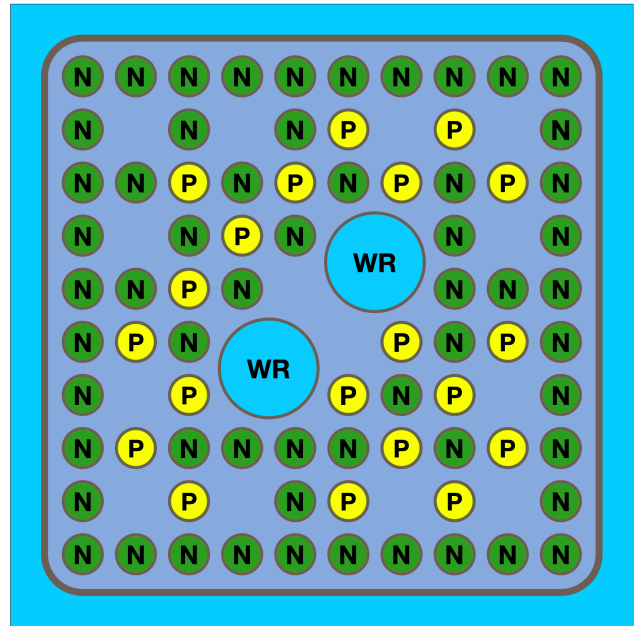

Figure 25. Fuel layout in the NT region (similar to the NV region, but full-length rods containing gadolinia at lower levels are now empty rods containing helium and no fuel inside the clad).

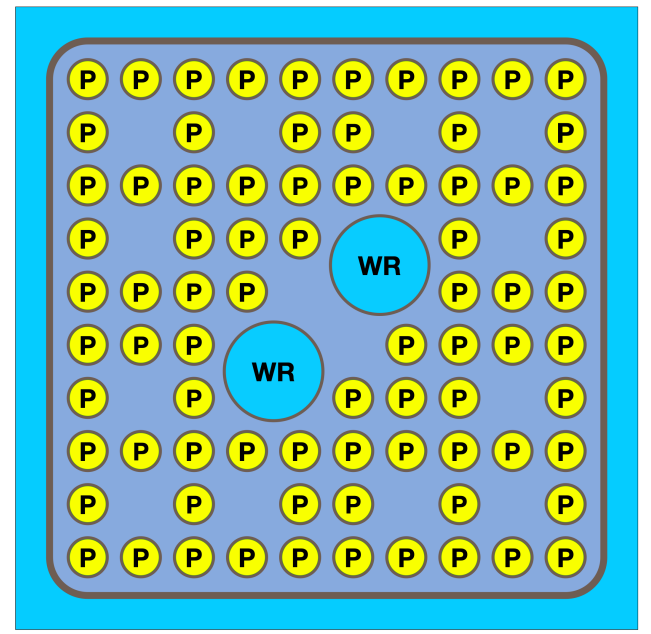

Figure 26. Layout in the PLEN region (plenum region for the full-length rods containing only helium inside the cladding). 


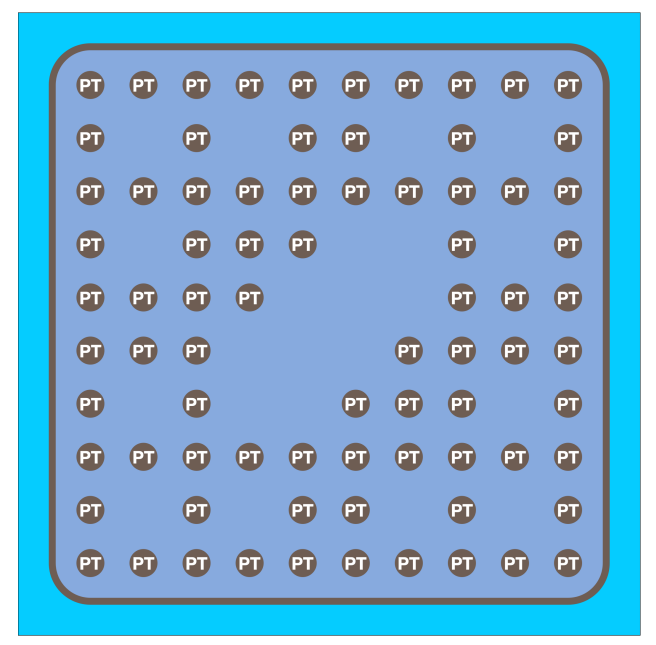

Figure 27. Layout in the upper plug region.

The GE-14 fuel bundle uses the specifications contained in this section and is used in all 3D progression problems.

\subsection{Axial Control Blade Description}

Axial data for the control blade were obtained from Table 11 in Larsen [9]. The OEM control blades are used in this model, and a radial profile of the active control region is shown in Figure 14. At the top of the blade, the outer radial profile is the same as that in Figure 14; however, in the progression problems, the blade becomes solid steel in this top region.

Table 14. Axial data for control blade.

\begin{tabular}{|c|c|}
\hline Control material length $(\mathrm{cm})$ & 363.22 \\
\hline Notch length/stroke $(\mathrm{cm})$ & 7.62 \\
\hline Number of notches & 48 \\
\hline Physical notch length/stroke $(\mathrm{cm})$ & 15.24 \\
\hline Top of control material at full withdrawal (top of bottom plate 0) & 6.1595 \\
\hline Top of control material at full insertion & 371.9195 \\
\hline Length of Steel Tip $(\mathrm{cm})$ & 7.62 \\
\hline
\end{tabular}

Notice that at full insertion the bottom of the control material is above the lower reflector. Any portion of control blade present above the lower reflector region is modeled as solid steel with the same outer profile as that shown in Figure 14. The control blade is neglected in the lower reflector region.

\subsection{Assumptions and Approximations for the 3D GE-14 Bundle Design}

Due to a lack of publicly available data for the GE-14 bundle, several sources were used to obtain different dimensions and material specifications to develop this representative 3D bundle. In some cases, data were only available for older bundles from the 1970s. This was the case with the grids and nozzles. As a result, several approximations and assumptions had to be made in the development of these specifications. 


\subsubsection{Spacer Grid Data}

A homogeneous treatment is used to model the spacer grids, so the mass and height of the grids must be known. Specific data on the GE-14 bundle spacer grids are unknown. The UK ABWR Generic Design Assessment [3] shows that there are eight grids, but the exact placement of these grids is unknown. To make the representative bundle, the grid spacing was obtained by spacing the eight grids evenly across the active fuel and plenum. In cases in which this would lead to a grid almost overlapping with a material boundary, the grid would be moved slightly up or down to align the top or bottom of the grid with the material boundary. The height of the grids was obtained from Larsen [9]; however, the height used is that of an old $8 \times 8$ bundle from the early cycles of the Peach Bottom 2 reactor. The mass of the grid was also estimated from the same data in Larsen [9]. The mass from the grids of the $8 \times 8$ bundle was extrapolated as

$$
M_{10 \times 10}=10 \times \frac{M_{8 \times 8}}{8} .
$$

This is not exact, but it serves as a better approximation than simply using grid mass from $8 \times 8$ grids.

\subsubsection{Nozzle Data}

The bundle model shown in this report extends from the bottom to the top of the channel box because specifications of materials, masses, and geometries above and below the channel box are limited. The mass of the top and bottom tie plates are provided in Larsen [9]; however, the top and bottom structures are partially protruding from the channel box. Based on diagrams in Larsen [9], 60\% of the mass of the top tie plate and hardware and $50 \%$ of the mass of the bottom tie plate and hardware are estimated to lie within the channel box. Thus, the nozzle mass specified in this problem represents those percentages of the total mass of the hardware provided in Larsen [9]. The remaining mass of the upper tie plate is assumed to lie outside the channel box and thus outside the problem domain. For the lower tie plate, the remaining mass is homogenized into the bottom reflector. The nozzles are modeled as a smeared coolant/steel mixture in the top and bottom of the channel box.

\subsubsection{Plug Regions}

The heights of the top and bottom plug regions are based on Figure 16 from Larsen [9]. In these plug regions, the diameters of the water rod and water rod plugs are unknown, so the plugs for water rods are neglected. The diameter of the bottom plug is estimated to be the same as the outer diameter of the fuel rod cladding. The diameter of the top plug region is estimated to be two-thirds of the inner diameter of the fuel rod cladding. These are only visual estimates and are also based on Figure 16 from Larsen [9]. The plugs at the top of the part length rods are assumed to be identical to those at the top of the full-length rods.

\subsubsection{Plenum Region}

The mass and volume of the springs in the plenum region are unknown. As a result, the plenum springs are neglected.

\subsubsection{Axial Void Distribution}

For the HFP problem, case 2, an axial void distribution was assumed. This distribution assigns increasing void in each quarter of the bundle axially.

\subsubsection{Control Blade}

The older OEM control blades are used for all controlled problems as opposed to newer designs. This decision is primarily due to the readily available specifications for them. The handles at the top of the control blades are neglected for these progression problems. 


\subsection{D Single Bundle Problems}

Several useful input parameters are provided in Table 15 through Table 17 for the 3D single bundle progression problems. The Zircaloy densities were obtained from Palmtag et al. [13]. This table describes the geometric and structural details of the 3D GE-14 bundle. The axial description of the fuel elements in these problems is that in Section 3.1.

Table 15. Input parameters for the 3D single bundle progression problems.

\begin{tabular}{|c|c|}
\hline Assembly pitch $(\mathrm{cm})$ & 15.24 \\
Height $(\mathrm{cm})$ & 413.6263 \\
Boundary condition (radial) & Reflecting \\
Boundary condition (top/bottom) & Vacuum \\
Pin pitch $(\mathrm{cm})$ & 1.3 \\
Gap (wide/narrow) $(\mathrm{cm})$ & $0.7549 / 0.7549$ \\
Channel box thickness $(\mathrm{cm})$ & 0.1651 \\
Channel box corner radius $(\mathrm{cm})$ & 0.9652 \\
Fuel pellet outer radius $(\mathrm{cm})$ & 0.438 \\
Fuel clad inner radius $(\mathrm{cm})$ & 0.447 \\
Fuel clad outer radius $(\mathrm{cm})$ & 0.515 \\
Water rod inner radius $(\mathrm{cm})$ & 1.170 \\
Water rod outer radius $(\mathrm{cm})$ & 1.245 \\
Channel box material (name/density) $(\mathrm{g} / \mathrm{cc})$ & Zircaloy-4/6.56 \\
Cladding material (name/density) $(\mathrm{g} / \mathrm{cc})$ & Zircaloy-2/6.56 \\
\hline
\end{tabular}

The three single bundle progression problems have an identical geometry and differ only by the state conditions. Those conditions are outlined in Table 16 and Table 17.

Table 16. Case specific parameters for the 3D single bundle problems.

\begin{tabular}{|c|c|c|c|c|}
\hline Case & Fuel Temperature (K) & Moderator Temperature (K) & Void (\%) & Pressure (psia) \\
\hline \hline HZP & 600.0 & 600.0 & 0 & 1,040 \\
\hline HFP & 900.0 & 600.0 & See Table 17 & 1,040 \\
\hline CZP & 293.6 & 293.6 & 0 & 14.69595 \\
\hline
\end{tabular}

Table 17. Axial void distribution for the 3D single bundle case at HFP.

\begin{tabular}{|c|c|}
\hline Void (\%) & Top of void region from base of core $(\mathrm{cm})$ \\
\hline \hline 5 & 102.0000 \\
\hline 25 & 200.0000 \\
\hline 40 & 300.0000 \\
\hline 60 & 413.6263 \\
\hline
\end{tabular}




\subsection{D Single Bundle Problems with Control Blade}

The thirteen controlled 3D single bundle problems are all based on the same details as shown in Table 15 and are at the HZP conditions shown in Table 16. The axial description of the fuel bundles is that from Section 3.1, while the control blade is described in Section 2.6 and Section 3.2. Table 18 contains the heights of the control blade in each of the problems.

Table 18. Height of control blade for each of the thirteen controlled single bundle problems.

\begin{tabular}{|c|c|c|}
\hline Steps Withdrawn & Top of Absorber $(\mathrm{cm})$ & Top of Steel Tip $(\mathrm{cm})$ \\
\hline \hline 0 & 371.9195 & 379.5395 \\
\hline 4 & 341.4395 & 349.0595 \\
\hline 8 & 310.9595 & 318.5795 \\
\hline 12 & 280.4795 & 288.0995 \\
\hline 16 & 249.9995 & 257.6195 \\
\hline 20 & 219.5195 & 227.1395 \\
\hline 24 & 189.0395 & 196.6595 \\
\hline 28 & 158.5595 & 166.1795 \\
\hline 32 & 128.0795 & 135.6995 \\
\hline 36 & 97.5995 & 105.2195 \\
\hline 40 & 67.1195 & 74.7395 \\
\hline 44 & 36.6395 & 44.2595 \\
\hline 48 & 6.1595 & 13.7795 \\
\hline
\end{tabular}

\subsection{D Control Cell}

The 3D control cell problem comprises four GE-14 bundles with an OEM control blade inserted in the center of the problem. To make the problem more difficult to solve, each bundle is assumed to have a different average void, as shown in Figure 28. The control blade is only 12 of 48 steps withdrawn. Input parameters are shown in Table 19. The bundles use standard BWR orientations with the control blade inserted in the wide-wide gap. In Figure 17 through Figure 27, the bundle is oriented with the wide-wide gap in the northwest corner.

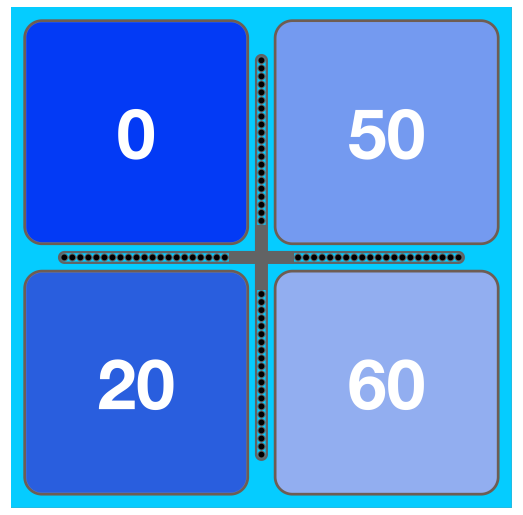

Figure 28. Radial void profile of the 3D control cell. Units are percentages. 
Table 19. Input parameters for the 3D control cell.

\begin{tabular}{|c|c|}
\hline Moderator temp. (K) & 600 \\
Fuel temp. (K) & 900 \\
Pressure (psia) & 1,040 \\
Void (\%) & See Figure 28 \\
Assembly pitch (cm) & 15.24 \\
Height (cm) & 413.6263 \\
Boundary condition (radial) & Reflecting \\
Boundary condition (top/bottom) & Vacuum \\
Pin pitch (cm) & 1.3 \\
Gap (wide/narrow) (cm) & $0.7549 / 0.7549$ \\
Channel box thickness $(\mathrm{cm})$ & 0.1651 \\
Channel box corner radius $(\mathrm{cm})$ & 0.9652 \\
Fuel pellet outer radius $(\mathrm{cm})$ & 0.438 \\
Fuel clad inner radius $(\mathrm{cm})$ & 0.447 \\
Fuel clad outer radius $(\mathrm{cm})$ & 0.515 \\
Water rod inner radius $(\mathrm{cm})$ & 1.170 \\
Water rod outer radius $(\mathrm{cm})$ & 1.245 \\
Channel box material (name/density) $(\mathrm{g} / \mathrm{cc})$ & Zircaloy-4/6.56 \\
Cladding material (name/density) $(\mathrm{g} / \mathrm{cc})$ & Zircaloy-2/6.56 \\
Height of active absorber $(\mathrm{cm})$ & 280.4795 \\
Height at top of control blade steel tip (cm) & 288.0995 \\
\hline
\end{tabular}




\subsection{D Mini-Core Problems}

The 3D mini-core cases comprise $16 \mathrm{GE}-14$ bundles (Section 3.1). The orientations of the GE-14 bundles match those in Figure 11. These are the standard BWR bundle orientations with the control blades inserted in the wide-wide gaps. In Figure 17 through Figure 27, the bundle is oriented with the wide-wide gap in the northwest corner. A checkerboard void distribution is used to alternate reactivities in adjacent bundles. Four OEM control blades are present in the core at the positions shown in Figure 29. There are three mini-core problems:

- one mini-core with mixed blade positions,

- one mini-core with all rods out, and

- one mini-core with all rods in.

All three problems are at HFP conditions. The radial void distribution is shown by the white numbers in Figure 29 and the steps withdrawn for the mixed blade position mini-core problem are represented by the black numbers in the same figure. Detailed descriptions of the heights of the active absorber and the height of the stainless-steel tip of the control blades are provided in Table 21 for the mixed blade case. The bottom of the core is considered to be the top of the bottom reflector region and this is where the height is $0 \mathrm{~cm}$.

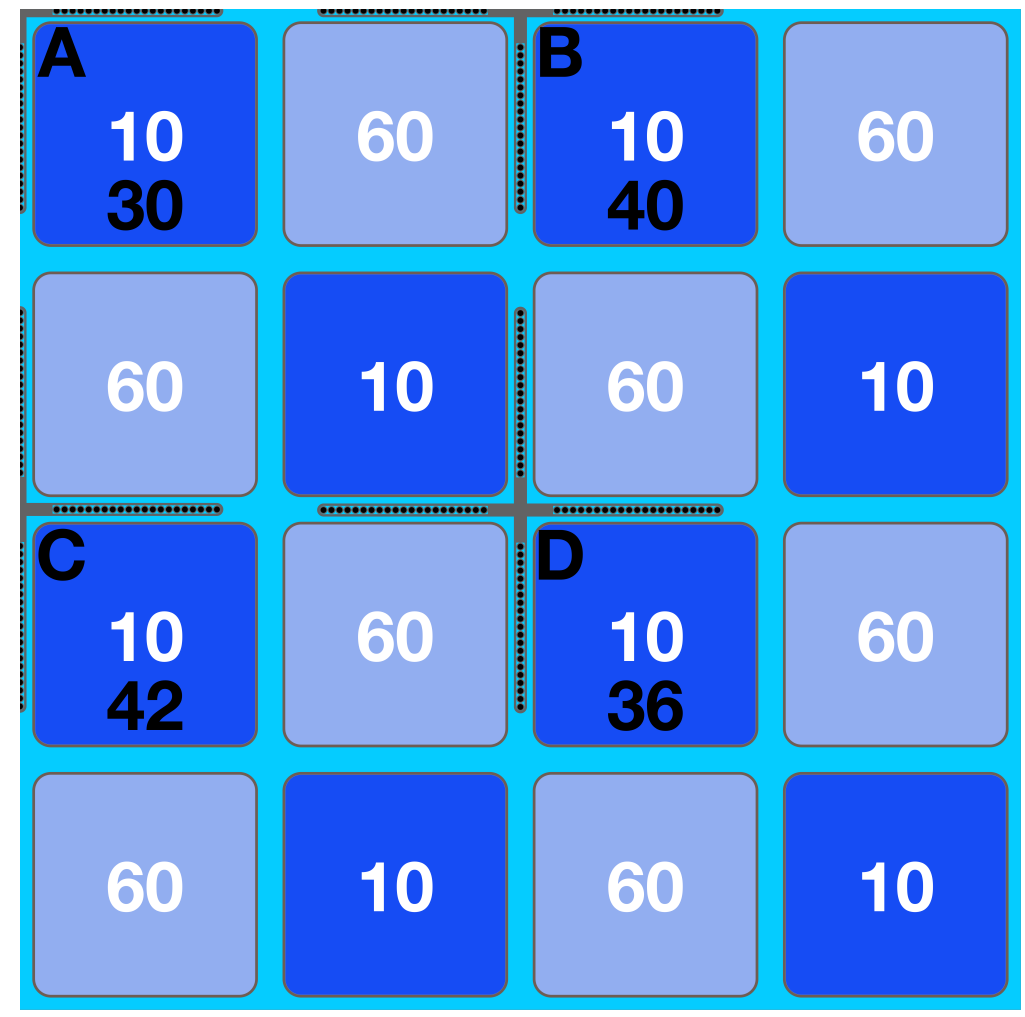

Figure 29. Radial void profile and control blade map. The top values are void (\%), and the bottom values are steps withdrawn of the control blade to the northwest corner of the given bundle (for the mixed blade mini-core problem). The letters represent the control blade labels.

Table 21 shows important geometric and structural specifications used for all three of the mini-core 
progression problems.

Table 20. Input parameters for the 3D mini-core.

\begin{tabular}{|c|c|}
\hline Moderator temp. (K) & 600 \\
Fuel temp. (K) & 900 \\
Pressure (psia) & 1,040 \\
Void (\%) & See Figure 29 \\
Assembly pitch (cm) & 15.24 \\
Height (cm) & 413.6263 \\
Boundary Condition (radial) & Reflecting \\
Boundary Condition (top/bottom) & Vacuum \\
Pin pitch (cm) & 1.3 \\
Gap (wide/narrow) (cm) & $0.7549 / 0.7549$ \\
Channel box thickness (cm) & 0.1651 \\
Channel box corner radius (cm) & 0.9652 \\
Fuel pellet outer radius (cm) & 0.438 \\
Fuel clad inner radius (cm) & 0.447 \\
Fuel clad outer radius (cm) & 0.515 \\
Water rod inner radius (cm) & 1.170 \\
Water rod outer radius $(\mathrm{cm})$ & 1.245 \\
Channel box material (name/density) (g/cc) & Zircaloy-4/6.56 \\
Cladding material (name/density) (g/cc) & Zircaloy-2/6.56 \\
\hline
\end{tabular}

Table 21. 3D mini-core control blade placements in the mixed blade position problem.

\begin{tabular}{|c|c|c|c|}
\hline Label & Steps withdrawn $(\max .=48)$ & Active absorber height $(\mathrm{cm})$ & Steel tip height $(\mathrm{cm})$ \\
\hline \hline A & 30 & 143.3195 & 150.9395 \\
\hline B & 40 & 67.1195 & 74.7395 \\
\hline C & 42 & 51.8795 & 59.4995 \\
\hline D & 36 & 97.5995 & 105.2195 \\
\hline
\end{tabular}

For the all rods out case, the heights for all control blades are those shown for the 48 steps withdrawn case in Table 18. For the all rods in mini-core problem, the heights of the control blades are those shown in Table 18 for the 0 steps withdrawn case. 



\section{RESULTS}

Where possible, reference solutions are provided for the VERA BWR progression problems from continuous energy Monte Carlo calculations. Results shown in this document are provided using Serpent 2 [11]. For 2D cases and select 3D cases, MCNP 6.2 [12] reference solutions are also provided in the BWR progression problem Github Repository [10]. For all problems, solutions from MPACT are compared with the Monte Carlo results from Serpent 2. The MPACT calculations used P2 scattering and were performed with VERA 4.3RC7.

When comparing normalized fission rates, all differences are always calculated as:

$$
\Delta p_{i, j}=\left(p_{i, j}^{M P A C T}-p_{i, j}^{\text {serp }}\right) \times 100,
$$

where $p_{i, j}^{M P A C T}$ is the normalized fission rate from MPACT in pin $(i, j)$, and $p_{i, j}^{\text {serp }}$ is that from Serpent. Additionally, the differences in eigenvalues are determined by using the formula:

$$
\Delta k=\left(k^{M P A C T}-k^{\text {serp }}\right) \times 10^{5} p c m .
$$

To supplement the results provided in this document, detailed fission rate distributions from all MC calculations are provided in HDF5 format in the progression problem Github repository [10]. These results are formatted to be analyzed with VERAView. All Serpent, MCNP, and VERA inputs used are also provided.

\subsection{D Results}

\subsubsection{Peach Bottom Lattice Type 6}

The eigenvalues calculated with Serpent for the Peach Bottom lattice are listed in Table 22 along with a summary of the comparisons between MPACT and Serpent for these models. The Serpent calculations used 1.32 billion active particles and this resulted in a uncertainty in the eigenvalue of around $1 \mathrm{pcm}$ or less in all cases. The Root Mean Square (RMS) of the differences in fission rates between Serpent an MPACT is larger in the controlled cases and decreases with increasing void fraction. 
Table 22. Summary of comparison between MPACT and Serpent results for the Peach Bottom 6 lattice.

\begin{tabular}{|c|c|c|c|c|c|}
\hline \multicolumn{6}{|c|}{ Uncontrolled } \\
\hline \multirow{2}{*}{ Void (\%) } & \multirow{2}{*}{$k_{\text {serp }}$} & $\Delta k(\mathrm{pcm})$ & \multicolumn{3}{|c|}{$\Delta P_{i, j}$ (absolute \%) } \\
& & Max. & Min. & RMS \\
\hline 00 & 1.105220 & -41.0 & 0.72 & -1.35 & 0.50 \\
40 & 1.083620 & -5.1 & 0.47 & -1.14 & 0.37 \\
80 & 1.042600 & -69.9 & 0.40 & -0.71 & 0.23 \\
\hline \multicolumn{5}{|c|}{ Controlled } \\
\hline \multirow{2}{*}{ Void (\%) } & \multirow{2}{*}{$k_{\text {serp }}$} & $\Delta k(\mathrm{pcm})$ & $\Delta P_{i, j}$ (absolute \%) \\
\hline 00 & 0.880892 & -170.8 & 0.61 & -2.01 & 0.57 \\
40 & 0.817562 & -76.5 & 0.50 & -1.88 & 0.50 \\
80 & 0.721281 & -38.3 & 0.39 & -1.61 & 0.42 \\
\hline
\end{tabular}

For all Peach Bottom type 6 lattice calculations, the maximum relative standard deviation in the fission rates was $0.03 \%$ for the Serpent results. In Figure 30 through Figure 35, more detailed descriptions of the differences in normalized fission rates between MPACT and Serpent results are provided.
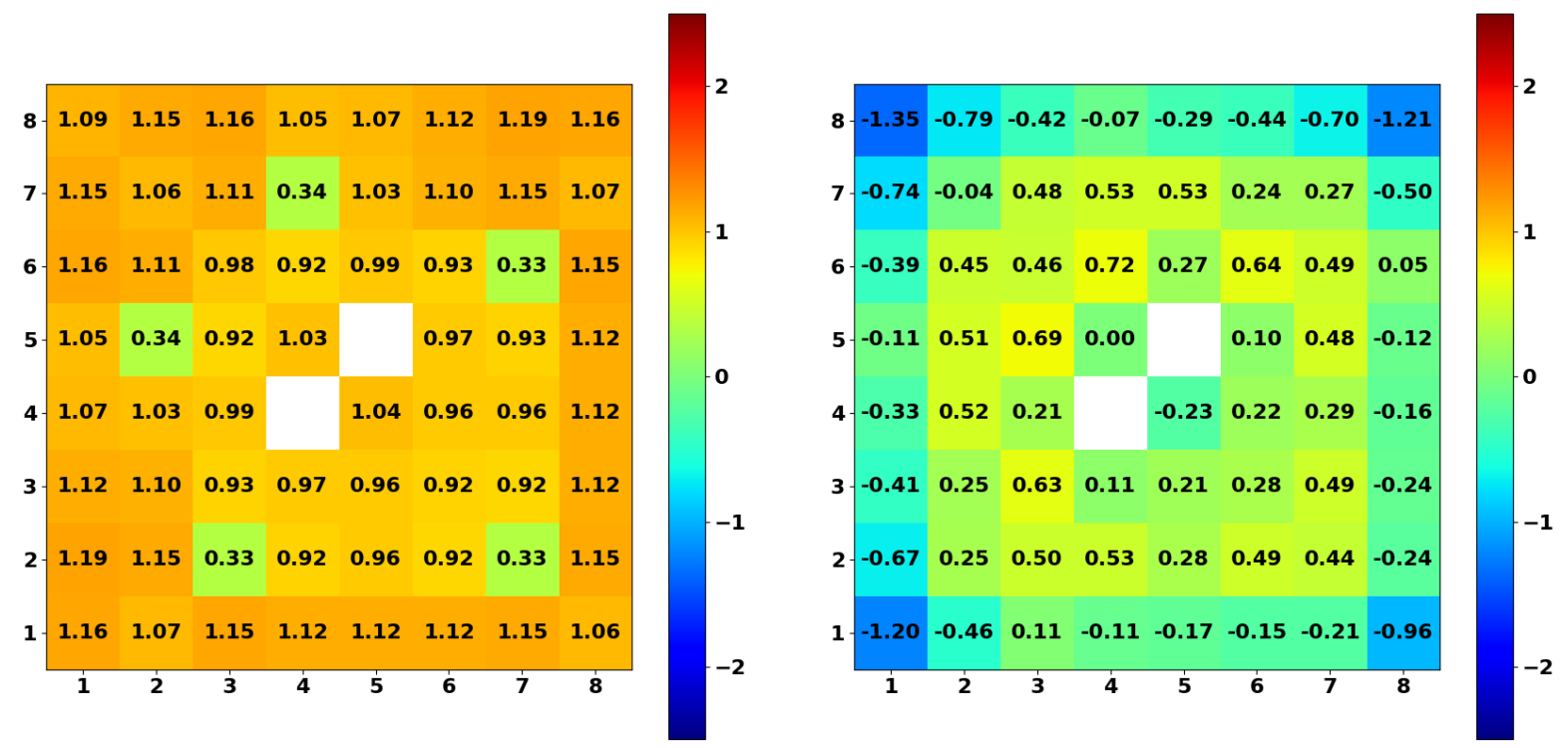

Figure 30. Normalized fission rates from Serpent (left) and $\Delta P_{i, j}$ (right) for the Peach Bottom 6 lattice at $0 \%$ void. 

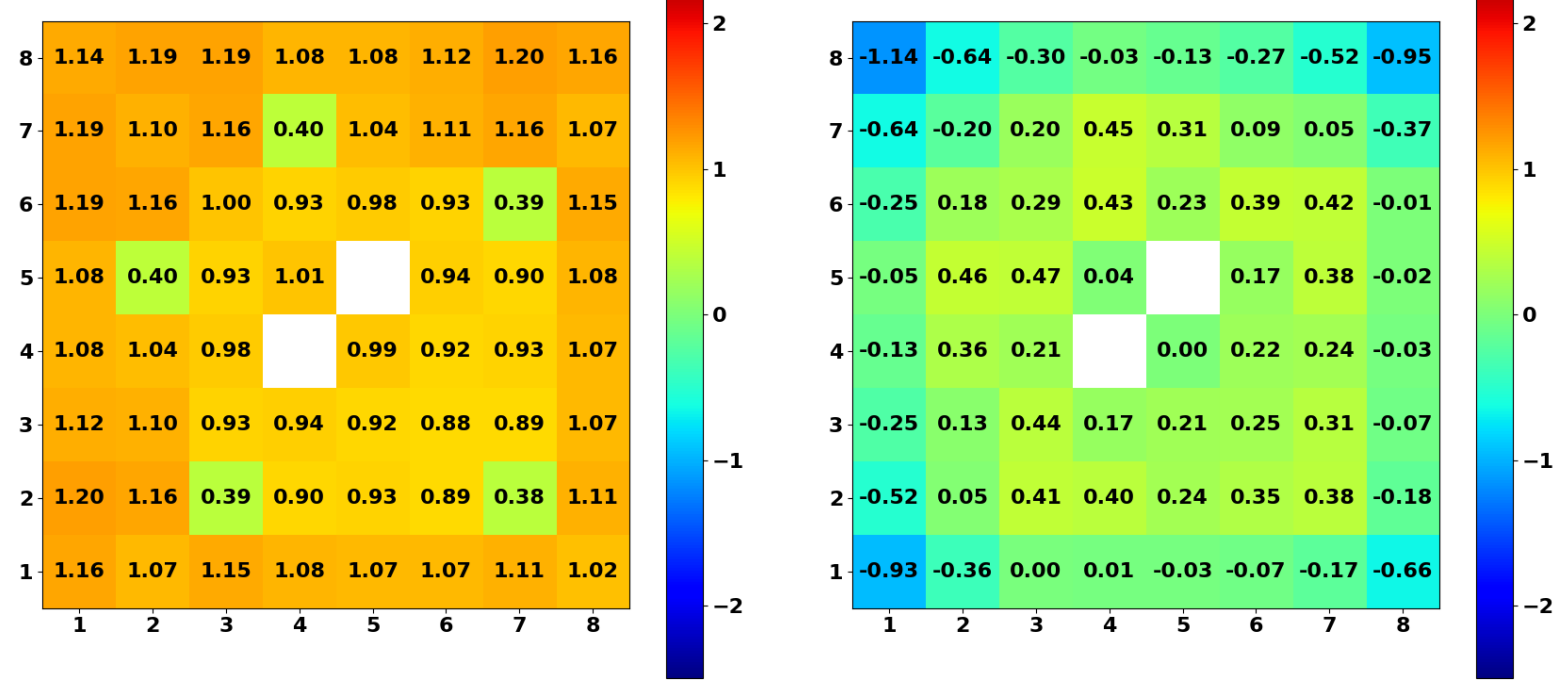

Figure 31. Normalized fission rates from Serpent (left) and $\Delta P_{i, j}$ (right) for the Peach Bottom 6 lattice at $40 \%$ void.
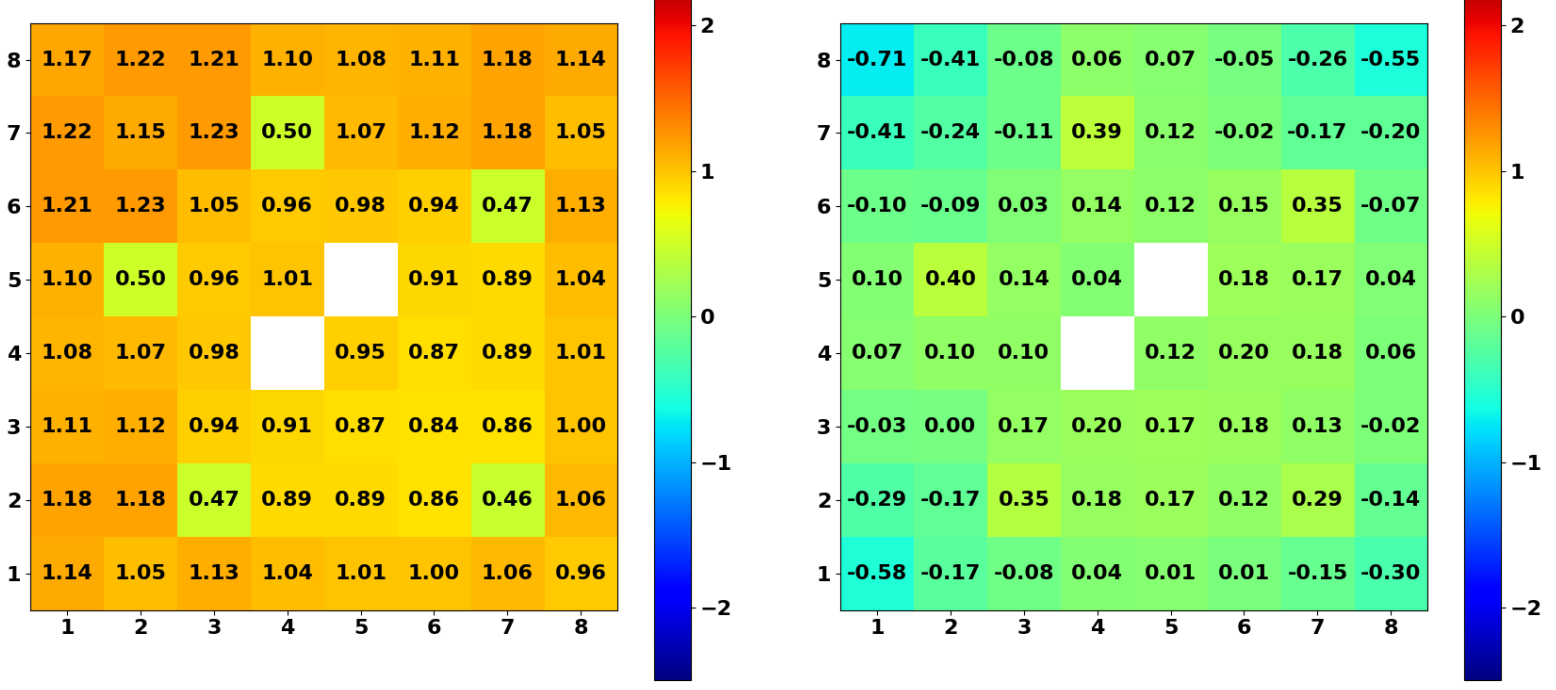

Figure 32. Normalized fission rates from Serpent (left) and $\Delta P_{i, j}$ (right) for the Peach Bottom 6 lattice at $80 \%$ void. 

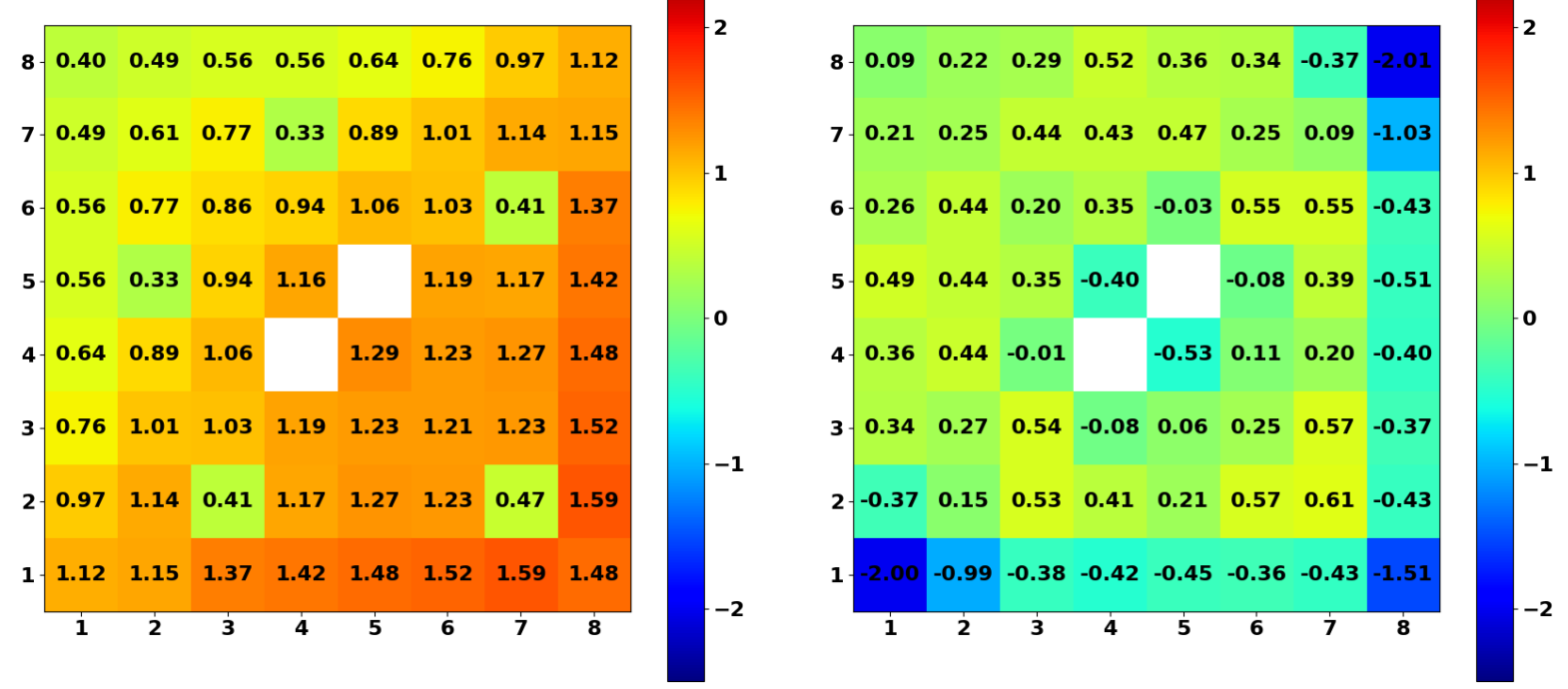

Figure 33. Normalized fission rates from Serpent (left) and $\Delta P_{i, j}$ (right) for the controlled Peach Bottom 6 lattice at $0 \%$ void.
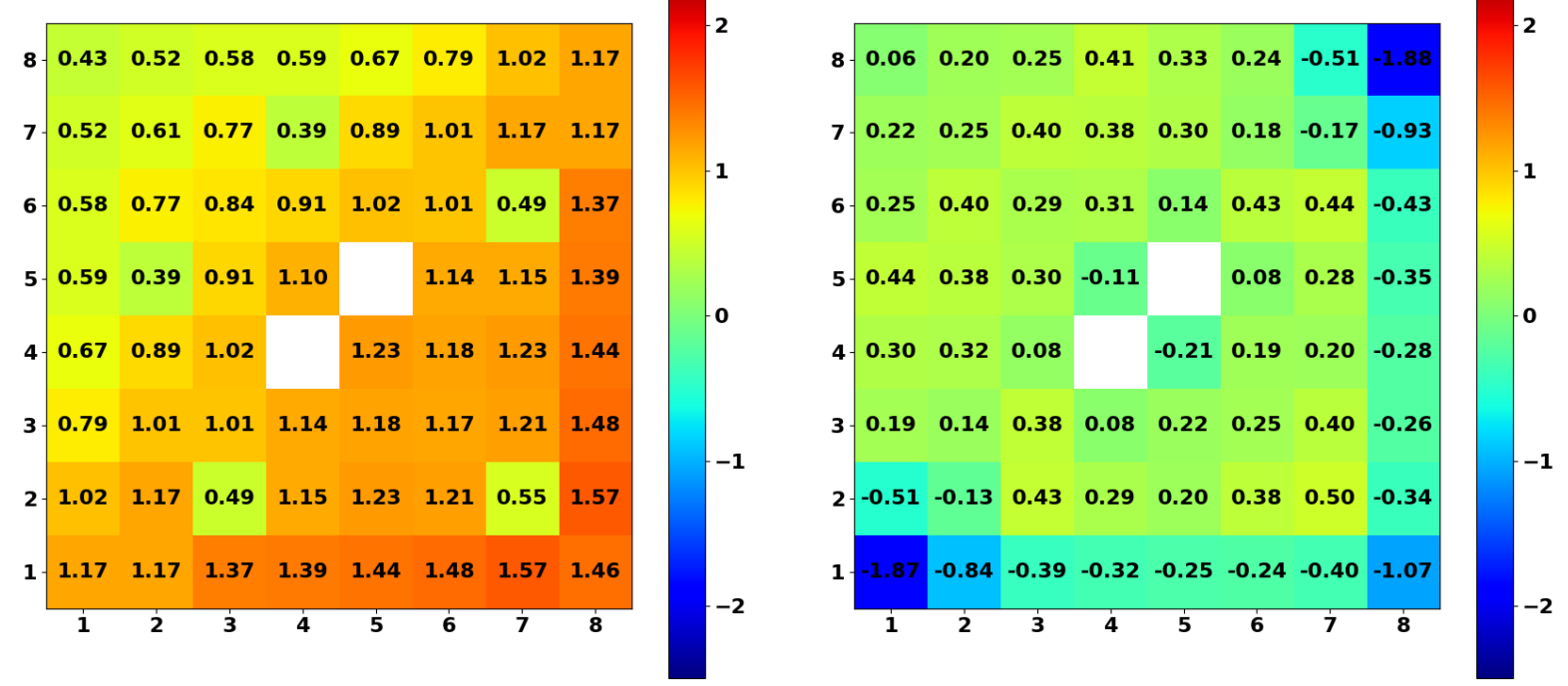

Figure 34. Normalized fission rates from Serpent (left) and $\Delta P_{i, j}$ (right) for the controlled Peach Bottom 6 lattice at $40 \%$ void. 

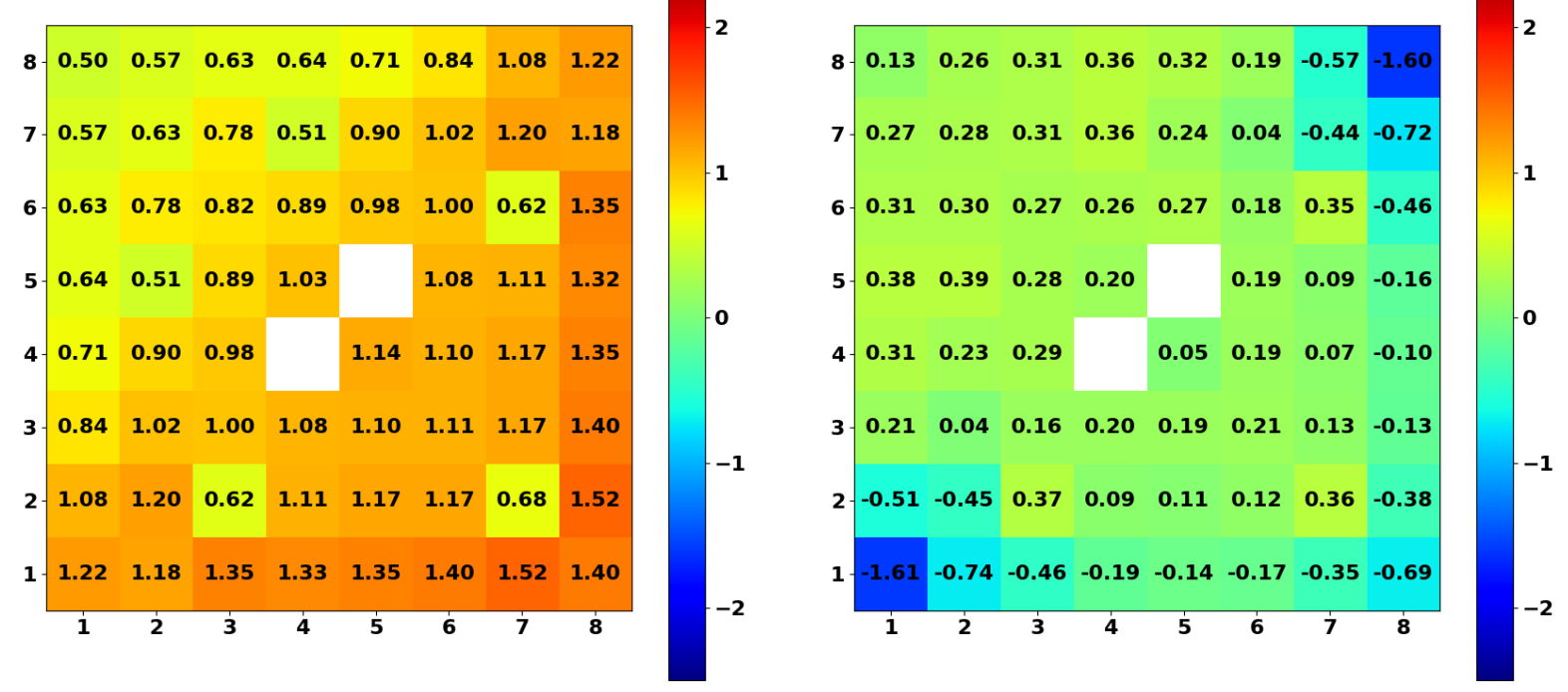

Figure 35. Normalized fission rates from Serpent (left) and $\Delta P_{i, j}$ (right) for the controlled Peach Bottom 6 lattice at $80 \%$ void.

In most cases MPACT underestimates fission rates in edge and corner pins, however, for most interior pins in the Peach Bottom lattice calculations there is good agreement between MPACT and the reference solution.

\subsubsection{GE-9 Single Assembly}

Table 23 shows the eigenvalues determined using Serpent for the GE-9 bundle described in Section 2.2. Serpent calculations for these lattices used 1.32 billion active particles leading to relative uncertainties in the eigenvalue of around $1 \mathrm{pcm}$ or less. The RMS in the difference in normalized fission rate between MPACT and the Serpent reference solution is again larger in controlled and low void cases.

Table 23. Summary of comparison between MPACT and Serpent results for the GE-9 lattice.

\begin{tabular}{|c|c|c|c|c|c|}
\hline \multicolumn{7}{|c|}{ Uncontrolled } \\
\hline \multirow{2}{*}{ Void (\%) } & \multirow{2}{*}{$k_{\text {serp }}$} & $\Delta k(\mathrm{pcm})$ & \multicolumn{3}{|c|}{$\Delta P_{i, j}$ (absolute \%) } \\
& & & Max. & Min. & RMS \\
\hline 00 & 1.086230 & -63.1 & 1.20 & -1.47 & 0.57 \\
40 & 1.069030 & -14.0 & 0.63 & -1.14 & 0.41 \\
80 & 1.036350 & -24.5 & 0.43 & -0.69 & 0.25 \\
\hline \multicolumn{7}{|c|}{ Controlled } \\
\hline \multirow{2}{*}{ Void (\%) } & \multirow{2}{|c|}{$k_{\text {serp }}$} & $\Delta k(\mathrm{pcm})$ & $\Delta P_{i, j}$ (absolute \%) \\
\hline 00 & 0.844339 & -170.9 & 1.25 & -2.43 & 0.75 \\
40 & 0.796580 & -84.5 & 0.85 & -2.17 & 0.60 \\
80 & 0.730167 & -40.0 & 0.50 & -1.66 & 0.45 \\
\hline
\end{tabular}


For all GE-9 lattice calculations, the maximum relative standard deviation in the fission rates was $0.03 \%$ for the Serpent results. In Figure 36 through Figure 41, more detailed descriptions of the differences in normalized fission rates between MPACT and Monte Carlo results are provided.
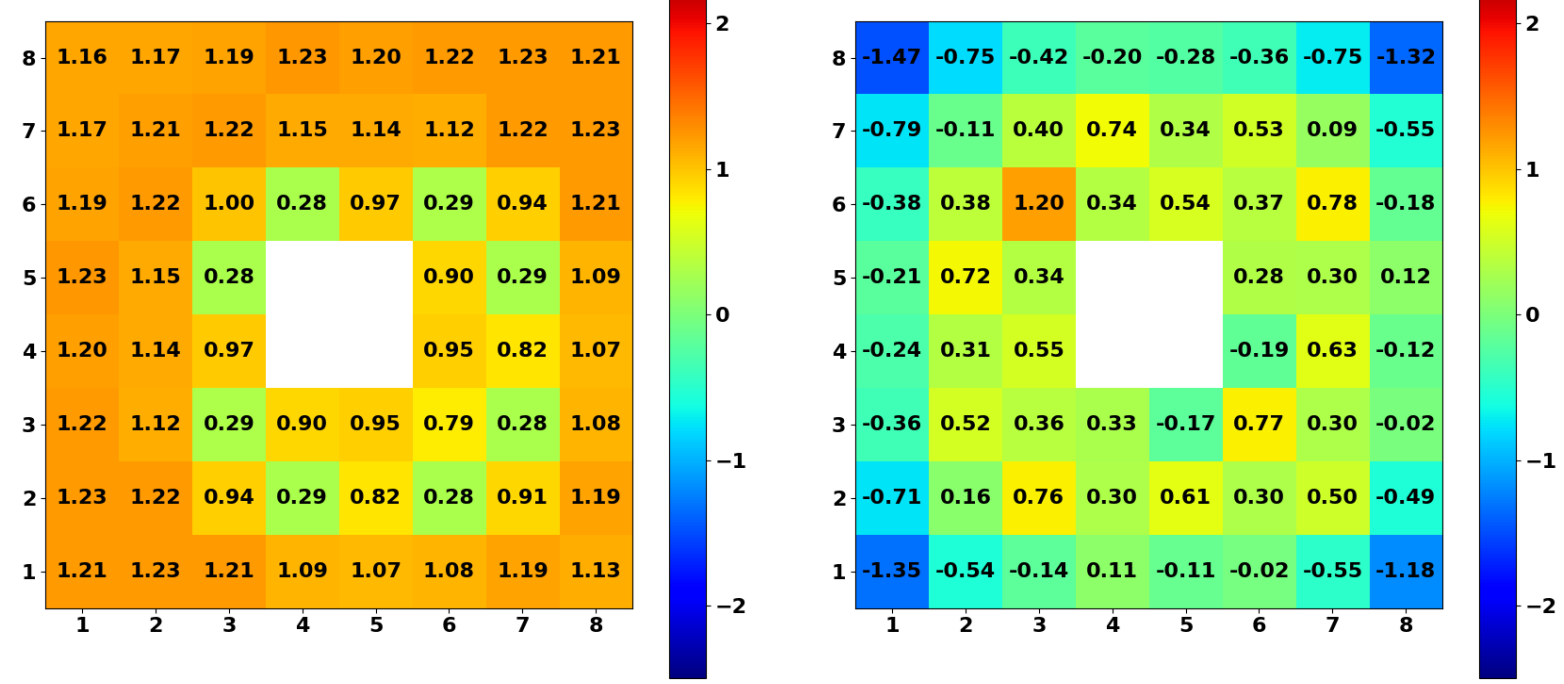

Figure 36. Normalized fission rates from Serpent (left) and $\Delta P_{i, j}$ (right) for the GE-9 lattice at $0 \%$ void.
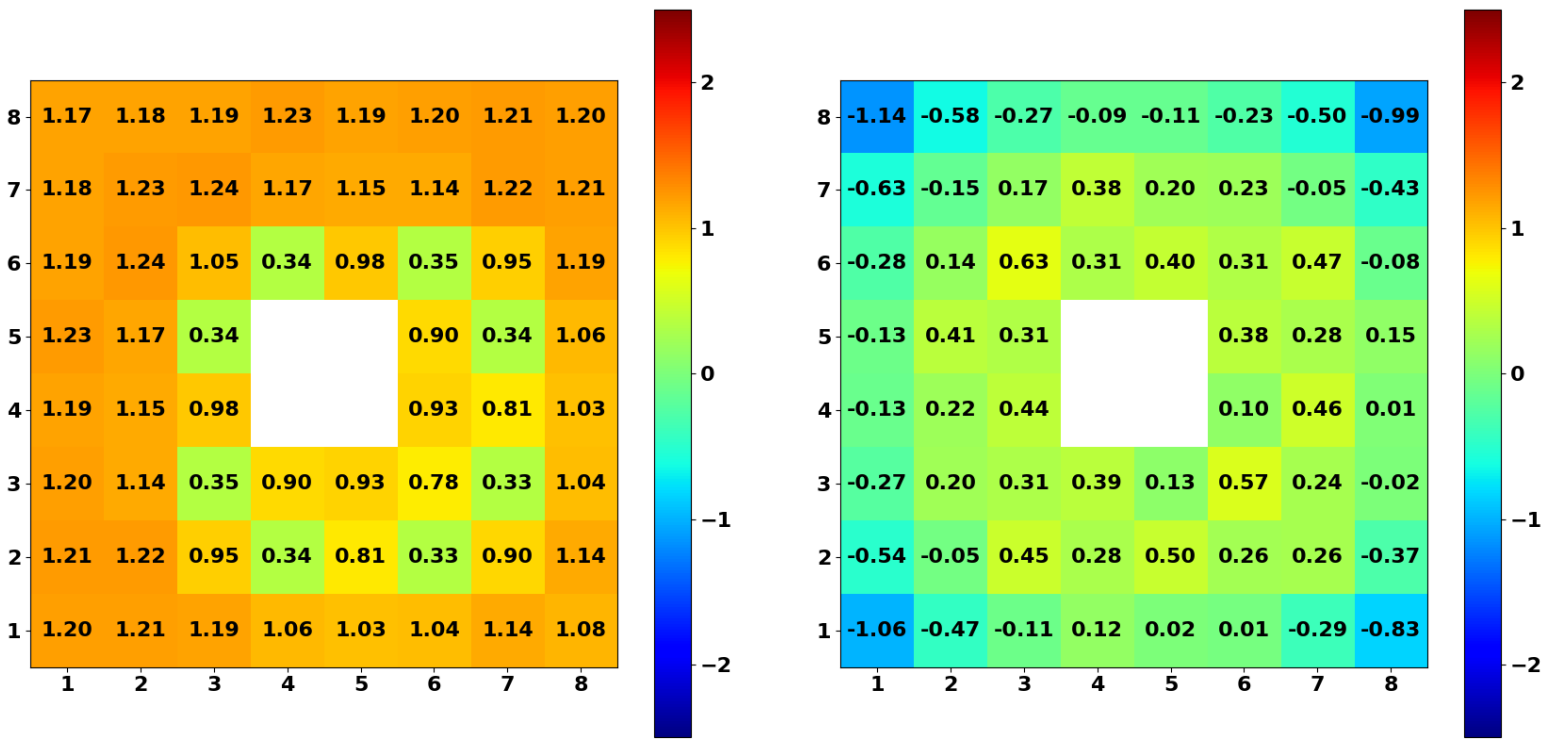

Figure 37. Normalized fission rates from Serpent (left) and $\Delta P_{i, j}$ (right) for the GE-9 lattice at $40 \%$ void. 

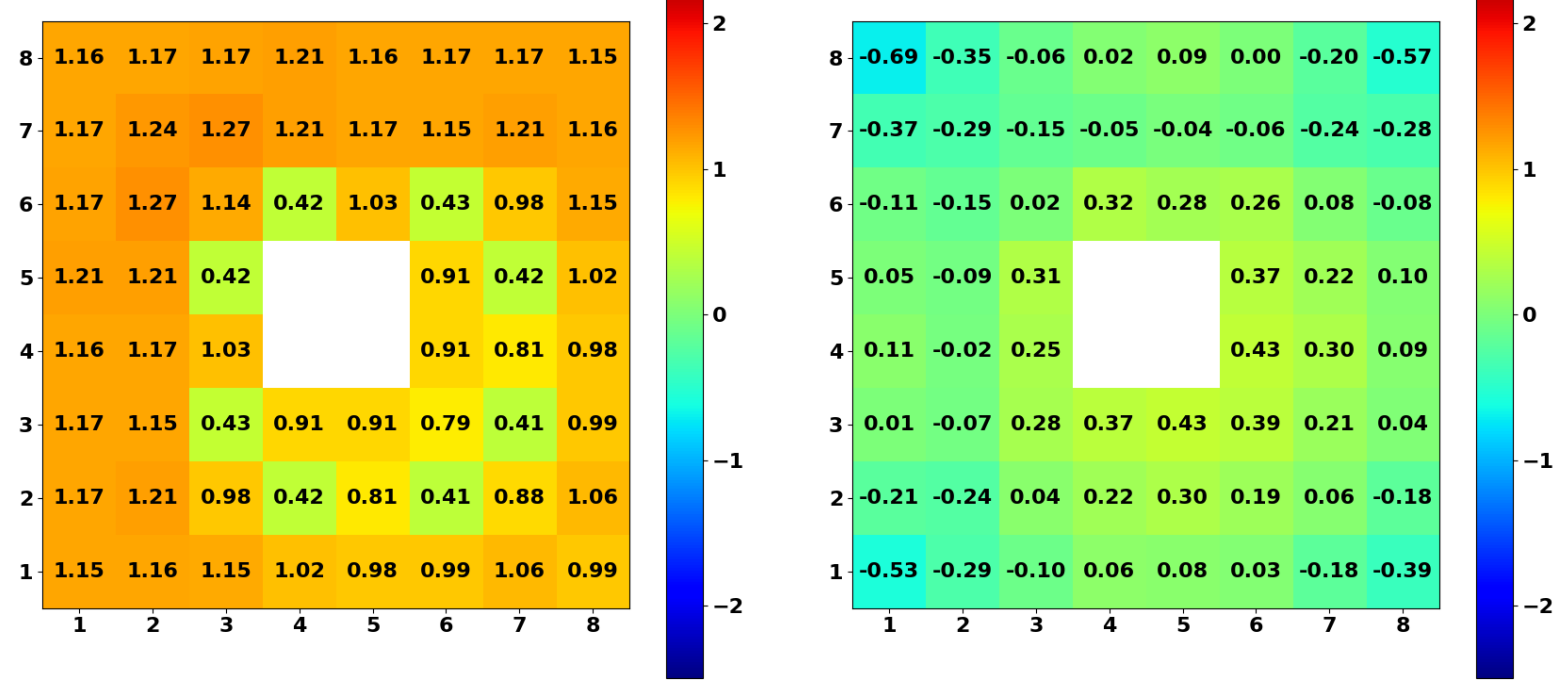

Figure 38. Normalized fission rates from Serpent (left) and $\Delta P_{i, j}$ (right) for the GE-9 lattice at $80 \%$ void.
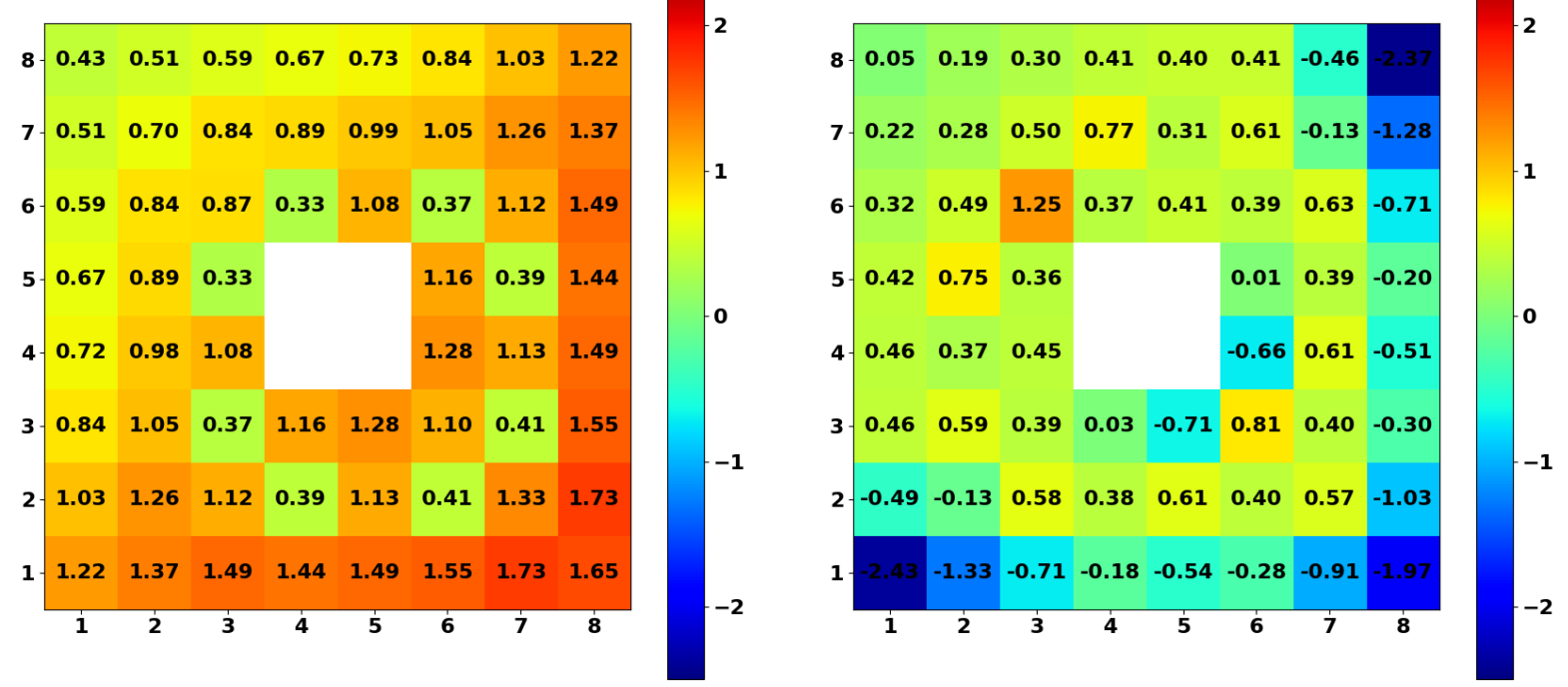

Figure 39. Normalized fission rates from Serpent (left) and $\Delta P_{i, j}$ (right) for the controlled GE-9 lattice at $0 \%$ void. 

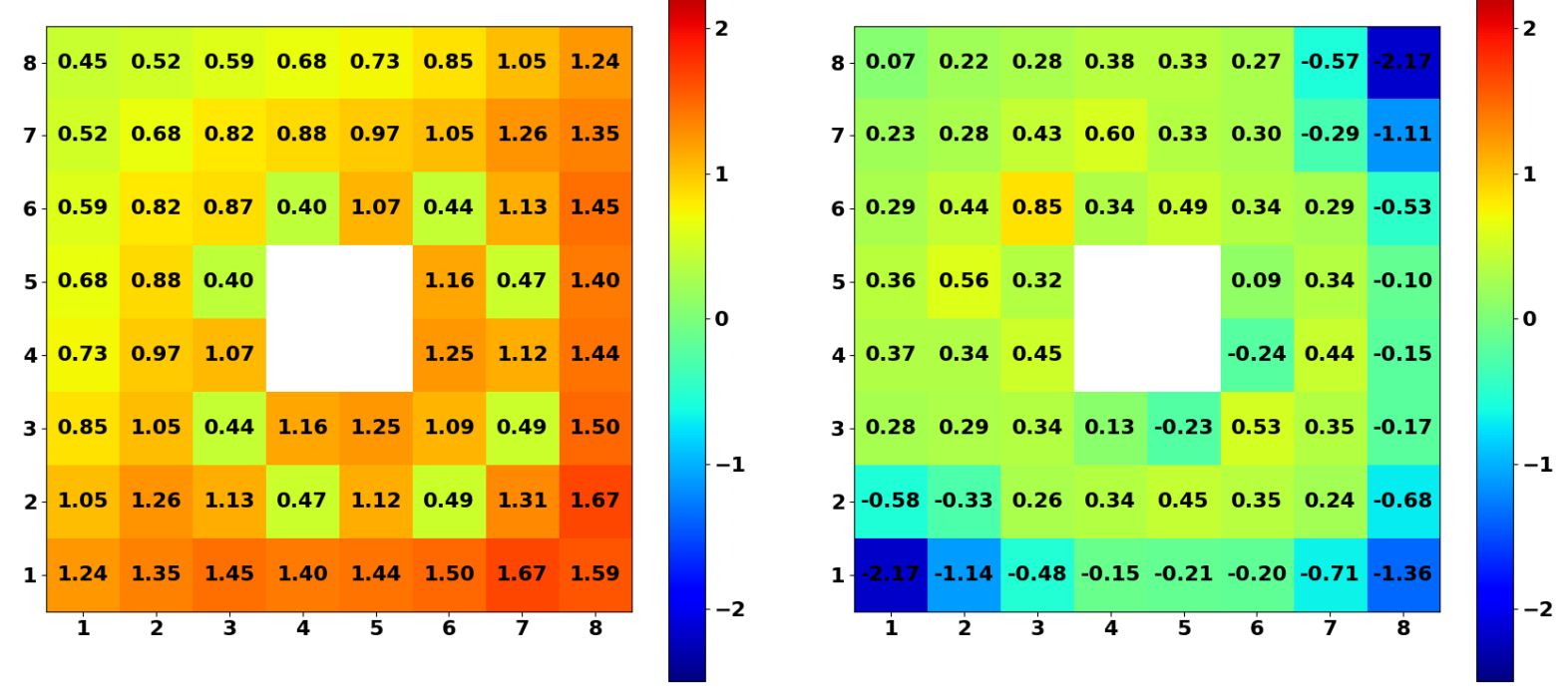

Figure 40. Normalized fission rates from Serpent (left) and $\Delta P_{i, j}$ (right) for the controlled GE-9 lattice at $40 \%$ void.
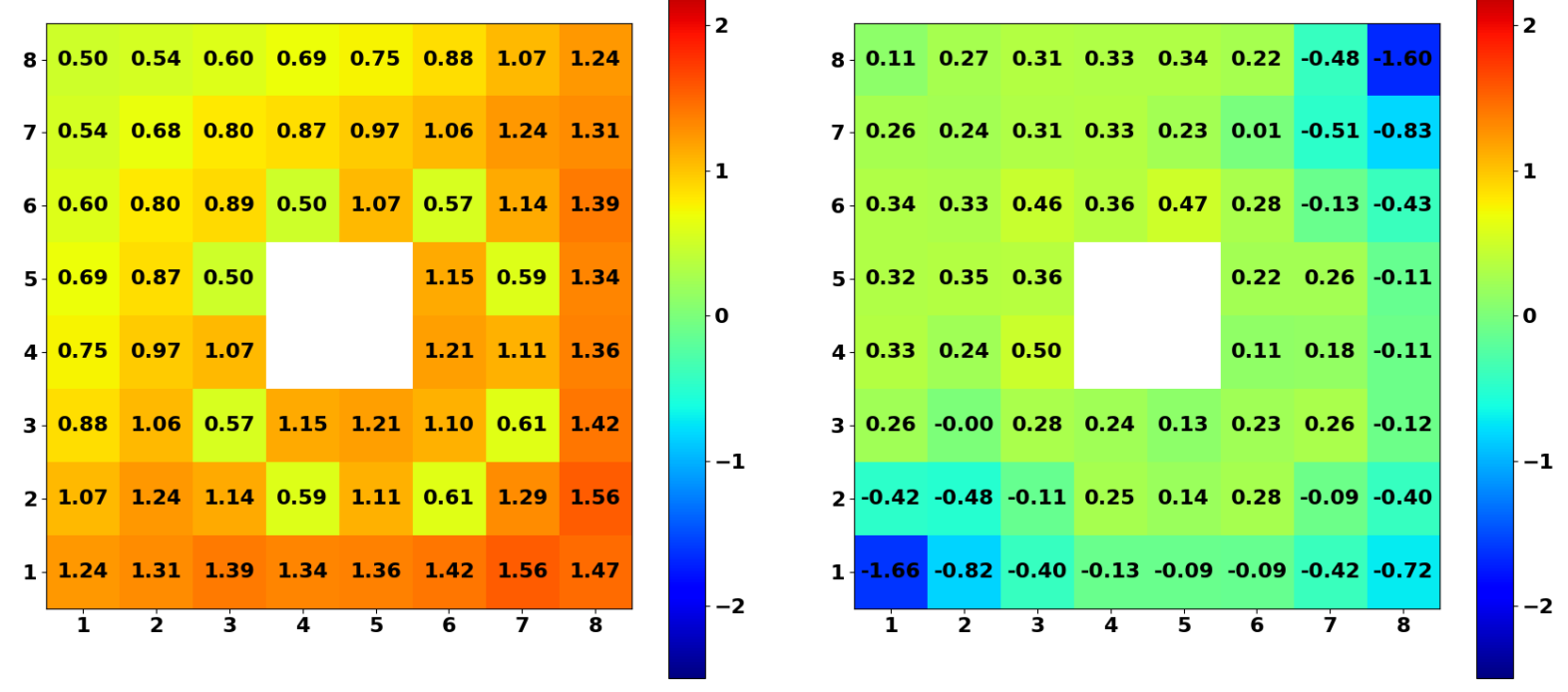

Figure 41. Normalized fission rates from Serpent (left) and $\Delta P_{i, j}$ (right) for the controlled GE-9 lattice at $80 \%$ void.

MPACT underestimates fission rates in corner pins, but agrees well with the reference solution for interior pins. The underestimation of corner pins is worse in controlled cases and in lower void cases. 


\subsubsection{GE-14 Single Assembly}

Table 24 shows the eigenvalues from Serpent for the GE-14 bundle described in Section 2.3 as well as a comparison with results from MPACT for the GE-14 lattice The Serpent calculations used 1.32 billion active particles leading to relative uncertainties in the eigenvalue of approximately $1 \mathrm{pcm}$ or less. A summary of the differences in normalized fission rate distribution are also provided. In the case of the GE-14 lattice calculations the MPACT calculations and the Serpent reference solutions agree to within 75 $\mathrm{pcm}$ in terms of the eigenvalues.

Table 24. Summary of comparison between MPACT and Serpent results for the GE-14 lattice.

\begin{tabular}{|c|c|c|c|c|c|}
\hline \multicolumn{5}{|c|}{ Uncontrolled } \\
\hline \multirow{2}{*}{ Void (\%) } & \multirow{2}{*}{$k_{\text {serp }}$} & $\Delta k(\mathrm{pcm})$ & \multicolumn{3}{|c|}{$\Delta P_{i, j}$ (absolute \%) } \\
& & & Max. & Min. & RMS \\
\hline 00 & 0.989207 & 18.3 & 1.13 & -1.55 & 0.58 \\
40 & 0.971401 & 74.6 & 0.74 & -1.15 & 0.42 \\
80 & 0.947437 & 40.8 & 0.43 & -0.70 & 0.25 \\
\hline \multicolumn{5}{|c|}{ Controlled } \\
\hline \multirow{2}{*}{ Void (\%) } & \multirow{2}{*}{$k_{\text {serp }}$} & $\Delta k(\mathrm{pcm})$ & $\Delta P_{i, j}$ (absolute \%) \\
\hline 00 & 0.816986 & -10.7 & 1.43 & -2.38 & 0.74 \\
40 & 0.785002 & 55.9 & 0.84 & -1.91 & 0.58 \\
80 & 0.748449 & 54.2 & 0.61 & -1.43 & 0.44 \\
\hline
\end{tabular}

For all GE-14 lattice calculations, the maximum relative standard deviation in the fission rates was $0.04 \%$ for the Serpent results. In Figure 42 through Figure 47, more detailed descriptions of the differences in normalized fission rates between MPACT and Monte Carlo results are provided. 

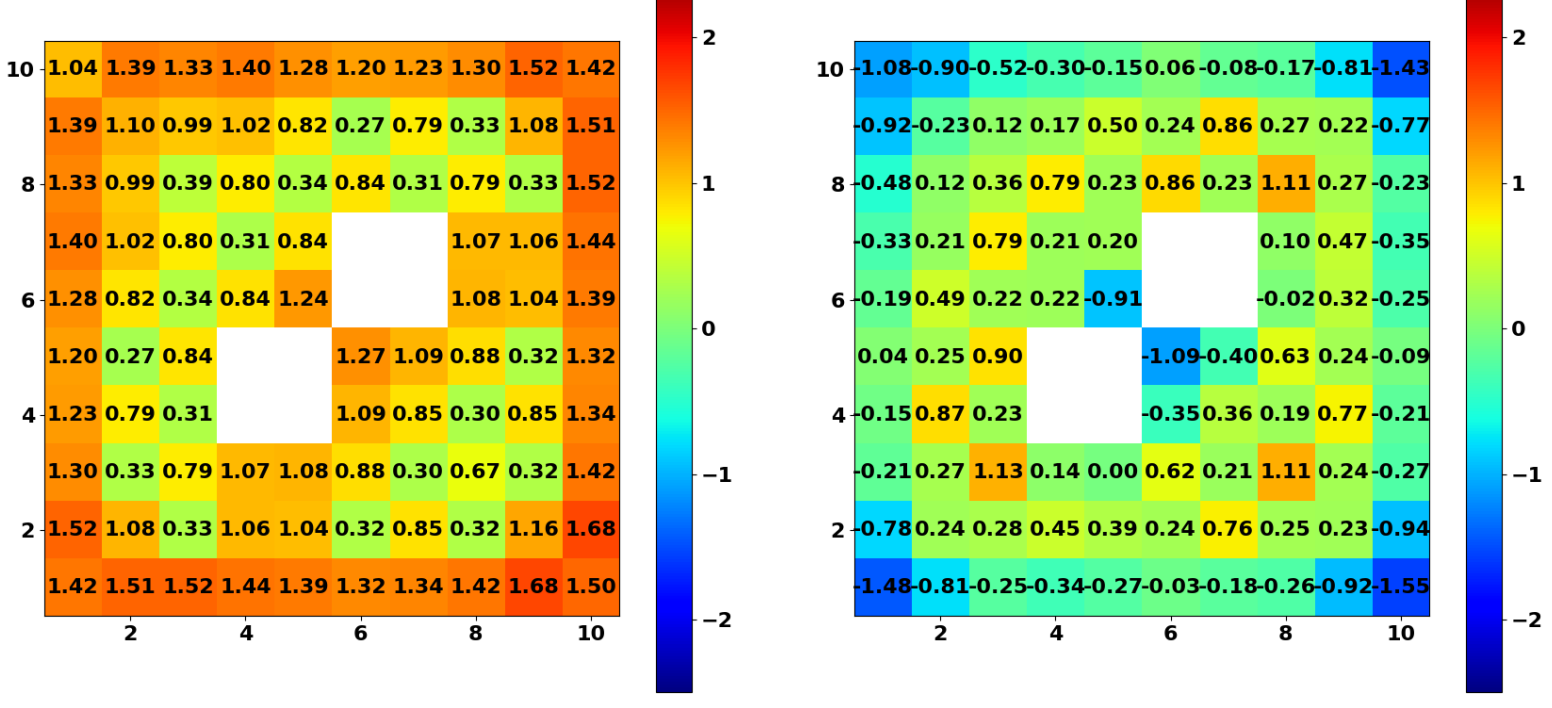

Figure 42. Normalized fission rates from Serpent (left) and $\Delta P_{i, j}$ (right) for the GE-14 lattice at $0 \%$ void.
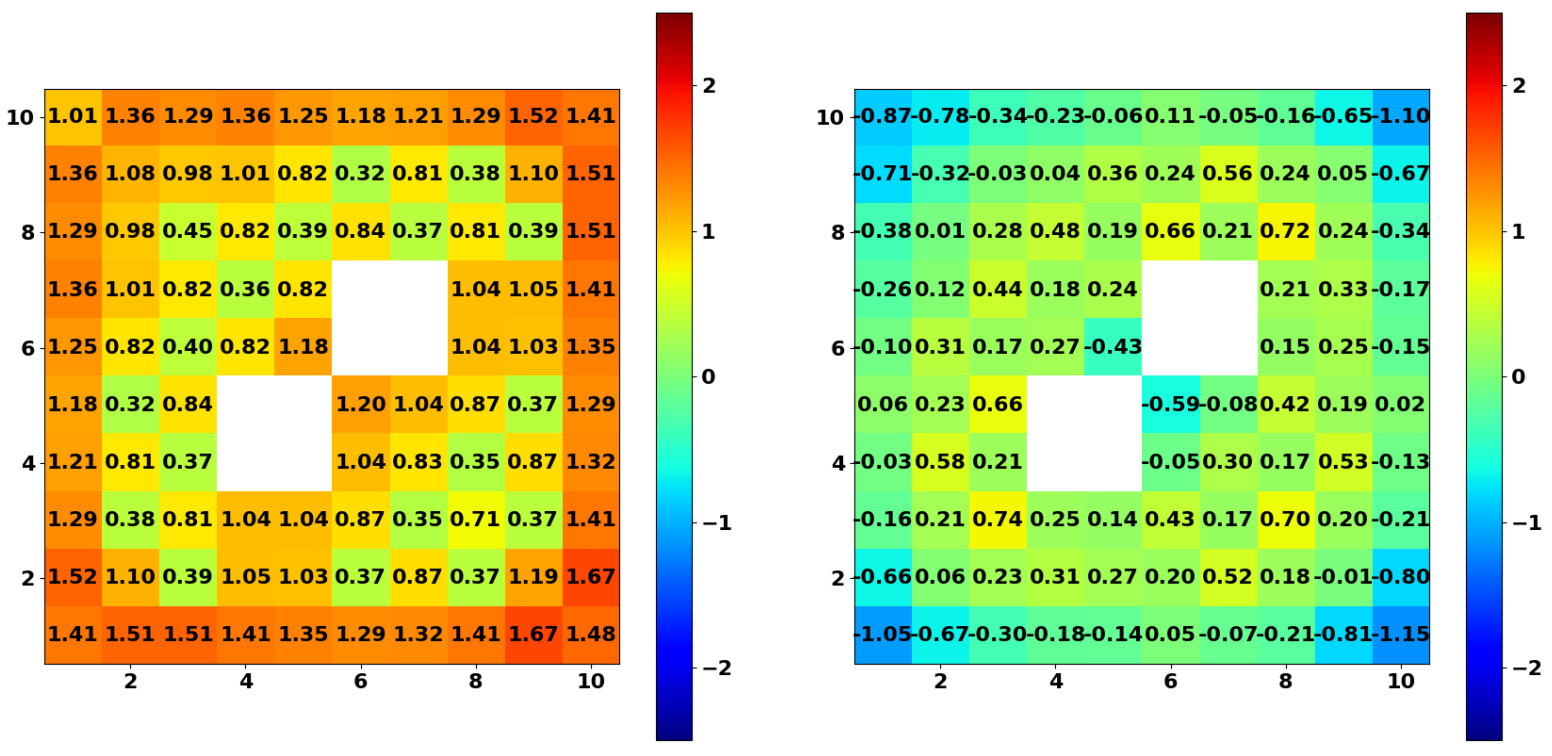

Figure 43. Normalized fission rates from Serpent (left) and $\Delta P_{i, j}$ (right) for the GE-14 lattice at $40 \%$ void. 

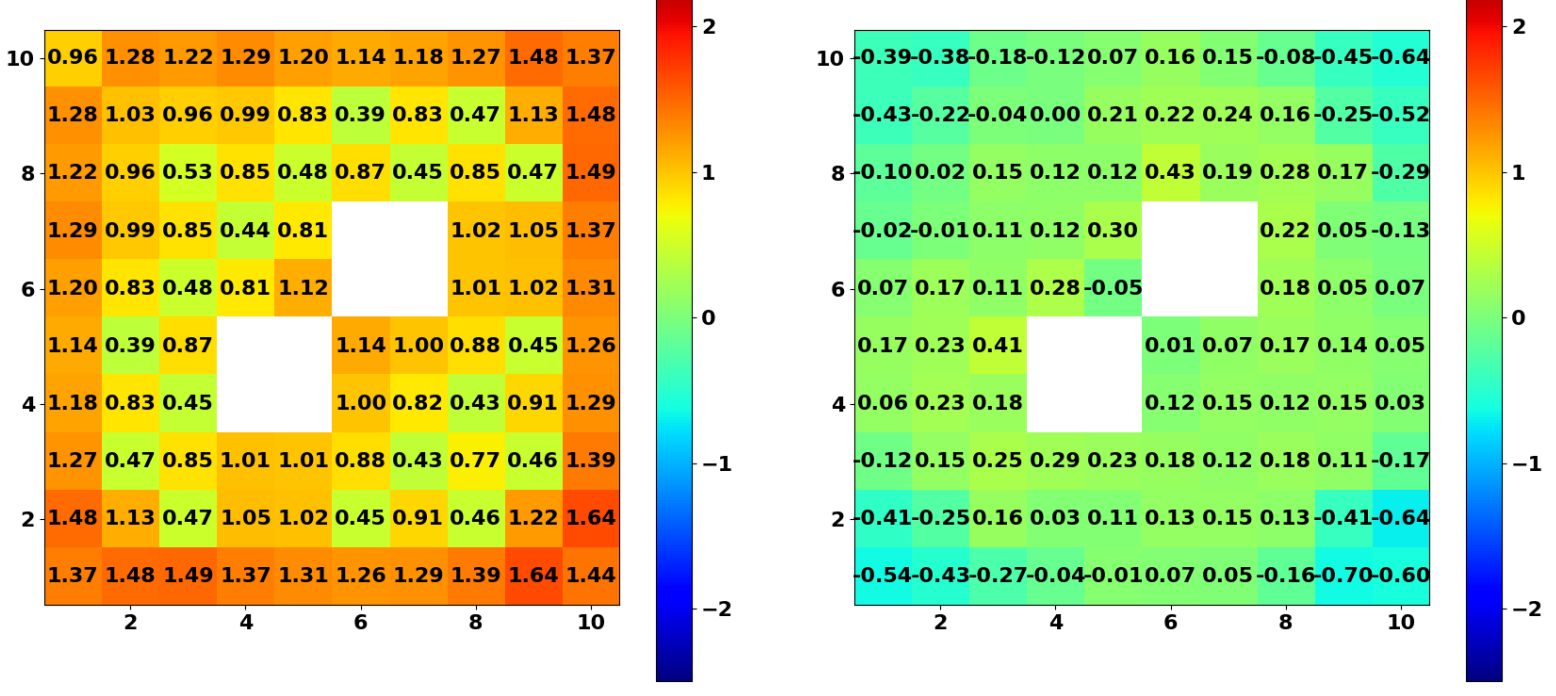

Figure 44. Normalized fission rates from Serpent (left) and $\Delta P_{i, j}$ (right) for the GE-14 lattice at $80 \%$ void.
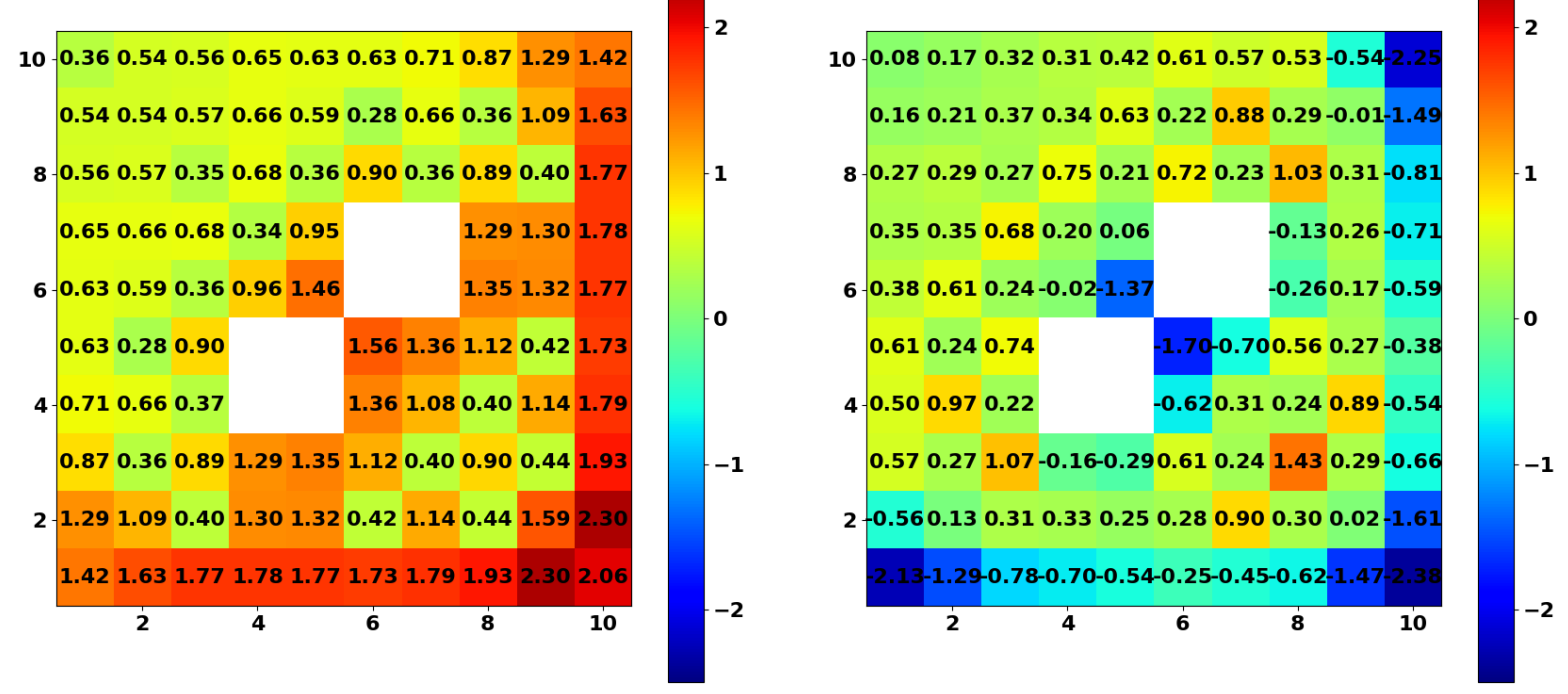

Figure 45. Normalized fission rates from Serpent (left) and $\Delta P_{i, j}$ (right) for the controlled GE-14 lattice at $0 \%$ void. 

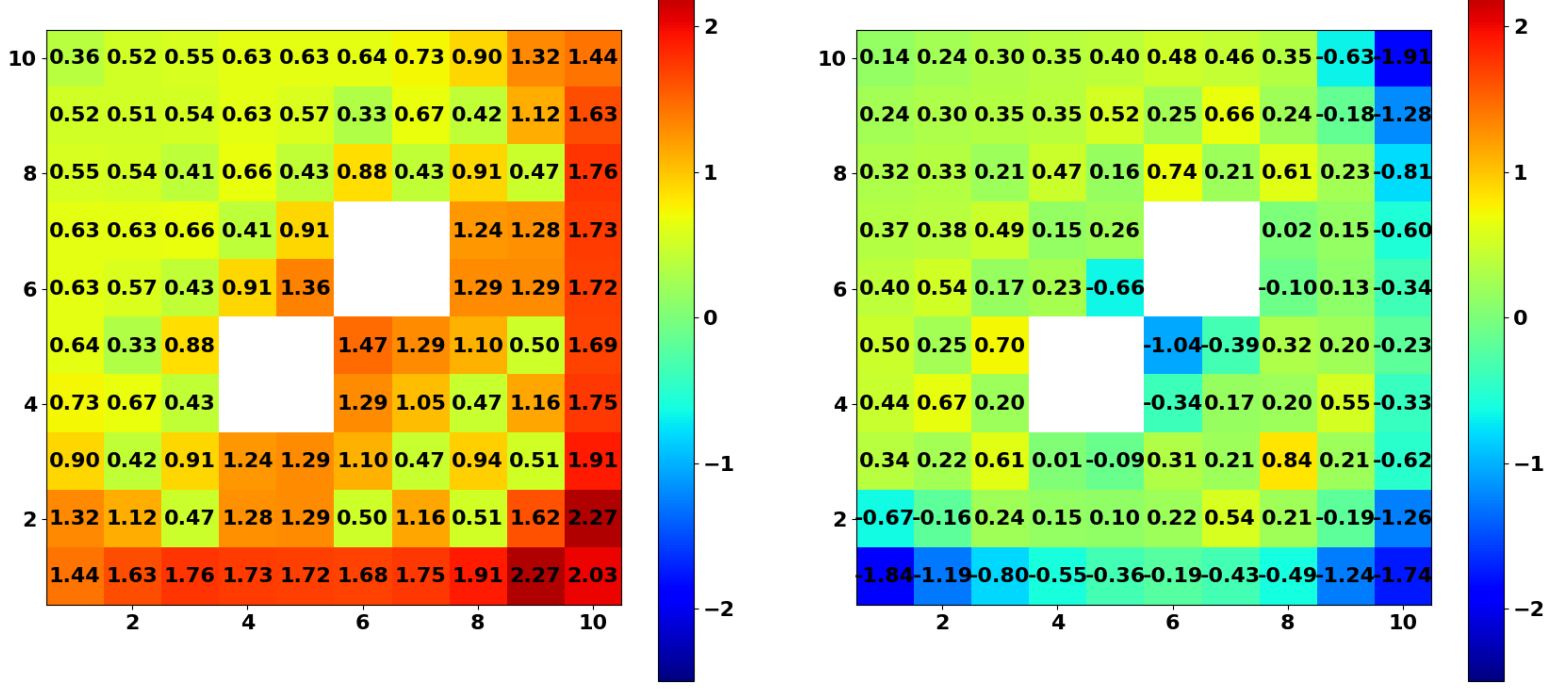

Figure 46. Normalized fission rates from Serpent (left) and $\Delta P_{i, j}$ (right) for the controlled GE-14 lattice at $40 \%$ void.
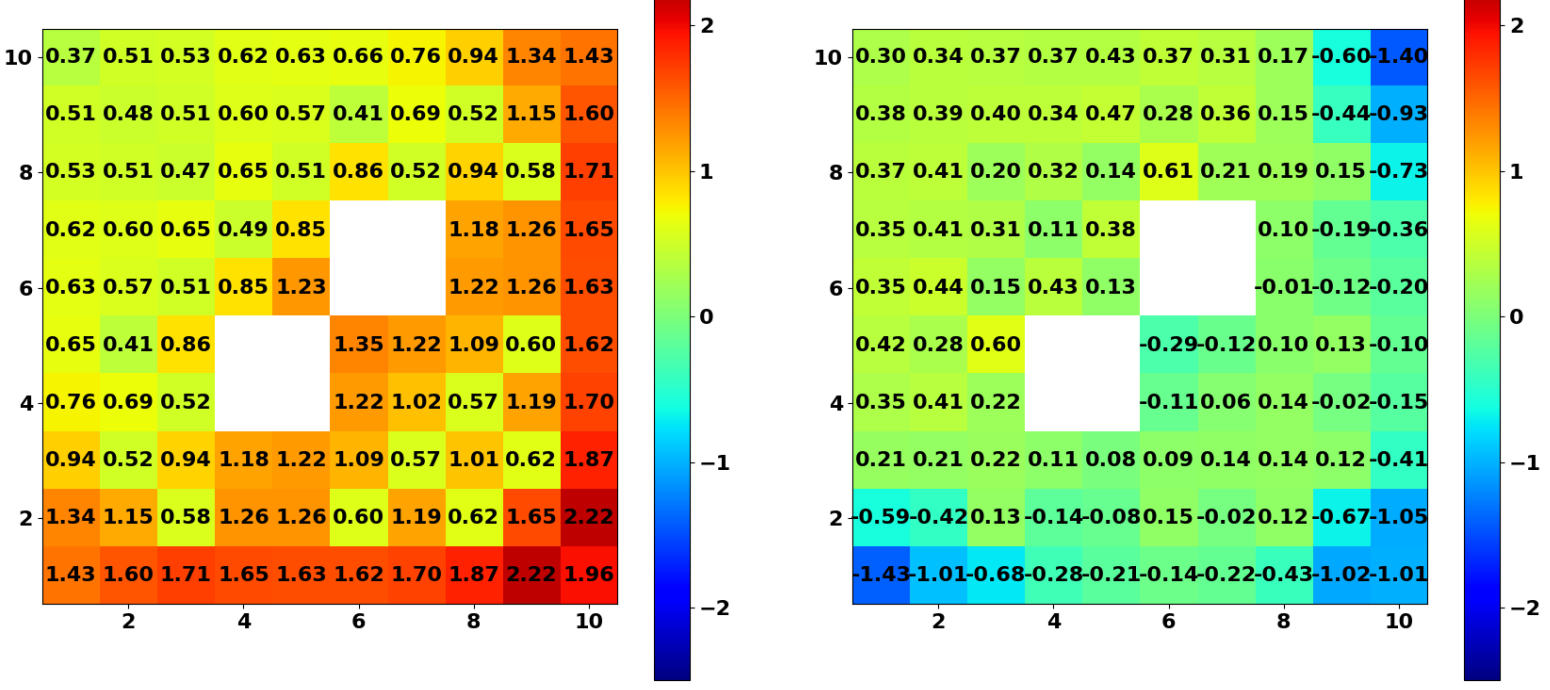

Figure 47. Normalized fission rates from Serpent (left) and $\Delta P_{i, j}$ (right) for the controlled GE-14 lattice at $80 \%$ void.

Similarly to the Peach Bottom lattice and the GE-9 lattice cases, MPACT under-predicts fission rates in the corner pins. However, in the case of the GE-14 lattices, this also occurs for the fuel pins between the two oversized water rods. 


\subsubsection{GE-14 Single Assembly with Vanished Rods}

Table 25 shows the eigenvalues from Serpent for the GE-14 lattice with vanished rods described in Section 2.4. It also provides a summary of the comparison between Serpent and MPACT calculations. The Serpent calculations used 1.32 billion active particles which was sufficient to drive the relative uncertainty in the eigenvalue to around $1 \mathrm{pcm}$ or less in all cases.

Table 25. Summary of comparison between MPACT and Serpent results for the GE-14 lattice with vanished rods.

\begin{tabular}{|c|c|c|c|c|c|}
\hline \multicolumn{5}{|c|}{ Uncontrolled } \\
\hline \multirow{2}{*}{ Void (\%) } & \multirow{2}{*}{$k_{\text {serp }}$} & $\Delta k(\mathrm{pcm})$ & \multicolumn{3}{|c|}{$\Delta P_{i, j}$ (absolute \%) } \\
& & & Max. & Min. & RMS \\
\hline 00 & 0.980903 & 63.5 & 1.50 & -1.27 & 0.62 \\
40 & 0.966607 & 126.3 & 0.90 & -0.97 & 0.44 \\
80 & 0.942449 & 117.1 & 0.38 & -0.53 & 0.22 \\
\hline \multicolumn{5}{|c|}{ Controlled } \\
\hline \multirow{2}{*}{ Void (\%) } & \multirow{2}{*}{$k_{\text {serp }}$} & $\Delta k(\mathrm{pcm})$ & $\Delta P_{i, j}$ (absolute \%) \\
\hline 00 & 0.782067 & 49.8 & 1.52 & -2.03 & 0.75 \\
40 & 0.751855 & 111.5 & 0.86 & -1.80 & 0.58 \\
80 & 0.713857 & 118.8 & 0.57 & -1.29 & 0.40 \\
\hline
\end{tabular}

For all vanished rod problems, the maximum relative standard deviation in the fission rates was $0.04 \%$ for the Serpent results. In Figure 48 through Figure 53, more detailed descriptions of the differences in normalized fission rates between MPACT and Serpent results are provided. 

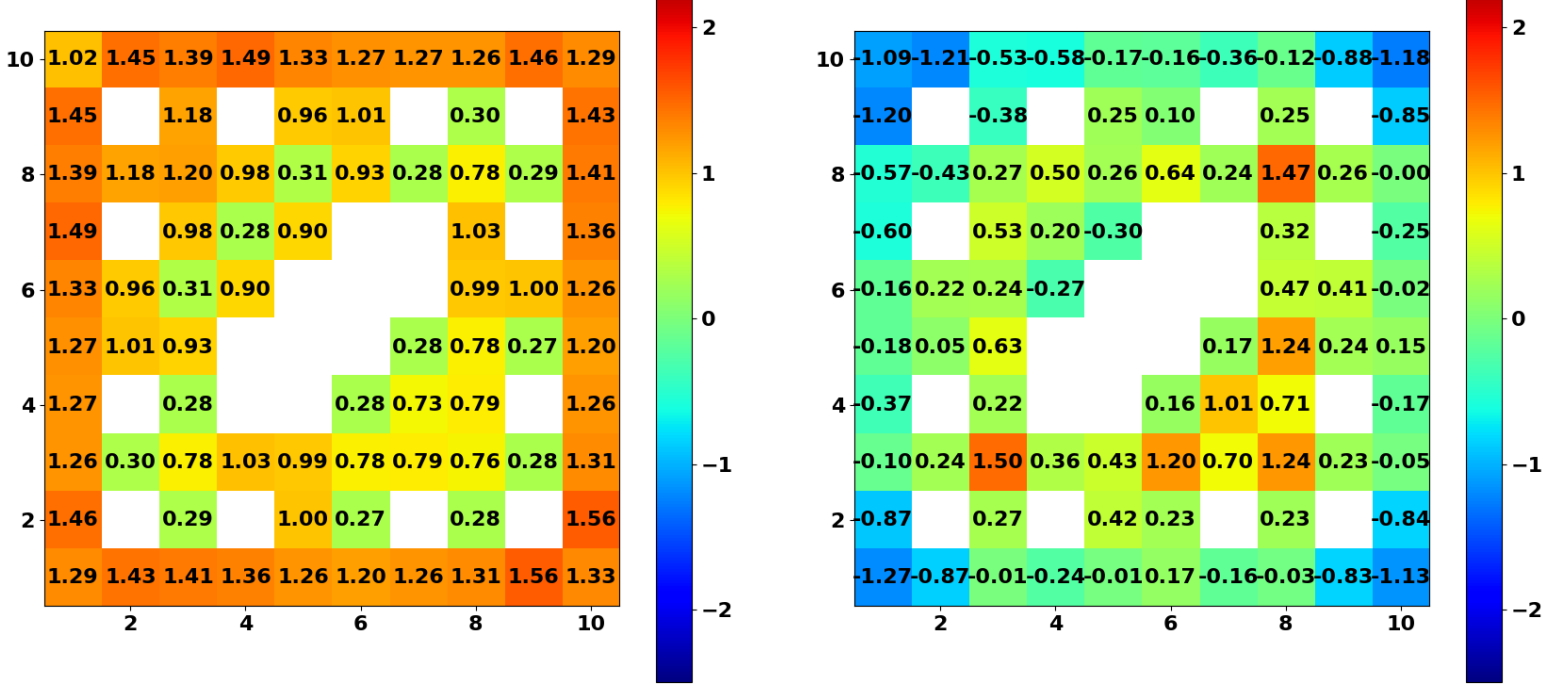

Figure 48. Normalized fission rates from Serpent (left) and $\Delta P_{i, j}$ (right) for the GE-14 lattice with vanished rods at $0 \%$ void.
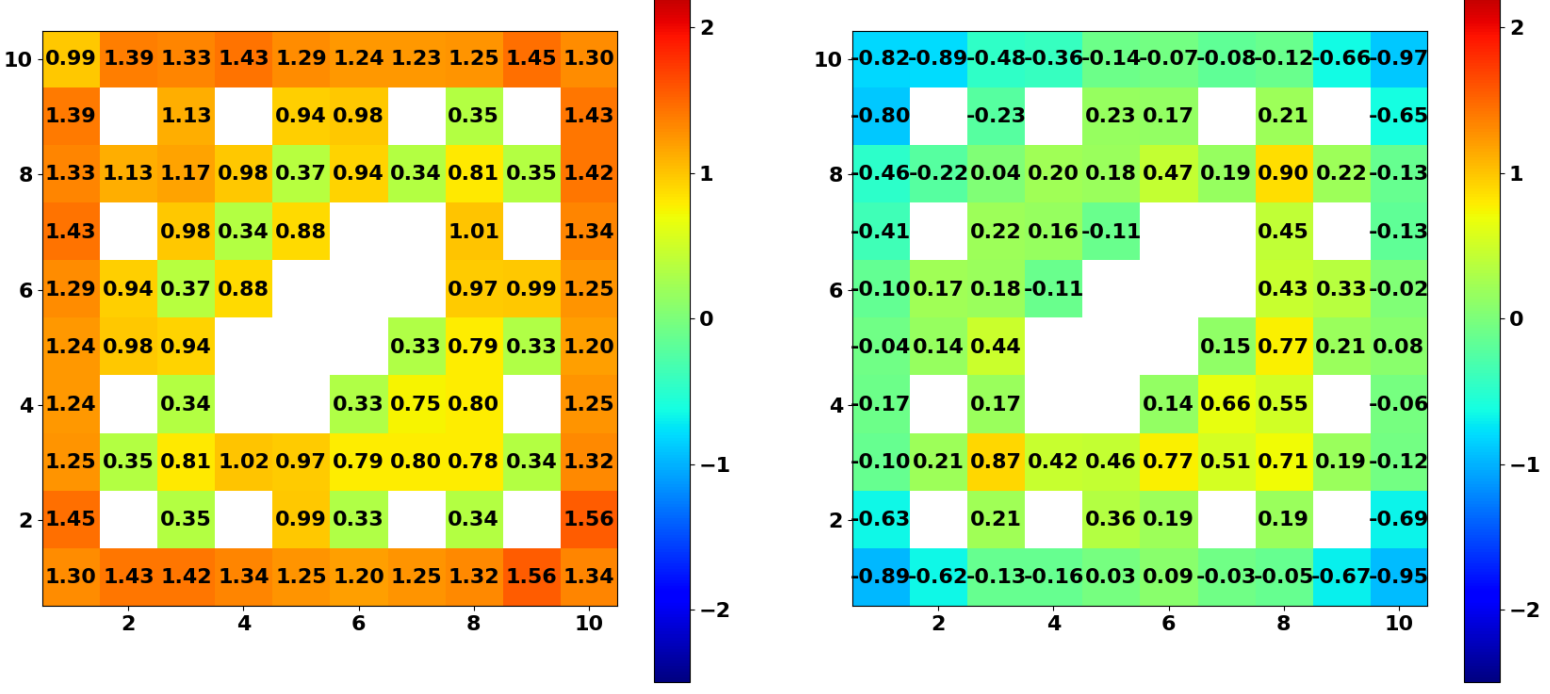

Figure 49. Normalized fission rates from Serpent (left) and $\Delta P_{i, j}$ (right) for the GE-14 lattice with vanished rods at $40 \%$ void. 

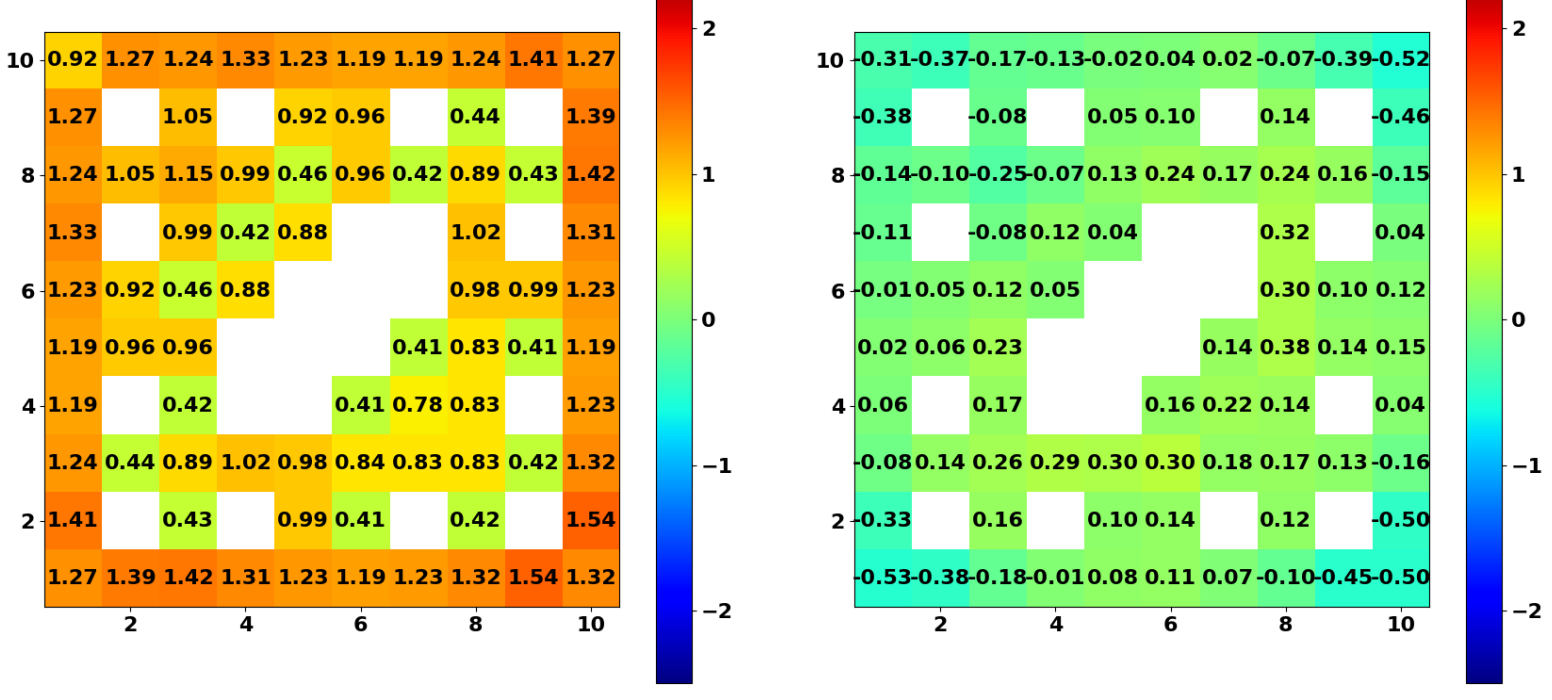

Figure 50. Normalized fission rates from Serpent (left) and $\Delta P_{i, j}$ (right) for the GE-14 lattice with vanished rods at $80 \%$ void.
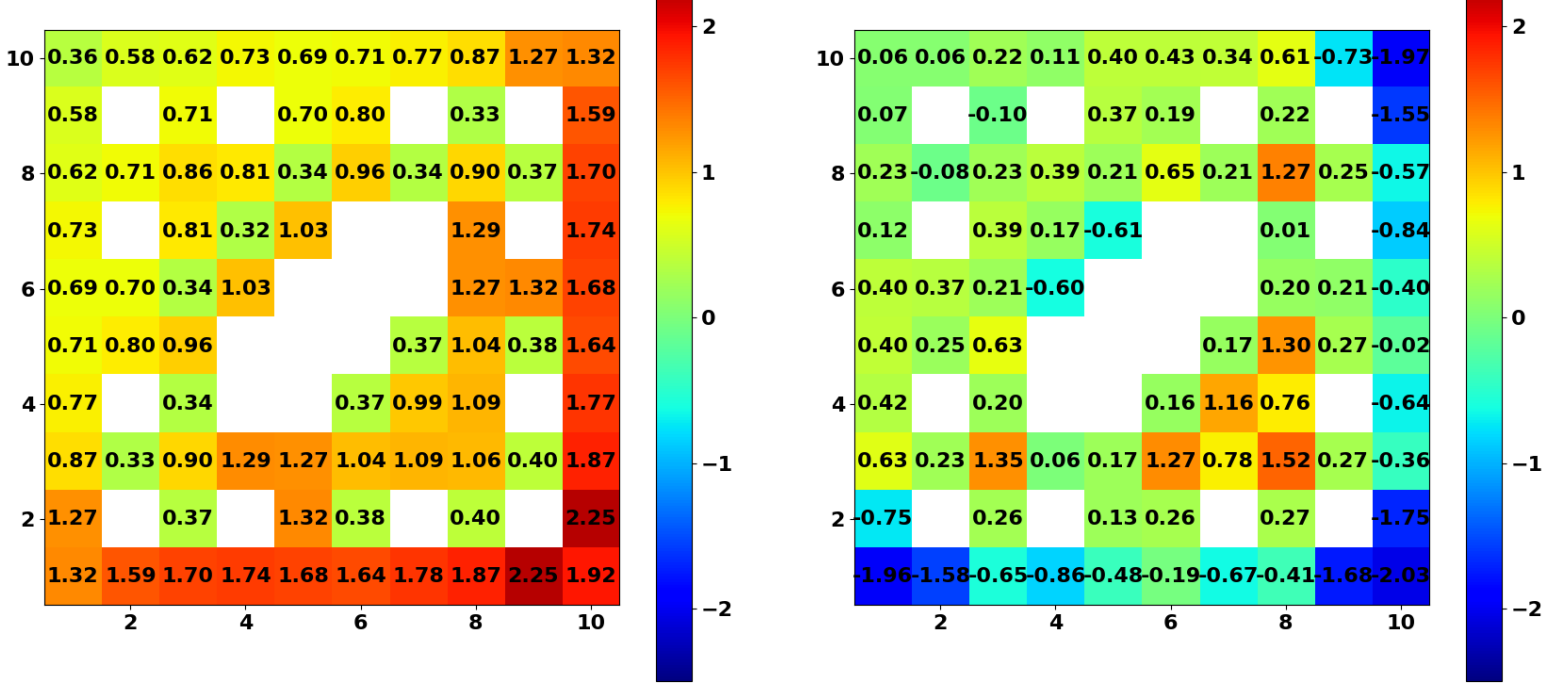

Figure 51. Normalized fission rates from Serpent (left) and $\Delta P_{i, j}$ (right) for the controlled GE-14 lattice with vanished rods at $0 \%$ void. 

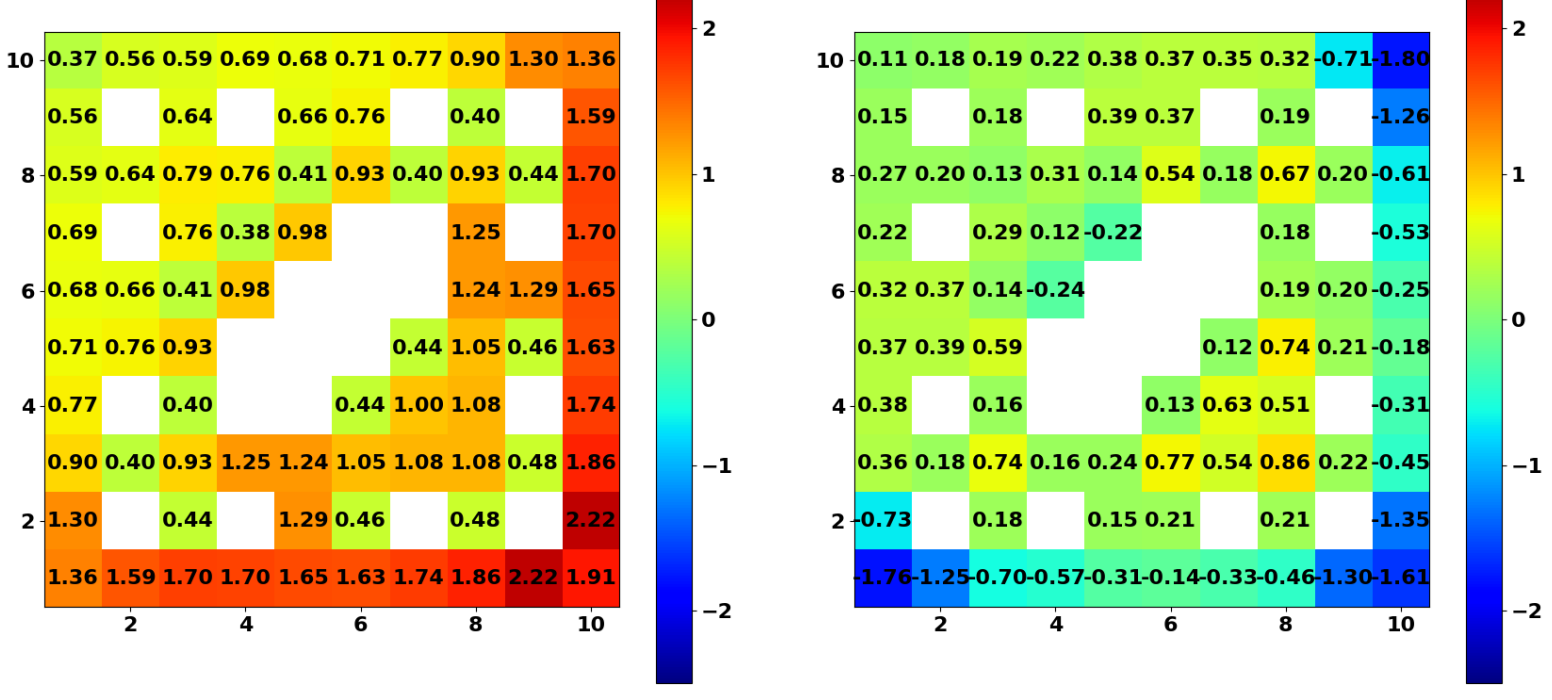

Figure 52. Normalized fission rates from Serpent (left) and $\Delta P_{i, j}$ (right) for the controlled GE-14 lattice with vanished rods at $40 \%$ void.
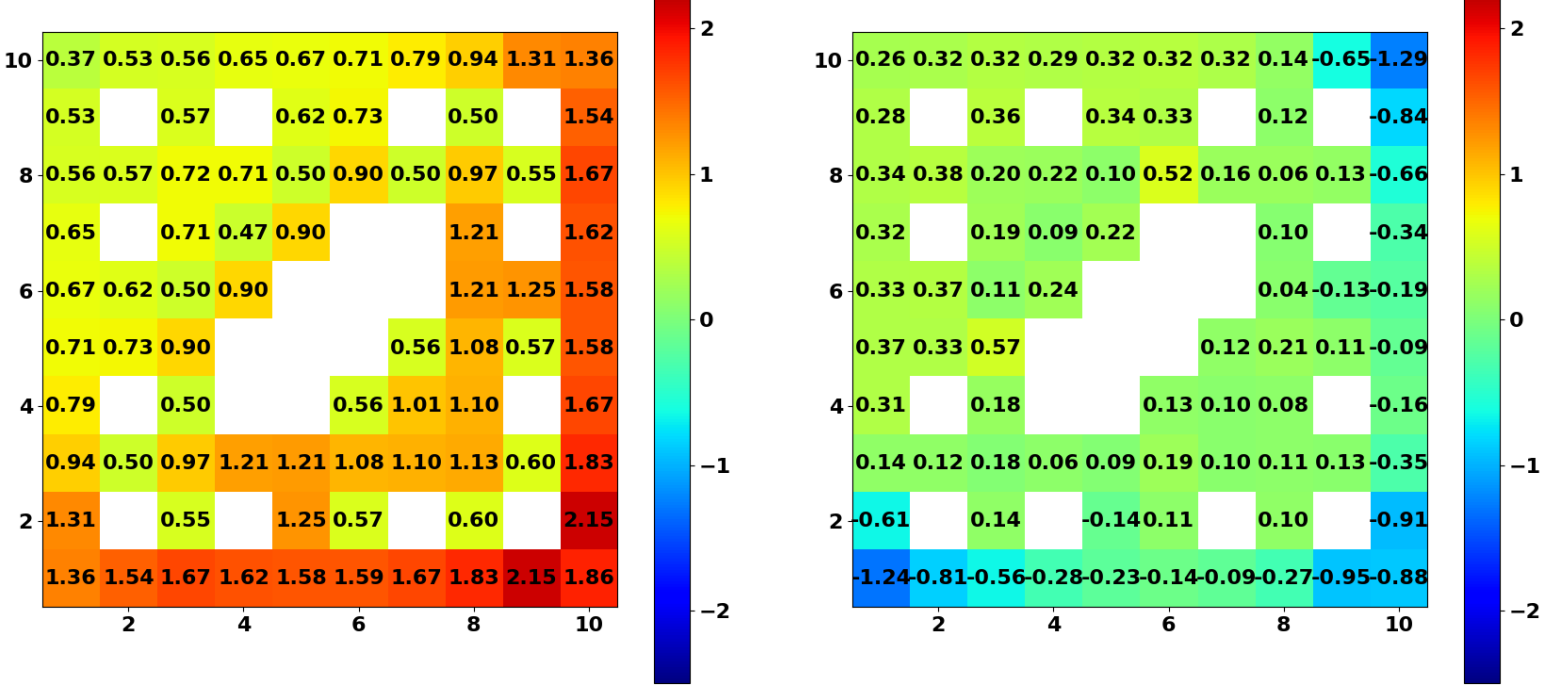

Figure 53. Normalized fission rates from Serpent (left) and $\Delta P_{i, j}$ (right) for the controlled GE-14 lattice with vanished rods at $80 \%$ void.

Again, fission rates in the corner pins are under-estimated in MPACT calculations compared to the Serpent reference solutions. As the void fraction increases this becomes less noticeable. 


\subsubsection{D Mini-Core}

Eigenvalues from the Serpent reference solutions for the 2D Mini-Core cases are provided in Table 26 and are compared with results from MPACT. The Serpent calculations tracked approximately 3 billion active particles and resulted in eigenvalue relative uncertainties of around $1 \mathrm{pcm}$ or less.

Table 26. Summary of comparison between MPACT and Serpent results for the 2D Mini-Core.

\begin{tabular}{|c|c|c|c|c|c|}
\hline \multicolumn{6}{|c|}{ Uncontrolled } \\
\hline \multirow{2}{*}{ Void (\%) } & \multirow{2}{*}{$k_{\text {serp }}$} & \multirow{2}{*}{$\Delta k(\mathrm{pcm})$} & \multicolumn{3}{|c|}{$\Delta P_{i, j}($ absolute $\%)$} \\
\hline & & & Max. & Min. & RMS \\
\hline 00 & 0.989180 & 21.0 & 1.24 & -1.66 & 0.58 \\
\hline 20 & 0.981137 & 50.1 & 1.14 & -1.68 & 0.50 \\
\hline 60 & 0.960171 & 72.8 & 0.84 & -1.35 & 0.35 \\
\hline \multicolumn{6}{|c|}{ Controlled } \\
\hline \multirow{2}{*}{ Void $(\%)$} & \multirow{2}{*}{$k_{\text {serp }}$} & \multirow{2}{*}{$\Delta k(\mathrm{pcm})$} & \multicolumn{3}{|c|}{$\Delta P_{i, j}($ absolute $\%)$} \\
\hline & & & Max. & Min. & RMS \\
\hline 00 & 0.982125 & 21.3 & 1.34 & -1.86 & 0.59 \\
\hline 20 & 0.972616 & 50.9 & 1.12 & -1.85 & 0.52 \\
\hline 60 & 0.949386 & 63.0 & 1.00 & -1.78 & 0.37 \\
\hline
\end{tabular}

The MPACT calculations agree with the reference solutions to within $73 \mathrm{pcm}$ in the eigenvalue and with an RMS in the differences in fission rate distribution of $0.59 \%$ or less.

Due to the large number of pins to track in the $4 \times 4$ mini-core cases, figures of the detailed fission rate distributions are not included for these larger cases. The reference solutions are provided in HDF5 format files in the progression problem Github repository [10], and are formatted to be compatible with VERAView for easy use in future comparisons. In general, the differences in the mini-core cases show a similar pattern of under-prediction of fission rates in corner pins compared to the reference solutions as was found in the single lattice cases.

\subsubsection{D Lattice Depletions}

The six uncontrolled lattices described in Section 2.7 were depleted with Serpent. The depletion steps used are those specified in Table 10. Each transport solve used 300 million active particles, which reduced the standard deviation of the eigenvalue to around 7-8 pcm and the relative standard deviation in fission rates to less than $0.1 \%$. Detailed normalized fission rate maps and maps with the fission rate standard deviations are provided in HDF5-formatted files in the BWR progression problem Github repository. The depletion calculation employed a higher order depletion method with linear extrapolation of the microscopic reaction rates in the predictor step and quadratic interpolation in the corrector step. In both the predictor and corrector steps, three sub-steps were used. This linear extrapolation/quadratic interpolation method is denoted as "LE/QI" and is described in Isotlo and Sahlberg [7].

Preliminary comparisons of MPACT calculations to the Serpent reference solutions are shown in Figures 54 and 55. The MPACT calculations employed the LE/QI depletion algorithm and used P2 scattering. The depletion steps used in the MPACT models are identical to those in Table 10. The eigenvalue as a function of burnup for the GE-9 bundle calculated with Serpent is shown for the uncontrolled 0, 40, and 80\% cases 
in Figure 54 along with the differences in the eigenvalue between MPACT and Serpent. Similar results are shown for the GE-14 lattice depletions in Figure 55. The differences in eigenvalue are calculated using Eq. (3). The depletion results for the 0 and $40 \%$ void cases are within $200 \mathrm{pcm}$ over the entire depletion, which is consistent with PWR results. The $80 \%$ void cases show higher errors, but this is expected.
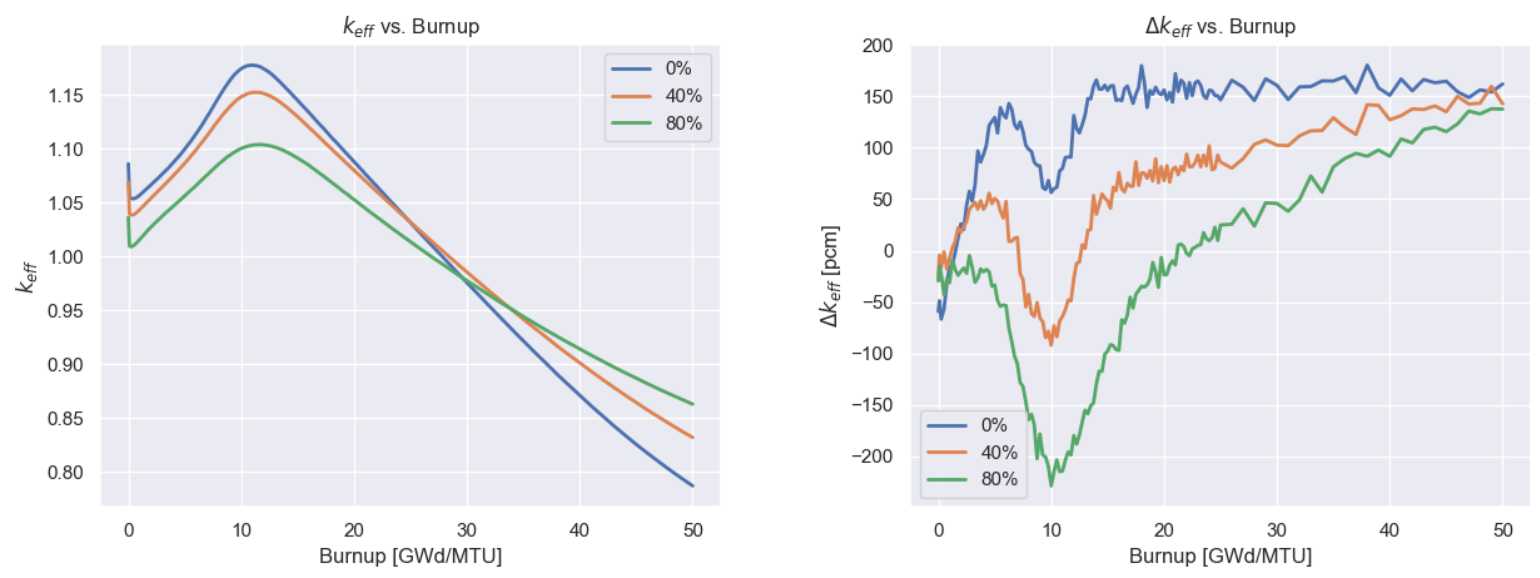

Figure 54. Eigenvalue as a function of burnup from the Serpent reference solutions for the GE-9 depletions (left) and the difference in eigenvalue compared with MPACT (right). Results are shown for 0,40 , and $80 \%$ void cases.
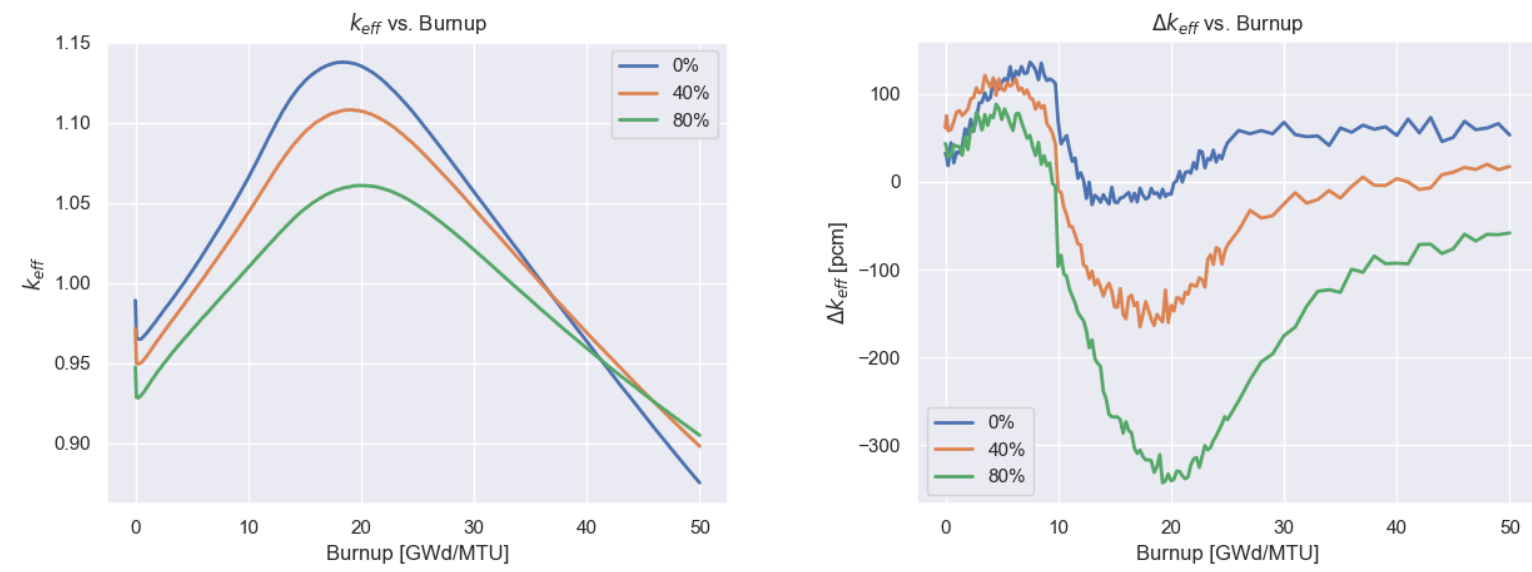

Figure 55. Eigenvalue as a function of burnup from the Serpent reference solutions for the GE-14 depletions (left) and difference in eigenvalue compared with MPACT (right). Results are shown for 0 , 40, and $80 \%$ void cases. 


\subsection{D Results}

\subsubsection{D GE-14 Single Bundle Problems}

For the 3D single bundle calculations outlined in Section 3.1 Serpent reference solutions were obtained. There are three single bundle progression problems without a control blade. For the Serpent simulations, 36 billion active particles were used. In all cases, this resulted in an eigenvalue error of $1 \mathrm{pcm}$ or less. In general, for regions with any significant fission rate the relative uncertainties in fission rates are $0.1 \%$ or less, however, in low power regions the uncertainties may be larger.

Table 27. Summary of comparison between Serpent and MPACT results for the 3D Single bundle models.

\begin{tabular}{|c|c|c|c|c|c|}
\hline \multirow{2}{*}{ Case } & \multirow{2}{*}{$k_{\text {serp }}$} & \multirow{2}{*}{$\Delta k(\mathrm{pcm})$} & \multicolumn{3}{|c|}{$\Delta P_{i, j}$ (absolute \%) } \\
& & & Max. & Min. & RMS \\
\hline \hline CZP & 1.041550 & -10.6 & 6.29 & -8.97 & 2.22 \\
HZP & 0.986263 & 57.3 & 5.93 & -4.37 & 1.32 \\
HFP & 0.968341 & 53.7 & 4.12 & -5.96 & 1.71 \\
\hline
\end{tabular}

In all three cases, the agreement in the eigenvalue between MPACT and Serpent is good. To demonstrate the comparison in normalized fission rates more thoroughly, in Figure 56 through Figure 59, four pins are selected in each of the 3D bundles and the fission rates from Serpent along with the differences between MPACT and Serpent results are plotted. The 3D cases have much higher peaking than the 2D cases, and because of this 3D fission rates are harder to predict. In all three cases, in high power regions, the fission rates predicted by MPACT are lower than the reference.
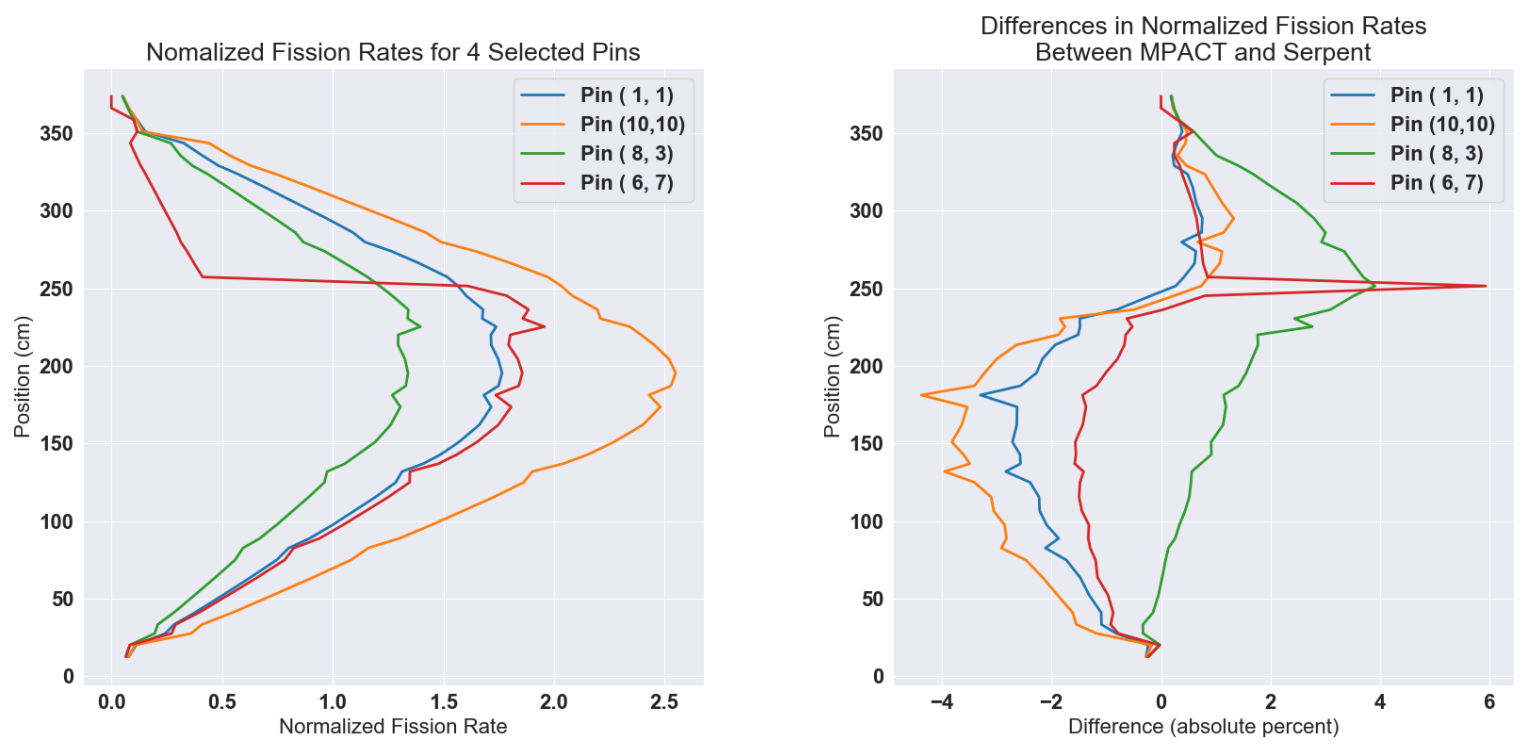

Figure 56. Normalized fission rates in 4 pins from Serpent (left) and $\Delta P_{i, j}$ (right) for the $\mathrm{HZP}$ single bundle. 


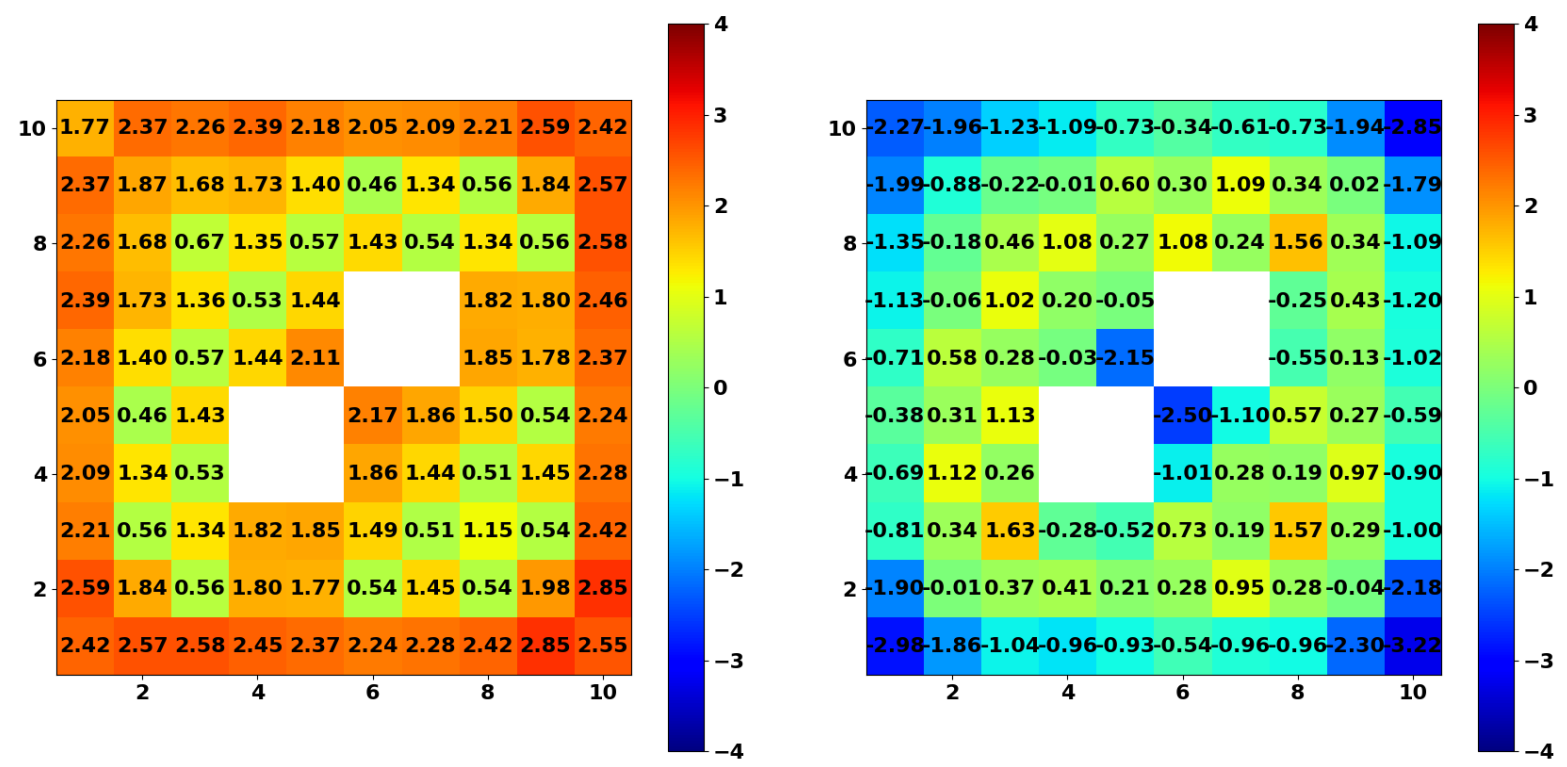

Figure 57. Normalized fission rates from Serpent (left) and $\Delta P_{i, j}$ (right) at $195.5 \mathrm{~cm}$ for the HZP bundle
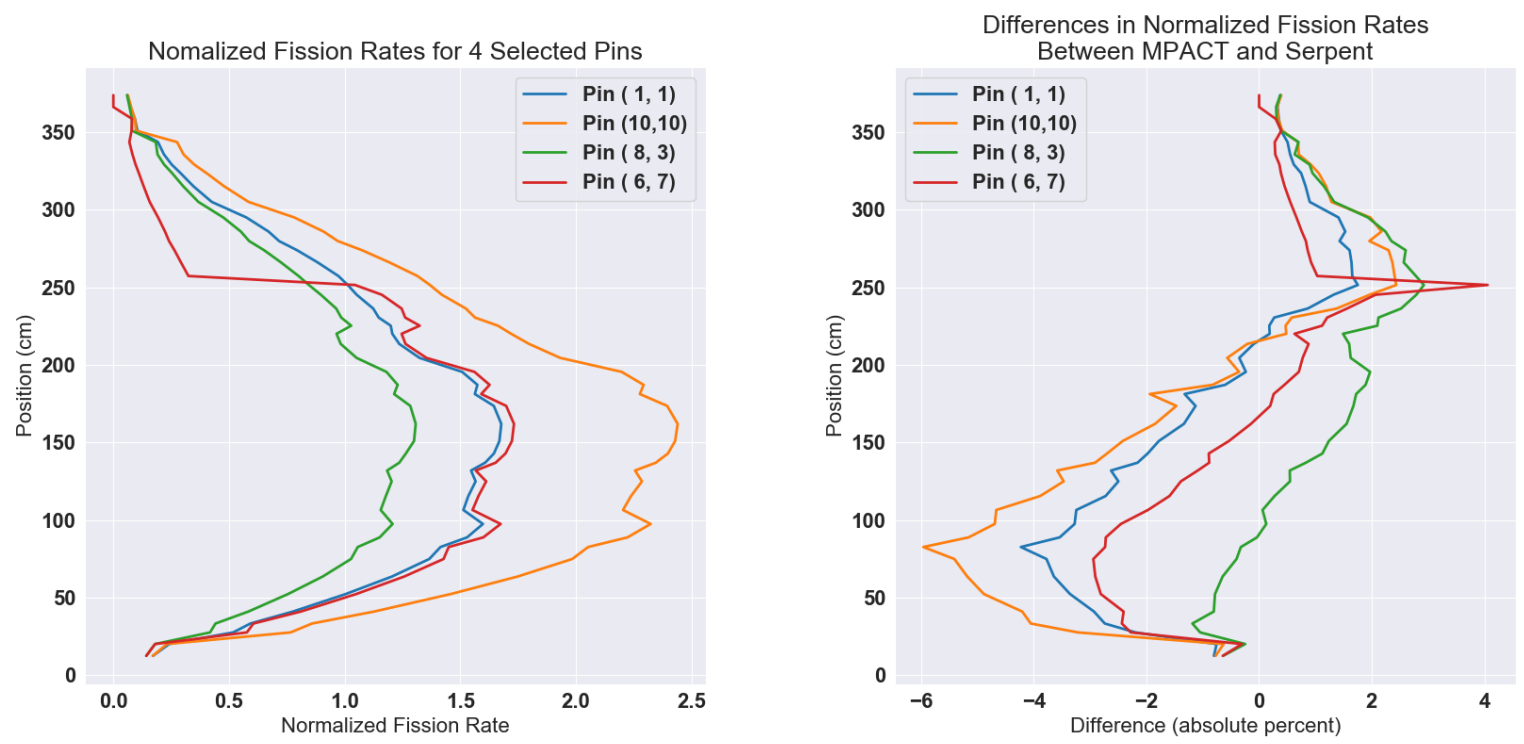

Figure 58. Normalized fission rates in 4 pins from Serpent (left) and $\Delta P_{i, j}$ (right) for the HFP single bundle. 

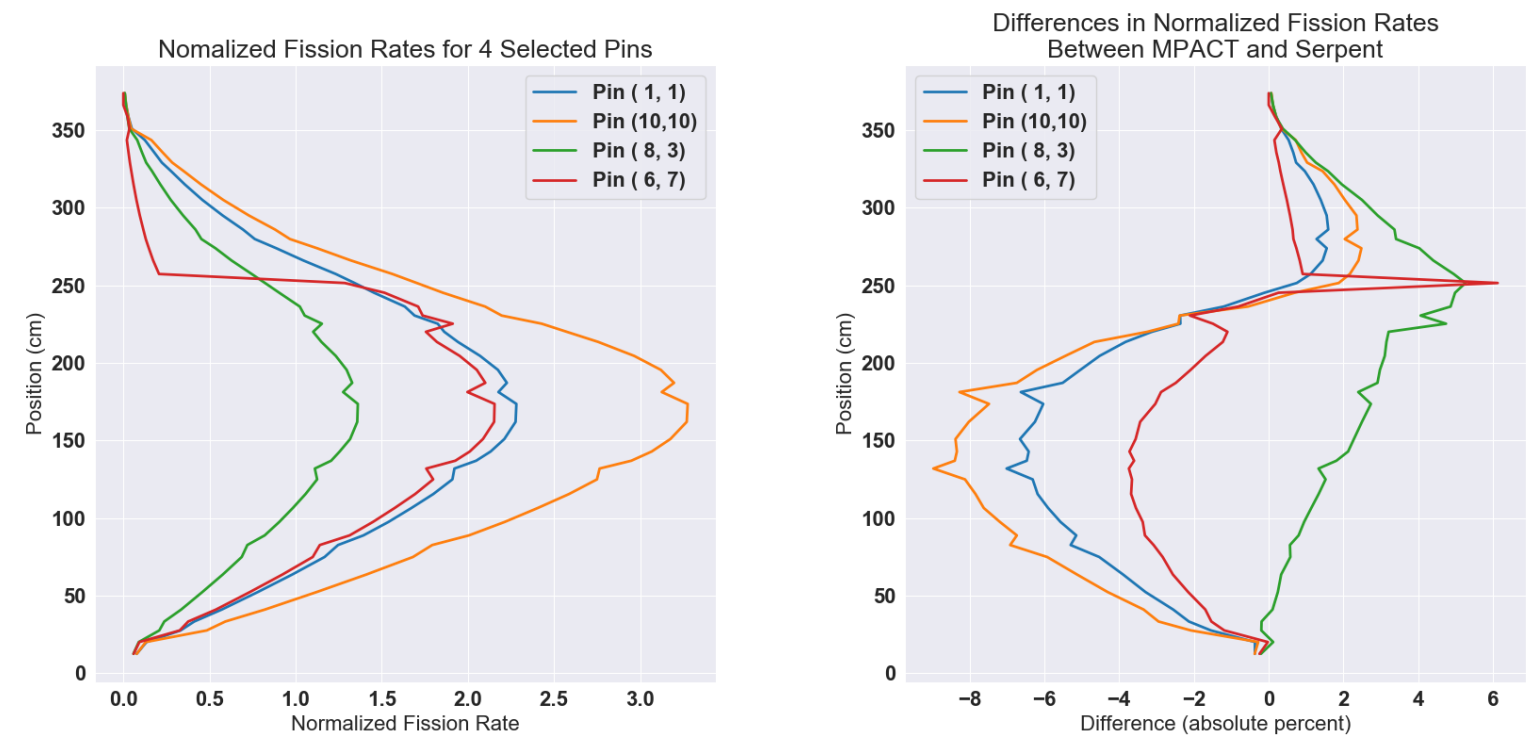

Figure 59. Normalized fission rates in 4 pins from Serpent (left) and $\Delta P_{i, j}$ (right) for the CZP single bundle.

\subsubsection{Controlled 3D GE-14 Single Bundle Problems}

The main purpose of the series of controlled 3D single bundle problems was to determine the ability of MPACT to estimate the worth of a control blade. The Serpent reference solutions in this series of problems used 36 billion active particles and had relative uncertainties in the eigenvalue of around $1 \mathrm{pcm}$ or less. The relative uncertainties in normalized fission rates were $0.1 \%$ or less except for extremely low power regions. Table 28 shows the Serpent eigenvalues for each case and shows the difference between the MPACT and Serpent results. 
Table 28. Summary of comparison between Serpent and MPACT results for the 3D controlled single bundles.

\begin{tabular}{|c|c|c|c|c|c|}
\hline \multirow{2}{*}{ Steps Withdrawn } & \multirow{2}{*}{$k_{\text {serp }}$} & $\Delta k(\mathrm{pcm})$ & \multicolumn{3}{|c|}{$\Delta P_{i, j}$ (absolute \%) } \\
& & & Max. & Min. & RMS \\
\hline \hline 00 & 0.810492 & 7.5 & 3.46 & -6.26 & 1.11 \\
04 & 0.810505 & 7.5 & 3.35 & -6.71 & 1.14 \\
08 & 0.883242 & 14.0 & 9.30 & -17.33 & 2.43 \\
12 & 0.932880 & 47.6 & 8.42 & -10.45 & 1.68 \\
16 & 0.953916 & 64.6 & 7.03 & -7.06 & 1.33 \\
20 & 0.965577 & 66.1 & 8.04 & -5.70 & 1.14 \\
24 & 0.973301 & 70.6 & 8.71 & -4.52 & 1.04 \\
28 & 0.978491 & 66.1 & 8.48 & -5.27 & 1.17 \\
32 & 0.981998 & 61.2 & 7.54 & -5.71 & 1.28 \\
36 & 0.984076 & 57.8 & 6.92 & -5.73 & 1.34 \\
40 & 0.985284 & 56.2 & 6.33 & -5.26 & 1.32 \\
44 & 0.985989 & 54.7 & 6.10 & -4.68 & 1.30 \\
48 & 0.986264 & 53.5 & 5.72 & -4.47 & 1.22 \\
\hline
\end{tabular}

The largest disagreement between MPACT and Serpent is $71 \mathrm{pcm}$ indicating MPACT is very capable of predicting control blade worth. In these controlled cases, peak differences in normalized fission rates are shown to be fairly large in some cases where the control blade is only slightly withdrawn. This is due to the fact that power is very highly peaked in these cases, and the differences are computed as an absolute percent instead of a relative percent.

\subsubsection{D Control Cell}

For the 3D control cell problem, the Serpent solution was obtained after simulating around 72 billion active particles. Since the control blade was only 12 of 48 steps withdrawn, much of the geometry saw little thermal flux and thus little fission. This large number of particles allowed for converged solutions farther into the controlled region of the geometry to facilitate comparisons with VERA models. The relative uncertainty in the Serpent eigenvalue was less than $1 \mathrm{pcm}$. Because of the lower relative fission rate near the bottom of the system in which the control blade is present, statistical errors in the fission rates could be large. However, in this region, the relative fission rates are very small compared with those in the top of the bundle where the power is produced. The 3D distribution of standard deviations in fission rate tallies is provided in each HDF5 file in the BWR progression problem Github repository. Table 29 shows that the MPACT and Serpent calculations agree to within $8 \mathrm{pcm}$ on the eigenvalue.

Table 29. Summary of comparison between Serpent and MPACT results for the 3D Control Cell.

\begin{tabular}{|c|c|c|c|c|c|}
\hline \multirow{2}{*}{ Case } & \multirow{2}{*}{$k_{\text {serp }}$} & \multirow{2}{*}{$\Delta k(\mathrm{pcm})$} & \multicolumn{3}{|c|}{$\Delta P_{i, j}$ (absolute \%) } \\
& & & Max. & Min. & RMS \\
\hline \hline HZP Control Cell & 0.907883 & -8.2 & 9.07 & -14.60 & 1.72 \\
\hline
\end{tabular}




\subsubsection{D Mini-Core}

Table 30 presents the eigenvalues obtained from Serpent models of the three 3D mini-core progression problems. For all three mini-core Serpent models, 100 billion active particles were used. The primary purpose of the All Rods In (ARI) and All Rods Out (ARO) cases was to have have a control rod worth study on the mini-core level. In all cases, the relative uncertainty in the eigenvalue was $1 \mathrm{pcm}$ or less. For all three cases, the relative uncertainties in fission rates were less than 0.1-0.2\% except low power regions. In all three models MPACT is capable of matching the reference eigenvalue to within around $66 \mathrm{pcm}$.

Table 30. Summary of comparison between Serpent and MPACT results for the 3D Mini Core Cases.

\begin{tabular}{|c|c|c|c|c|c|}
\hline \multirow{2}{*}{ Case } & \multirow{2}{*}{$k_{\text {serp }}$} & \multirow{2}{*}{$\Delta k(\mathrm{pcm})$} & \multicolumn{3}{|c|}{$\Delta P_{i, j}$ (absolute \%) } \\
& & & Max. & Min. & RMS \\
\hline \hline ARI & 0.887591 & 46.1 & 9.54 & -7.67 & 1.28 \\
Mixed Blades & 0.961932 & 65.6 & 7.06 & -4.78 & 1.06 \\
ARO & 0.964383 & 62.1 & 5.87 & -4.37 & 1.05 \\
\hline
\end{tabular}

In general, in the 3D mini-core problems, the disagreement in normalized fission rates matches the trends shown for the 2D and 3D single bundle problems. That is, in higher powered regions axially, MPACT typically underestimates the fission rate. This is also usually true in corner and edge pins of the fuel bundles. Full 3D fission rate distributions from the Serpent reference solutions are provided in HDF5 format in the progression problem Github repository [10]. These reference solutions will aid in future benchmarking efforts. 



\section{CONCLUSION}

The BWR progression problems have been defined used to test VERA during the development of its BWR capabilities. Four 2D lattice problems have been developed that consist of two $8 \times 8$ bundles and two $10 \times$ 10 bundles, one of which has 14 vanished rods. Each lattice is tested with a void concentration of 0,40 , and $80 \%$ and with a controlled and uncontrolled variant, resulting in 24 lattice progression problems. Additionally, a 2D 16 bundle mini-core problem was developed that has controlled and uncontrolled variations with three different assembly void distributions.

Twenty 3D progression problems have been specified, including 16 single bundle problems, one control cell, and three mini-core cases. For all 3D cases detailed reference solutions were obtained from continuous energy Monte Carlo calculations with Serpent 2.1.32.

All VERA, MCNP, and Serpent inputs are provided in a public Github repository [10]. Additionally, the MCNP and Serpent results are provided in HDF5 files that can be visualized with VERAView. These files will allow for easy comparison with future results using VERAView. This is especially important for the 2D mini-core and 3D problems for which it would be impractical to provide detailed fission rate distributions in this report.

For all progression problems, MPACT calculations have been compared to the Serpent reference solutions. In both 2D and 3D cases, the MPACT results show great agreement with the MC reference eigenvalues. In fact, in all of the 3D progression problems MPACT is able to match the reference eigenvalues to well within $100 \mathrm{pcm}$. As for comparisons of normalized fission rates, the results from MPACT typically underestimate the fission rate in corner pins and in higher powered axial regions of 3D progression problems. 



\section{REFERENCES}

[1] General Electric Systems and Technology Manual: Chapter 2.2 Fuel and Control Rods System. Technical report, US NRC. URL https://www.nrc.gov/docs/ML1125/ML11258A302.pdf.

[2] Spent Nuclear Fuel for Disposal in the KBS-3 Repository. Technical report, Svensk Kärnbränslehantering AB, December 2010. URL https://skb.se/upload/publications/pdf/TR-10-13.pdf. TR-10-13.

[3] UK ABWR Generic Deign Assessment. Technical Report UE-GD-0182, GE-Hitachi, 2014.

[4] M. Fensin. Optimum Boiling Water Reactor Fuel Design Strategies to Enhance Reactor Shutdown by the Standby Liquid Control System. Master's thesis, University of Florida, 2004.

[5] A. Godfrey. VERA Core Physics Benchmark Progression Problem Specifications. Technical Report CASL-U-2012-0131-004, CASL, August 2014. URL https://www.casl.gov/sites/default/files/docs/CASL-U-2012-0131-004.pdf.

[6] MegaWatSoft Inc. Steam Tables Online. URL https://www.steamtablesonline.com/Steam97Web.aspx.

[7] A. Isotlo and V. Sahlberg. Comparison of Neutronics-Depletion Coupling Schemes for Burnup Calculations. Nuclear Science and Engineering, 179:434-459, 2015. doi: http://dx.doi.org/10.13182/NSE14-35.

[8] D. Kelly. Depletion of a BWR Lattice Using the RACER Continuous Energy Monte Carlo Code. In Proceedings of the International Conference on Mathematics and Computations, Reactor Physics, and Environmental Analyses. American Nuclear Society, 1995.

[9] N. Larsen. Core Design and Operating Data for Cycle 1 and 2 of Peach Bottom 2. Technical Report NP-563, EPRI, June 1978.

[10] C. Lawing. BWR Progression Problems. https://github.com/cdlawing1/BWRProgressionProblemInputs, 2021.

[11] J. Leppänen, M. Pusa, T. Viitanen, V. Valtavirta, and T. Kaltiaisenaho. The Serpent Monte Carlo Code: Status, Development, and Applications in 2013. Annals of Nuclear Energy, 82:142-150, 2015.

[12] MCNP Users Manual - Code Version 6.2. Los Alamos National Laboratory, 2017. LA-UR-17-29981.

[13] S. Palmtag, A. Godfrey, M. Baird, and E. Walker. VERA Common Input User Manual. Technical Report CASL-U-2014-0014-003, CASL, July 2019.

[14] J. Solis, K. Ivanov, and B. Sarikaya. Boiling Water Reactor Turbine Trip (TT) Benchmark, Volume I Final Specifications. Technical report, OECD NEA, February 2001.

[15] H. Williamson and D. Zimmerman. Effects of Irradiation On $\mathrm{B}_{4} \mathrm{C}$ Filled Stainless Steel Tubes in the Dresden Nuclear Power Station. Technical Report APED-4426, GE, March 1964. 



\section{Appendices}

\section{A Number Densities for All Materials}

Number densities for all materials used in the BWR progression problems are provided in the following sections. Isotopes are referenced by the ZAID format used in MCNP. All number densities are in units of atom/barn - cm. 


\section{A.1 Structural Material for the Peach Bottom 6 Lattice}

Number densities for the structural materials in the Peach Bottom 6 lattice are provided in the following listing. For the Peach Bottom 6 lattice, a specific Zircaloy density $(6.5514 \mathrm{~g} / \mathrm{cc})$ was provided in Solis, Ivanov, and Sarikaya [14]. This density matches the number densities shown here.

\begin{tabular}{|c|c|c|c|c|c|}
\hline & Zircaloy-4 & & Zircaloy-2 & & $\mathbf{B}_{4} \mathbf{C}$ \\
\hline 24050 & $3.2968866141 \mathrm{E}-06$ & 24050 & $3.2968866141 \mathrm{E}-06$ & 5010 & $1.5209107996 \mathrm{E}-02$ \\
\hline 24052 & 6.3577105908E-05 & 24052 & $6.3577561664 \mathrm{E}-05$ & 5011 & $6.1218387852 \mathrm{E}-02$ \\
\hline 24053 & 7.2091359200E-06 & 24053 & 7.2091210153E-06 & 6000 & $1.9106892039 \mathrm{E}-02$ \\
\hline 24054 & $1.7945095672 \mathrm{E}-06$ & 24054 & $1.7944876240 \mathrm{E}-06$ & \multirow{2}{*}{\multicolumn{2}{|c|}{ Stainless-steel 304}} \\
\hline 26054 & $8.6716696590 \mathrm{E}-06$ & 26054 & $5.5746761283 \mathrm{E}-06$ & & \\
\hline 26056 & $1.3612707909 \mathrm{E}-04$ & 26056 & 8.7510768952E-05 & 6000 & $3.2089651597 \mathrm{E}-04$ \\
\hline 26057 & $3.1437631362 \mathrm{E}-06$ & 26057 & 2.0210029618E-06 & 14028 & $1.5820983472 \mathrm{E}-03$ \\
\hline 26058 & $4.1837688557 \mathrm{E}-07$ & 26058 & 2.6895496406E-07 & 14029 & $8.0331416675 \mathrm{E}-05$ \\
\hline 40090 & 2.1857820282E-02 & 28058 & $2.5168392905 \mathrm{E}-05$ & 14030 & $5.2953893503 \mathrm{E}-05$ \\
\hline 40091 & $4.7666719010 \mathrm{E}-03$ & 28060 & 9.6948943550E-06 & 15031 & $6.9994311570 \mathrm{E}-05$ \\
\hline 40092 & 7.2859564333E-03 & 28061 & 4.2142787756E-07 & 24050 & 7.6491929953E-04 \\
\hline 40094 & 7.3836454528E-03 & 28062 & $1.3437099713 \mathrm{E}-06$ & 24052 & $1.4750737064 \mathrm{E}-02$ \\
\hline 40096 & $1.1895401226 \mathrm{E}-03$ & 28064 & $3.4220074608 \mathrm{E}-07$ & 24053 & $1.6726151145 \mathrm{E}-03$ \\
\hline 50112 & $4.6745084653 \mathrm{E}-06$ & 40090 & 2.1862296412E-02 & 24054 & 4.1634851483E-04 \\
\hline 50114 & $3.1806027268 \mathrm{E}-06$ & 40091 & 4.7676267110E-03 & 25055 & $1.7538799140 \mathrm{E}-03$ \\
\hline 50115 & $1.6384932071 \mathrm{E}-06$ & 40092 & 7.2874160028E-03 & 26054 & $3.4477864939 \mathrm{E}-03$ \\
\hline 50116 & 7.0069536357E-05 & 40094 & 7.3851579439E-03 & 26056 & $5.4122852675 \mathrm{E}-02$ \\
\hline 50117 & 3.7010617333E-05 & 40096 & $1.1897828288 \mathrm{E}-03$ & 26057 & 1.2499292713E-03 \\
\hline 50118 & $1.1671854166 \mathrm{E}-04$ & 50112 & 4.6745437217E-06 & 26058 & $1.6634315959 \mathrm{E}-04$ \\
\hline 50119 & 4.1396077147E-05 & 50114 & $3.1806096543 \mathrm{E}-06$ & 28058 & $5.3085758033 \mathrm{E}-03$ \\
\hline 50120 & $1.5700601411 \mathrm{E}-04$ & 50115 & $1.6384966407 \mathrm{E}-06$ & 28060 & $2.0448505596 \mathrm{E}-03$ \\
\hline 50122 & $2.2312399102 \mathrm{E}-05$ & 50116 & 7.0069536357E-05 & 28061 & $8.8888000669 \mathrm{E}-05$ \\
\hline 50124 & $2.7902567370 \mathrm{E}-05$ & 50117 & 3.7010617333E-05 & 28062 & 2.8341488223E-04 \\
\hline 72174 & $3.5367440362 \mathrm{E}-09$ & 50118 & $1.1671820703 \mathrm{E}-04$ & 28064 & 7.2177469964E-05 \\
\hline 72176 & $1.1627038879 \mathrm{E}-07$ & 50119 & 4.1396077147E-05 & & \\
\hline 72177 & $4.1114602978 \mathrm{E}-07$ & 50120 & $1.5700634316 \mathrm{E}-04$ & & \\
\hline 72178 & $6.0301550100 \mathrm{E}-07$ & 50122 & $2.2312463831 \mathrm{E}-05$ & & \\
\hline 72179 & $3.0106525787 \mathrm{E}-07$ & 50124 & 2.7902535529E-05 & & \\
\hline 72180 & 7.7543042177E-07 & 72174 & $3.5367440362 \mathrm{E}-09$ & & \\
\hline & & 72176 & 1.1627038879E-07 & & \\
\hline & He-4 & 72177 & 4.1114602978E-07 & & \\
\hline 2004 & $2.6480209540 \mathrm{E}-05$ & 72178 & $6.0301550100 \mathrm{E}-07$ & & \\
\hline & & 72179 & $3.0106525787 \mathrm{E}-07$ & & \\
\hline & & 72180 & $7.7543042177 \mathrm{E}-07$ & & \\
\hline
\end{tabular}

\section{A.2 Structural Materials for All Problems Except the Peach Bottom 6 Lattice}

For all problems except the Peach Bottom 6 lattice, a specific density for Zircaloy was not provided; thus, the default density for Zircaloy from Palmtag et al. [13] $(6.56 \mathrm{~g} / \mathrm{cc})$ is used in all other problems. This results in some slight but nonnegligible differences in the Zircaloy number densities. 


\begin{tabular}{|c|c|c|c|c|c|}
\hline \multicolumn{2}{|r|}{ Zircaloy-4 } & \multicolumn{2}{|r|}{ Zircaloy-2 } & \multicolumn{2}{|r|}{$\mathrm{B}_{\mathbf{4}} \mathrm{C}$} \\
\hline 24050 & $3.3012144257 \mathrm{E}-06$ & 24050 & 3.3012144257E-06 & 5010 & $1.5209107996 \mathrm{E}-02$ \\
\hline 24052 & $6.3660563353 \mathrm{E}-05$ & 24052 & $6.3661019708 \mathrm{E}-05$ & 5011 & $6.1218387852 \mathrm{E}-02$ \\
\hline 24053 & 7.2185993277E-06 & 24053 & 7.2185844034E-06 & 6000 & 1.9106892039E-02 \\
\hline 24054 & $1.7968652137 \mathrm{E}-06$ & 24054 & $1.7968432416 \mathrm{E}-06$ & \multirow{2}{*}{\multicolumn{2}{|c|}{ Stainless-steel 304}} \\
\hline 26054 & $8.6830529296 \mathrm{E}-06$ & 26054 & 5.5819939862E-06 & & \\
\hline 26056 & $1.3630577263 \mathrm{E}-04$ & 26056 & $8.7625644034 \mathrm{E}-05$ & 6000 & $3.2089651597 \mathrm{E}-04$ \\
\hline 26057 & 3.1478899432E-06 & 26057 & 2.0236559253E-06 & 14028 & $1.5820983472 \mathrm{E}-03$ \\
\hline 26058 & 4.1892608745E-07 & 26058 & $2.6930802030 \mathrm{E}-07$ & 14029 & $8.0331416675 \mathrm{E}-05$ \\
\hline 40090 & $2.1886512966 \mathrm{E}-02$ & 28058 & $2.5201431366 \mathrm{E}-05$ & 14030 & $5.2953893503 \mathrm{E}-05$ \\
\hline 40091 & 4.7729290946E-03 & 28060 & 9.7076208091E-06 & 15031 & $6.9994311570 \mathrm{E}-05$ \\
\hline 40092 & 7.2955206830E-03 & 28061 & 4.2198108447E-07 & 24050 & 7.6491929953E-04 \\
\hline 40094 & 7.3933379385E-03 & 28062 & $1.3454738547 \mathrm{E}-06$ & 24052 & $1.4750737064 \mathrm{E}-02$ \\
\hline 40096 & $1.1911016278 \mathrm{E}-03$ & 28064 & $3.4264995181 \mathrm{E}-07$ & 24053 & $1.6726151145 \mathrm{E}-03$ \\
\hline 50112 & 4.6806446763E-06 & 40090 & 2.1890994972E-02 & 24054 & 4.1634851483E-04 \\
\hline 50114 & $3.1847778929 \mathrm{E}-06$ & 40091 & $4.7738851580 \mathrm{E}-03$ & 25055 & $1.7538799140 \mathrm{E}-03$ \\
\hline 50115 & $1.6406440514 \mathrm{E}-06$ & 40092 & 7.2969821685E-03 & 26054 & 3.4477864939E-03 \\
\hline 50116 & 7.0161516394E-05 & 40094 & 7.3948524151E-03 & 26056 & $5.4122852675 \mathrm{E}-02$ \\
\hline 50117 & $3.7059201042 \mathrm{E}-05$ & 40096 & $1.1913446526 \mathrm{E}-03$ & 26057 & 1.2499292713E-03 \\
\hline 50118 & $1.1687175769 \mathrm{E}-04$ & 50112 & 4.6806799790E-06 & 26058 & $1.6634315959 \mathrm{E}-04$ \\
\hline 50119 & 4.1450417634E-05 & 50114 & $3.1847848296 \mathrm{E}-06$ & 28058 & $5.3085758033 \mathrm{E}-03$ \\
\hline 50120 & $1.5721211536 \mathrm{E}-04$ & 50115 & 1.6406474895E-06 & 28060 & $2.0448505596 \mathrm{E}-03$ \\
\hline 50122 & $2.2341688511 \mathrm{E}-05$ & 50116 & 7.0161516394E-05 & 28061 & 8.8888000669E-05 \\
\hline 50124 & 2.7939194974E-05 & 50117 & 3.7059201042E-05 & 28062 & $2.8341488223 \mathrm{E}-04$ \\
\hline 72174 & $3.5413867078 \mathrm{E}-09$ & 50118 & $1.1687142262 \mathrm{E}-04$ & 28064 & 7.2177469964E-05 \\
\hline 72176 & $1.1642301652 \mathrm{E}-07$ & 50119 & 4.1450417634E-05 & & \\
\hline 72177 & 4.1168573974E-07 & 50120 & $1.5721244484 \mathrm{E}-04$ & & \\
\hline 72178 & $6.0380707735 \mathrm{E}-07$ & 50122 & $2.2341753325 \mathrm{E}-05$ & & \\
\hline 72179 & $3.0146046519 \mathrm{E}-07$ & 50124 & $2.7939163090 \mathrm{E}-05$ & & \\
\hline 72180 & 7.7644832659E-07 & 72174 & 3.5413867078E-09 & & \\
\hline \multirow{5}{*}{2004} & \multirow{5}{*}{$\begin{array}{c}\text { He-4 } \\
2.6871394453 \mathrm{E}-05\end{array}$} & 72176 & $1.1642301652 \mathrm{E}-07$ & & \\
\hline & & 72177 & 4.1168573974E-07 & & \\
\hline & & 72178 & $6.0380707735 \mathrm{E}-07$ & & \\
\hline & & 72179 & $3.0146046519 \mathrm{E}-07$ & & \\
\hline & & 72180 & 7.7644832659E-07 & & \\
\hline
\end{tabular}




\section{A.3 Fuels}

This section provides the number densities for all fuels. A separate listing is provided for each bundle type, and the fuels are labeled following the rod labels provided in tables in the problem descriptions.

\section{A.3.1 Peach Bottom Type 6}

The fuel names in the following listing match the rod labels from Table 3.

\begin{tabular}{|c|c|c|c|c|c|}
\hline \multicolumn{2}{|r|}{ Fuel: 1} & \multicolumn{2}{|r|}{ Fuel: 2} & \multicolumn{2}{|r|}{ Fuel: 3} \\
\hline 92235 & $7.0155366968 \mathrm{E}-04$ & 92235 & $5.1743125385 \mathrm{E}-04$ & 92235 & $4.3585660109 \mathrm{E}-04$ \\
\hline 92234 & $6.2705860564 \mathrm{E}-06$ & 92234 & 4.6248738276E-06 & 92234 & 3.8957480283E-06 \\
\hline 92236 & $3.2134519291 \mathrm{E}-06$ & 92236 & $2.3700830495 \mathrm{E}-06$ & 92236 & $1.9964320566 \mathrm{E}-06$ \\
\hline 92238 & 2.2310983408E-02 & 92238 & $2.2495514040 \mathrm{E}-02$ & 92238 & 2.2577269552E-02 \\
\hline 8016 & 4.6044042232E-02 & 8016 & 4.6039880502E-02 & 8016 & 4.6038036666E-02 \\
\hline & Fuel: 4 & & Fuel: 5 & & \\
\hline 92235 & $3.3796585825 \mathrm{E}-04$ & 92235 & $6.8152675969 \mathrm{E}-04$ & & \\
\hline 92234 & $3.0207867051 \mathrm{E}-06$ & 92234 & $6.0915826986 \mathrm{E}-06$ & & \\
\hline 92236 & $1.5480455539 \mathrm{E}-06$ & 92236 & $3.1217190862 \mathrm{E}-06$ & & \\
\hline 92238 & $2.2675377327 \mathrm{E}-02$ & 92238 & $2.1674082661 \mathrm{E}-02$ & & \\
\hline 8016 & 4.6035824036E-02 & 64152 & $1.3596568956 \mathrm{E}-06$ & & \\
\hline & & 64154 & $1.4820017148 \mathrm{E}-05$ & & \\
\hline & & 64155 & $1.0061252739 \mathrm{E}-04$ & & \\
\hline & & 64156 & $1.3915845081 \mathrm{E}-04$ & & \\
\hline & & 64157 & $1.0639132099 \mathrm{E}-04$ & & \\
\hline & & 64158 & $1.6886620921 \mathrm{E}-04$ & & \\
\hline & & 64160 & $1.4860810463 \mathrm{E}-04$ & & \\
\hline & & 8016 & $4.5749372650 \mathrm{E}-02$ & & \\
\hline
\end{tabular}

\section{A.3.2 GE9}

The fuel numbers in the following listing match the rod labels from Table 5. 


\begin{tabular}{|c|c|c|c|c|c|}
\hline \multicolumn{2}{|r|}{ Fuel: 1} & \multicolumn{2}{|r|}{ Fuel: 2} & \multicolumn{2}{|r|}{ Fuel: 3} \\
\hline 92235 & $3.6368330841 \mathrm{E}-04$ & 92235 & 4.5460133817E-04 & 92235 & $5.0005993347 \mathrm{E}-04$ \\
\hline 92234 & $3.2506529168 \mathrm{E}-06$ & 92234 & 4.0632911430E-06 & 92234 & 4.4696065058E-06 \\
\hline 92236 & $1.6658437971 \mathrm{E}-06$ & 92236 & 2.0822919333E-06 & 92236 & $2.2905140794 \mathrm{E}-06$ \\
\hline 92238 & $2.2079156652 \mathrm{E}-02$ & 92238 & 2.1988037049E-02 & 92238 & $2.1942477667 \mathrm{E}-02$ \\
\hline 8016 & 4.4895512914E-02 & 8016 & 4.4897567940E-02 & 8016 & 4.4898595443E-02 \\
\hline \multicolumn{2}{|r|}{ Fuel: 4} & \multicolumn{2}{|r|}{ Fuel: 5} & \multicolumn{2}{|r|}{ Fuel: 6} \\
\hline 92235 & $5.4551824904 \mathrm{E}-04$ & 92235 & $5.9097628490 \mathrm{E}-04$ & 92235 & $6.3643404104 \mathrm{E}-04$ \\
\hline 92234 & 4.8759193684E-06 & 92234 & 5.2822297309E-06 & 92234 & 5.6885375931E-06 \\
\hline 92236 & 2.4987349443E-06 & 92236 & $2.7069545280 \mathrm{E}-06$ & 92236 & $2.9151728304 \mathrm{E}-06$ \\
\hline 92238 & 2.1896918567E-02 & 92238 & 2.1851359746E-02 & 92238 & $2.1805801206 \mathrm{E}-02$ \\
\hline 8016 & 4.4899622940E-02 & 8016 & 4.4900650430E-02 & 8016 & 4.4901677915E-02 \\
\hline \multicolumn{2}{|r|}{ Fuel: 7} & \multicolumn{2}{|r|}{ Fuel: 8} & \multicolumn{2}{|r|}{ Fuel: 9} \\
\hline 92235 & $6.8189151747 \mathrm{E}-04$ & 92235 & $8.1826226850 \mathrm{E}-04$ & 92235 & $8.6371862610 \mathrm{E}-04$ \\
\hline 92234 & $6.0948429553 \mathrm{E}-06$ & 92234 & 7.3137440414E-06 & 92234 & 7.7200394034E-06 \\
\hline 92236 & $3.1233898516 \mathrm{E}-06$ & 92236 & $3.7480332280 \mathrm{E}-06$ & 92236 & $3.9562451245 \mathrm{E}-06$ \\
\hline 92238 & $2.1760242946 \mathrm{E}-02$ & 92238 & 2.1623569848E-02 & 92238 & $2.1578012710 \mathrm{E}-02$ \\
\hline 8016 & 4.4902705393E-02 & 8016 & 4.4905787789E-02 & 8016 & 4.4906815241E-02 \\
\hline \multicolumn{2}{|r|}{ Fuel: 10} & \multicolumn{2}{|r|}{ Fuel: 51} & \multicolumn{2}{|r|}{ Fuel: 52} \\
\hline 92235 & $8.9781071075 \mathrm{E}-04$ & 92235 & $8.5117615190 \mathrm{E}-04$ & 92235 & 7.7575965692E-04 \\
\hline 92234 & 8.0247592842E-06 & 92234 & 7.6079329926E-06 & 92234 & 6.9338496797E-06 \\
\hline 92236 & 4.1124032061E-06 & 92236 & 3.8987945834E-06 & 92236 & $3.5533509035 \mathrm{E}-06$ \\
\hline 92238 & $2.1543845040 \mathrm{E}-02$ & 92238 & 2.0424803245E-02 & 92238 & $2.0500386945 \mathrm{E}-02$ \\
\hline \multirow[t]{8}{*}{8016} & \multirow[t]{8}{*}{ 4.4907585827E-02 } & 64152 & 2.6419608770E-06 & 64152 & $2.6419608770 \mathrm{E}-06$ \\
\hline & & 64154 & 2.8796901355E-05 & 64154 & $2.8796901355 \mathrm{E}-05$ \\
\hline & & 64155 & $1.9550105763 \mathrm{E}-04$ & 64155 & $1.9550105763 \mathrm{E}-04$ \\
\hline & & 64156 & 2.7039996922E-04 & 64156 & 2.7039996922E-04 \\
\hline & & 64157 & 2.0672988062E-04 & 64157 & $2.0672988062 \mathrm{E}-04$ \\
\hline & & 64158 & $3.2812536722 \mathrm{E}-04$ & 64158 & $3.2812536722 \mathrm{E}-04$ \\
\hline & & 64160 & 2.8876167193E-04 & 64160 & 2.8876167193E-04 \\
\hline & & 8016 & 4.4556412853E-02 & 8016 & 4.4554708209E-02 \\
\hline
\end{tabular}

\section{A.3.3 GE14}

The fuel numbers in the following listing match the rod labels from Table 7. These fuel number densities are used in all GE-14, GE-14 with vanished rods, mini-core, and 3D GE-14 cases. 


\begin{tabular}{|c|c|c|c|c|c|}
\hline \multicolumn{2}{|r|}{ Fuel: 1} & \multicolumn{2}{|r|}{ Fuel: 2} & \multicolumn{2}{|r|}{ Fuel: 3} \\
\hline 92235 & 3.7581788989E-04 & 92235 & 6.5766916663E-04 & 92235 & 7.5161727982E-04 \\
\hline 92234 & 3.3591135247E-06 & 92234 & 5.8783401531E-06 & 92234 & $6.7180616940 \mathrm{E}-06$ \\
\hline 92236 & $1.7214259941 \mathrm{E}-06$ & 92236 & $3.0124398796 \mathrm{E}-06$ & 92236 & $3.4427672495 \mathrm{E}-06$ \\
\hline 92238 & 2.2815845192E-02 & 92238 & $2.2533369025 \mathrm{E}-02$ & 92238 & $2.2439212620 \mathrm{E}-02$ \\
\hline 8016 & 4.6393487243E-02 & 8016 & 4.6399857943E-02 & 8016 & 4.6401981458E-02 \\
\hline \multicolumn{2}{|r|}{ Fuel: 4} & \multicolumn{2}{|r|}{ Fuel: 5} & \multicolumn{2}{|r|}{ Fuel: 6} \\
\hline 92235 & $8.4556423684 \mathrm{E}-04$ & 92235 & $9.2776687584 \mathrm{E}-04$ & 92235 & $1.0334546825 \mathrm{E}-03$ \\
\hline 92234 & 7.5577729010E-06 & 92234 & 8.2925117303E-06 & 92234 & $9.2371643140 \mathrm{E}-06$ \\
\hline 92236 & 3.8730893237E-06 & 92236 & 4.2496167945E-06 & 92236 & 4.7337175851E-06 \\
\hline 92238 & 2.234 & 92238 & 2.226 & 92238 & 2.2156750 \\
\hline 8016 & 4.6404104946E-02 & 8016 & 4.6405962977E-02 & 8016 & 4.6408351845E-02 \\
\hline \multicolumn{2}{|r|}{ Fuel: 7} & \multicolumn{2}{|r|}{ Fuel: 5G } & \multicolumn{2}{|r|}{ Fuel: $6 H$} \\
\hline 92235 & $1.1508838627 \mathrm{E}-03$ & 92235 & $8.3631047188 \mathrm{E}-04$ & 92235 & 9.518316366 \\
\hline 92234 & 1.02867625 & 92234 & 7.475 & 92234 & 8.50 \\
\hline 92236 & 5.2715994919E-06 & 92236 & $3.8307026466 \mathrm{E}-06$ & 92236 & 4.3598449289E-06 \\
\hline 92238 & $2.2039060827 \mathrm{E}-02$ & 92238 & 2.006 & 92238 & E-02 \\
\hline 8016 & 4.6411006103E-02 & 64152 & 5.41736217 & 64152 & 4.063 \\
\hline \multirow{2}{*}{\multicolumn{2}{|c|}{ Fuel: N }} & 64154 & $5.9048279466 \mathrm{E}-05$ & 64154 & 4.428620 \\
\hline & & 64155 & $4.0087650210 \mathrm{E}-04$ & 64155 & 3.006 \\
\hline 92235 & $1.6677147196 \mathrm{E}-04$ & 64156 & $5.5445732697 \mathrm{E}-04$ & 64156 & 4.1584299522E-04 \\
\hline 92234 & $1.4906270352 \mathrm{E}-06$ & 64157 & 4.2390129459E-04 & 64157 & 3.179 \\
\hline 92236 & 7.6389324357E-07 & 64158 & 6.72823723 & 64158 & E-04 \\
\hline 92238 & $2.3025355085 \mathrm{E}-02$ & 64160 & $5.9210814709 \mathrm{E}-04$ & 64160 & 4.4408111 \\
\hline 8016 & 4.6388762155E-02 & 8016 & 4.5894365941E-02 & 8016 & $4.5790204522 \mathrm{E}-02$ \\
\hline \multicolumn{2}{|r|}{ Fuel: 6K } & \multicolumn{2}{|r|}{ Fuel: 7G } & \multicolumn{2}{|r|}{ Fuel: $7 H$} \\
\hline 92235 & 9.82209242 & 92235 & 1.03743327 & 92235 & 1.05 \\
\hline 92234 & 8.7791253104E-06 & 92234 & 9.2727255165E-06 & 92234 & $9.4743065060 \mathrm{E}-06$ \\
\hline 92236 & 4.4989889160E-06 & 92236 & 4.7519414343E-06 & 92236 & 4.8552445090E-06 \\
\hline 92238 & $2.1058073804 \mathrm{E}-02$ & 92238 & $1.9866518023 \mathrm{E}-02$ & 92238 & 2.0298398849E-02 \\
\hline 64152 & $2.0315108162 \mathrm{E}-06$ & 64152 & $5.4173621766 \mathrm{E}-06$ & 64152 & 4.0630216324E-06 \\
\hline 64154 & $2.2143104800 \mathrm{E}-05$ & 64154 & $5.9048279466 \mathrm{E}-05$ & 64154 & 4.4286209599E-05 \\
\hline 64155 & $1.5032868829 \mathrm{E}-04$ & 64155 & $4.0087650210 \mathrm{E}-04$ & 64155 & $3.0065737658 \mathrm{E}-04$ \\
\hline 64156 & 2.0792149761E-04 & 64156 & $5.5445732697 \mathrm{E}-04$ & 64156 & 4.1584299522E-04 \\
\hline 64157 & $1.5896298547 \mathrm{E}-04$ & 64157 & 4.2390129459E-04 & 64157 & $3.1792597094 \mathrm{E}-04$ \\
\hline 64158 & $2.5230889617 \mathrm{E}-04$ & 64158 & $6.7282372311 \mathrm{E}-04$ & 64158 & 5.0461779233E-04 \\
\hline 64160 & $2.2204055516 \mathrm{E}-04$ & 64160 & $5.9210814709 \mathrm{E}-04$ & 64160 & 4.4408111032E-04 \\
\hline 8016 & 4.5630732324E-02 & 8016 & 4.5898911931E-02 & 8016 & 4.5792649145E-02 \\
\hline
\end{tabular}




\section{A.4 Smeared Grid and Nozzle Number Densities}

The spacer grids and nozzles are all homogenized into coolant by using the data from Table 12 to perform volume-weighted averaging on the number densities. This process depends on the local coolant void fraction and the lattice geometry, meaning there will be a separate set of number densities for each different local void and lattice combination present in spacer grid locations. Because of the complexity of the 3D progression problems, this results in many unique homogenized grid materials and thus tables are not included in this report. All Serpent and MCNP inputs used to generate reference solutions are provided in the BWR progression problem Github repository [10]. The material cards in these inputs contain the exact number density specifications for all homogenized materials, which can be easily copied into other inputs, as needed. 


\section{A.5 Coolant Number Densities}

Number densities for coolant in HZP or HFP cases at 1,040 psia are shown below.

\begin{tabular}{|c|c|c|c|c|c|}
\hline \multicolumn{2}{|r|}{$\mathrm{H}_{2} \mathrm{O}: 0 \%$ void } & \multicolumn{2}{|r|}{$\mathrm{H}_{2} \mathrm{O}: 5 \%$ void } & \multicolumn{2}{|c|}{$\mathrm{H}_{2} \mathrm{O}: 10 \%$ void } \\
\hline 1001 & 4.9264973479E-02 & 1001 & 4.6927189356E-02 & 1001 & 4.4589405233E-02 \\
\hline 8016 & 2.4632486739E-02 & 8016 & $2.3463594678 \mathrm{E}-02$ & 8016 & $2.2294702616 \mathrm{E}-02$ \\
\hline \multicolumn{2}{|c|}{$\mathrm{H}_{2} \mathrm{O}: 15 \%$ void } & \multicolumn{2}{|c|}{$\mathrm{H}_{2} \mathrm{O}: 20 \%$ void } & \multicolumn{2}{|c|}{$\mathrm{H}_{2} \mathrm{O}: 25 \%$ void } \\
\hline 1001 & $4.2251621110 \mathrm{E}-02$ & 1001 & $3.9913836986 \mathrm{E}-02$ & 1001 & $3.7576052863 \mathrm{E}-02$ \\
\hline 8016 & $2.1125810555 \mathrm{E}-02$ & 8016 & $1.9956918493 \mathrm{E}-02$ & 8016 & $1.8788026432 \mathrm{E}-02$ \\
\hline \multicolumn{2}{|r|}{$\mathrm{H}_{2} \mathrm{O}: 30 \%$ void } & \multicolumn{2}{|r|}{$\mathrm{H}_{2} \mathrm{O}: 35 \%$ void } & \multicolumn{2}{|c|}{$\mathrm{H}_{2} \mathrm{O}: 40 \%$ void } \\
\hline 1001 & $3.5238268740 \mathrm{E}-02$ & 1001 & $3.2900484617 \mathrm{E}-02$ & 1001 & 3.0562700494E-02 \\
\hline 8016 & 1.7619134370E-02 & 8016 & 1.6450242309E-02 & 8016 & $1.5281350247 \mathrm{E}-02$ \\
\hline \multicolumn{2}{|r|}{$\mathrm{H}_{2} \mathrm{O}: 45 \%$ void } & \multicolumn{2}{|c|}{$\mathrm{H}_{2} \mathrm{O}: 50 \%$ void } & \multicolumn{2}{|c|}{$\mathrm{H}_{2} \mathrm{O}: 55 \%$ void } \\
\hline 1001 & $2.8224916371 \mathrm{E}-02$ & 1001 & $2.5887132248 \mathrm{E}-02$ & 1001 & $2.3549348125 \mathrm{E}-02$ \\
\hline 8016 & $1.4112458186 \mathrm{E}-02$ & 8016 & $1.2943566124 \mathrm{E}-02$ & 8016 & $1.1774674063 \mathrm{E}-02$ \\
\hline \multicolumn{2}{|c|}{$\mathrm{H}_{2} \mathrm{O}: 60 \%$ void } & \multicolumn{2}{|c|}{$\mathrm{H}_{2} \mathrm{O}: 65 \%$ void } & \multicolumn{2}{|c|}{$\mathrm{H}_{2} \mathrm{O}: 70 \%$ void } \\
\hline 1001 & $2.1211564002 \mathrm{E}-02$ & 1001 & $1.8873779879 \mathrm{E}-02$ & 1001 & $1.6535995756 \mathrm{E}-02$ \\
\hline 8016 & $1.0605782001 \mathrm{E}-02$ & 8016 & $9.4368899395 \mathrm{E}-03$ & 8016 & 8.2679978780E-03 \\
\hline \multicolumn{2}{|r|}{$\mathrm{H}_{2} \mathrm{O}: 75 \%$ void } & \multicolumn{2}{|c|}{$\mathrm{H}_{2} \mathrm{O}: 80 \%$ void } & \multicolumn{2}{|c|}{$\mathrm{H}_{2} \mathrm{O}: 85 \%$ void } \\
\hline 1001 & $1.4198211633 \mathrm{E}-02$ & 1001 & $1.1860427510 \mathrm{E}-02$ & 1001 & $9.5226433869 \mathrm{E}-03$ \\
\hline 8016 & 7.0991058165E-03 & 8016 & $5.9302137550 \mathrm{E}-03$ & 8016 & 4.7613216934E-03 \\
\hline \multicolumn{2}{|r|}{$\mathrm{H}_{2} \mathrm{O}: 90 \%$ void } & \multicolumn{2}{|c|}{$\mathrm{H}_{2} \mathrm{O}: 95 \%$ void } & \multicolumn{2}{|c|}{$\mathrm{H}_{2} \mathrm{O}: 100 \%$ void } \\
\hline 1001 & $7.1848592638 \mathrm{E}-03$ & 1001 & $4.8470751408 \mathrm{E}-03$ & 1001 & 2.5092910177E-03 \\
\hline 8016 & $3.5924296319 \mathrm{E}-03$ & 8016 & $2.4235375704 \mathrm{E}-03$ & 8016 & $1.2546455089 \mathrm{E}-03$ \\
\hline
\end{tabular}

For CZP conditions, the pressure drops to 1 atmosphere or 14.69595 psia. The number densities for the coolant in this case are shown below.

\begin{tabular}{|ll|}
\hline & $\mathbf{H}_{2}$ O: $\mathbf{C Z P}$ \\
1001 & $6.4089471333 \mathrm{E}-02$ \\
8016 & $3.2044735667 \mathrm{E}-02$ \\
\hline
\end{tabular}

